Regioselective Synthesis of $2^{\circ}$ Amides using Visible-Light-Induced Photoredox Catalyzed Non-aqueous Oxidative C-N Cleavage of $N, N$-dibenzylanilines

Nalladhambi Neerathilingam, Mandapati Bhargava Reddy and Ramasamy Anandhan*

Department of Organic Chemistry, University of Madras, Guindy Campus, Chennai-600 025,

Tamil Nadu, India.Email: ananthanramasamy@gmail.com

S.No Table of contents

$\underline{\text { Pages }}$

$1 \quad$ General considerations

2 General Experimental Procedures

3 Preliminary mechanistic study

3.1 Intermediate-trapping experiments

3.2 Quenching experiments

3.3 Studies on C-N bond cleavage

3.4 Determination of singlet oxygen species

3.5 UV-Visible absorption spectra

3.6 Evaluation of green chemistry metrics for the synthesis of $2 \mathrm{a}$

$4 \quad$ Copies of ${ }^{1} \mathrm{H}$ and ${ }^{13} \mathrm{C}$ NMR and HRMS 


\section{General considerations:}

The ${ }^{1} \mathrm{H}$ and ${ }^{13} \mathrm{C}$ NMR spectra were recorded in $\mathrm{CDCl}_{3}$ on Bruker spectrometers $300 \mathrm{MHz}$, $400 \mathrm{MHz}$, and 500MHz NMR spectrometer with TMS as an internal standard. Mass spectra were recorded on Xevo G2S Q-TOF spectrometer. The light source for photochemical reactions was Kessil 456nm Blue LED (model number: KSPR160L-456-EU). Different wave lengths containing LEDs such as $370 \mathrm{~nm}, 390 \mathrm{~nm}, 427 \mathrm{~nm}, 467 \mathrm{~nm}$ and $527 \mathrm{~nm}$ were purchased from Kessil and used. Reaction tubes made of borosilicate glass were used as reaction vessels. The distance between the light source and the reaction vessel was $8 \mathrm{~cm}$. TLC was performed on using Merck pre-coated TLC plates (Merck 60 F254) and detected under UV light. Column chromatographic separation was carried out with silica gel (100-200 mesh). Reagents and solvents were purified as per standard procedures and used.

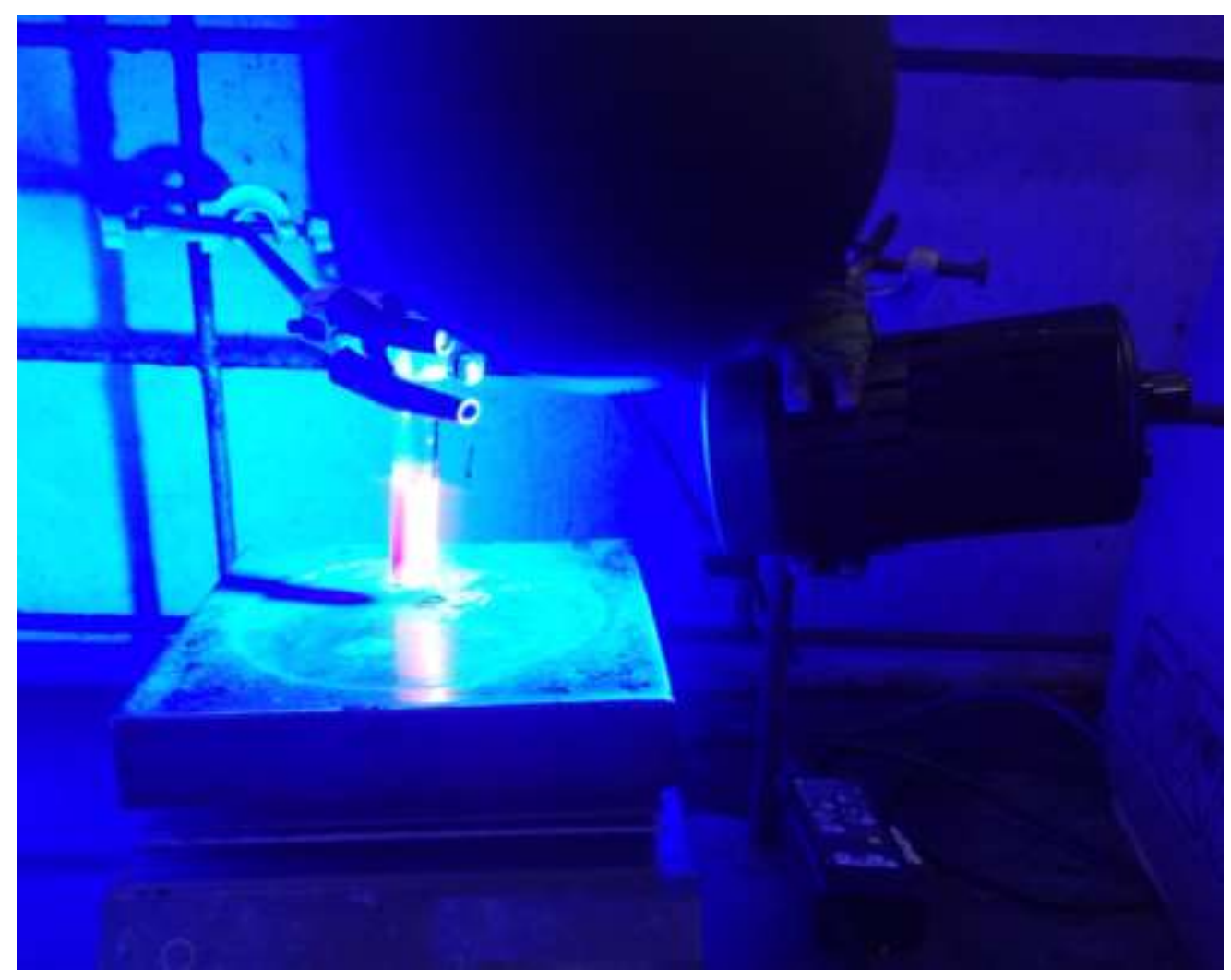

Image S1: Reaction setup with Kessil PR160L-456nm Blue LED 


\section{General Experimental Procedure.}

\section{1: General procedure A for synthesis of $N, N$-dibenzylanilines.}

To a mixture of aniline $(2.19 \mathrm{~g}, 10 \mathrm{mmol})$ and $\mathrm{K}_{2} \mathrm{CO}_{3}$ (2.0 equiv $2.76 \mathrm{~g}$ ) in DMF was added benzyl bromide (3.0 equiv $4.26 \mathrm{~g}$ ) dropwise. The mixture was stirred at room temperature overnight. Water was added to the mixture and extracted with ethyl acetate twice. The combined organic phase was washed with brine and dried over $\mathrm{Na}_{2} \mathrm{SO}_{4}$. The concentrated residue was purified by column chromatography over silica gel using EtOAc/Hexanes (1:9) as eluent to furnish the corresponding $N, N$-dibenzylanilines.

\section{2: Typical Procedure B for the Preparation of amides.}

Reaction tube was charged with $N, N$-dibenzylanilines $(0.36 \mathrm{mmol})$ and rose bengal $(5 \mathrm{~mol} \%)$ in acetone $(8 \mathrm{~mL})$. The reaction mixture was stirred in the presence of $\mathrm{O}_{2}$ (balloon) under blue light for 35 hours. After completion of the reaction, solvent was evaporated under reduced pressure. The crude product was purified by column chromatography using EtOAc/Hexanes (2:8) as eluent to furnish the corresponding amide compounds.

\section{3: Typical Procedure C for the Preparation of 2-Arylquinazolin-4(3H)-ones.}

Reaction tube was charged with 2-(benzylamino)benzamide $(0.25 \mathrm{mmol}), \mathrm{NH}_{4} \mathrm{~S}_{2} \mathrm{O}_{8}(0.5$ mmol) and rose bengal $(5 \mathrm{~mol} \%)$ in acetonitrile $(5 \mathrm{~mL})$. The mixture was stirred in the presence of $\mathrm{O}_{2}$ (balloon) under blue light for 12 hours. After completion of the reaction (monitored by TLC analysis), water $(25 \mathrm{~mL})$ was added, and the resulting mixture was extracted with EtOAc $(3 \times 20 \mathrm{~mL})$ and then dried over anhydrous $\mathrm{Na}_{2} \mathrm{SO}_{4}$. The mixture was concentrated under reduced pressure followed by column chromatography using EtOAc/Hexanes (3:7) as eluent to give 2-arylquinazolin-4(3H)-ones. 


\section{Preliminary mechanistic study}

\section{1: Intermediate-trapping experiments and By-products.}

Reaction tube was charged with $N, N$-dibenzylanilines $(0.36 \mathrm{mmol})$ and rose bengal $(5 \mathrm{~mol} \%)$ in acetone $(8 \mathrm{~mL})$. The reaction mixture was stirred in the presence of $\mathrm{O}_{2}$ (balloon) under blue light for 10 hours. The formation of intermediates $\mathbf{D}$ (Figure S1) and $\mathbf{1 0}$ (Figure S2) were detected. The formation of by-products benzaldehyde $\mathbf{E}$ (Figure S3) and benzoic acid $\mathbf{F}$ (Figure S5) were also detected by using HRMS showing bellow.
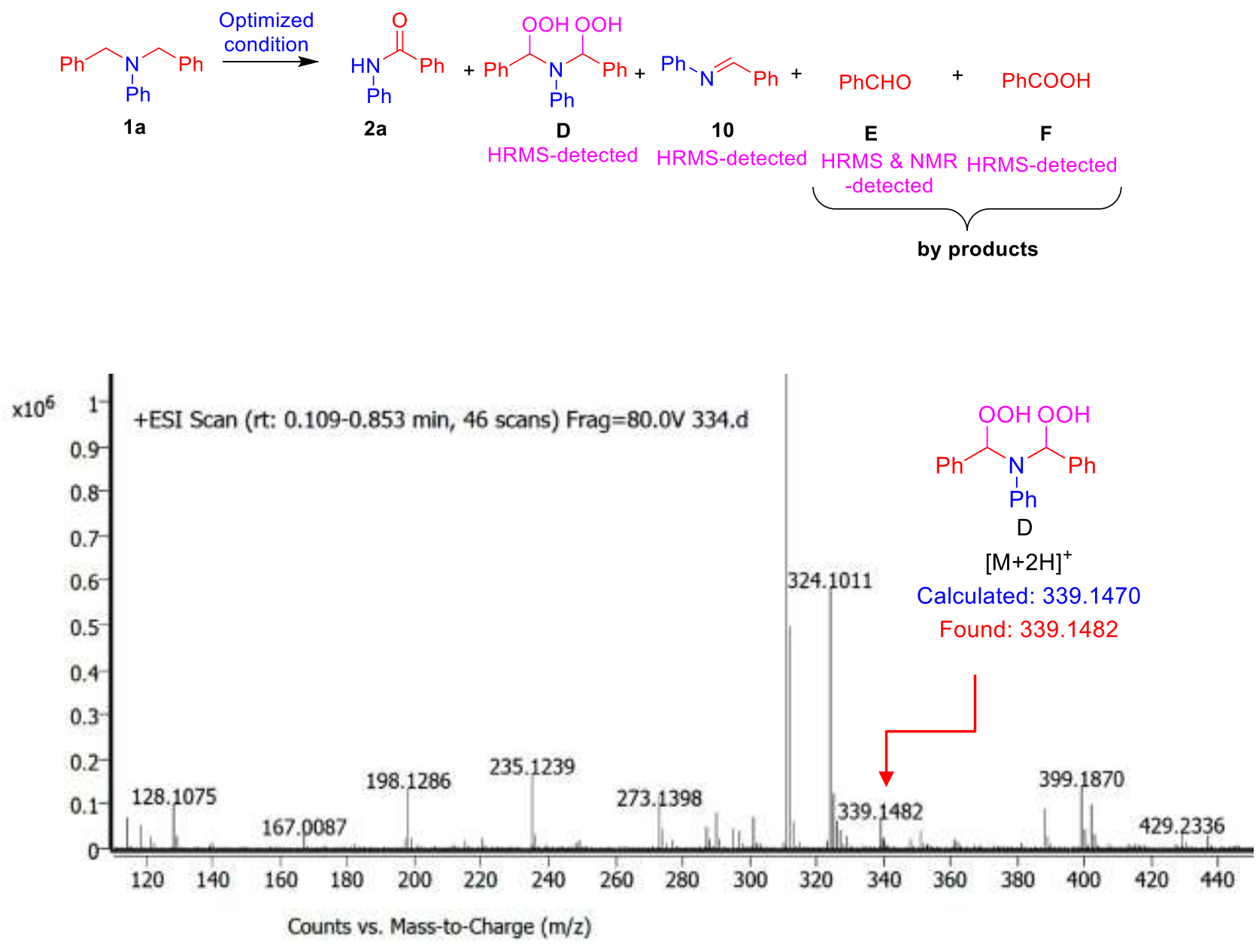

Figure S1. Analysis of reaction mixture by HRMS 


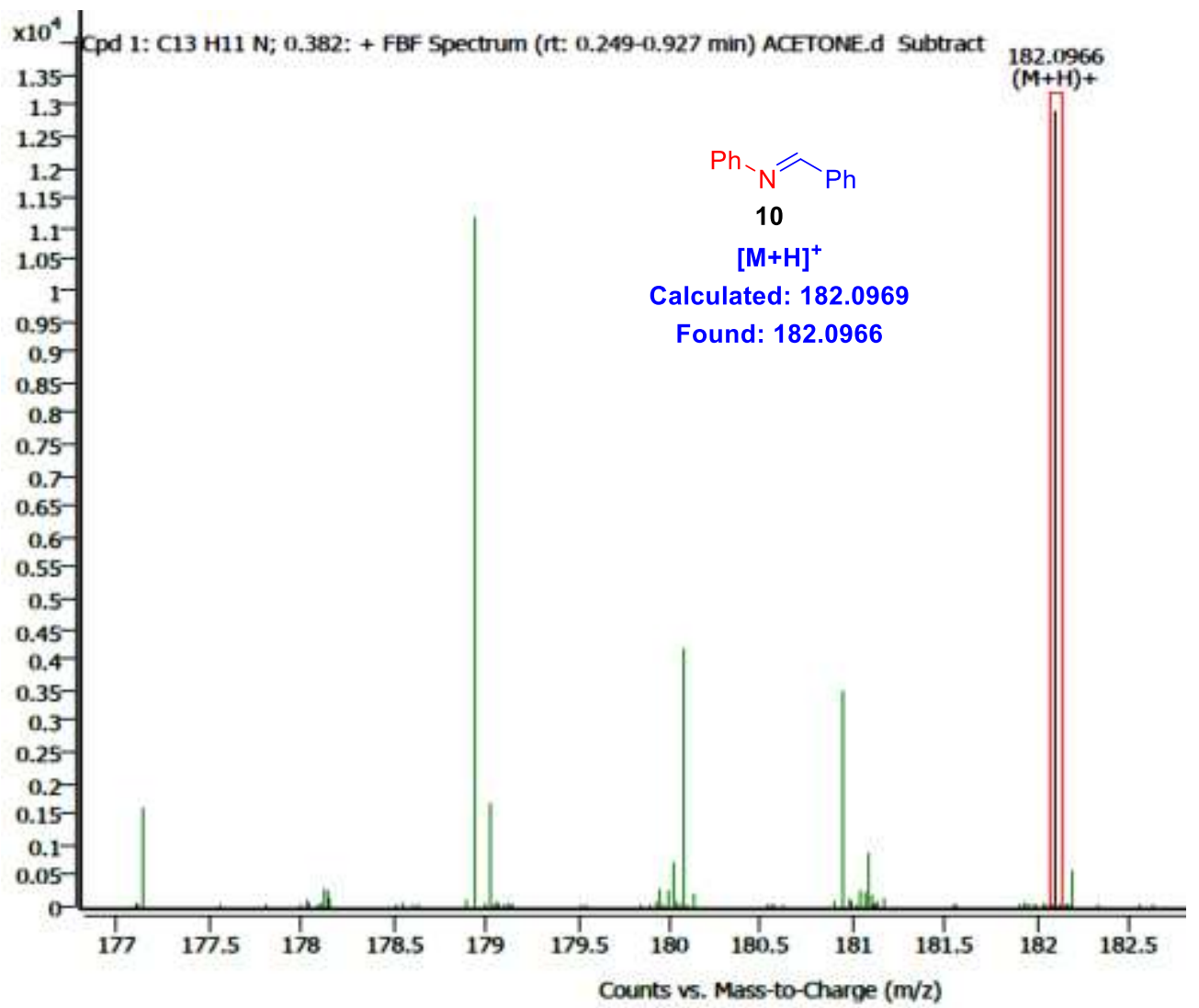

Figure S2. Analysis of reaction mixture by HRMS

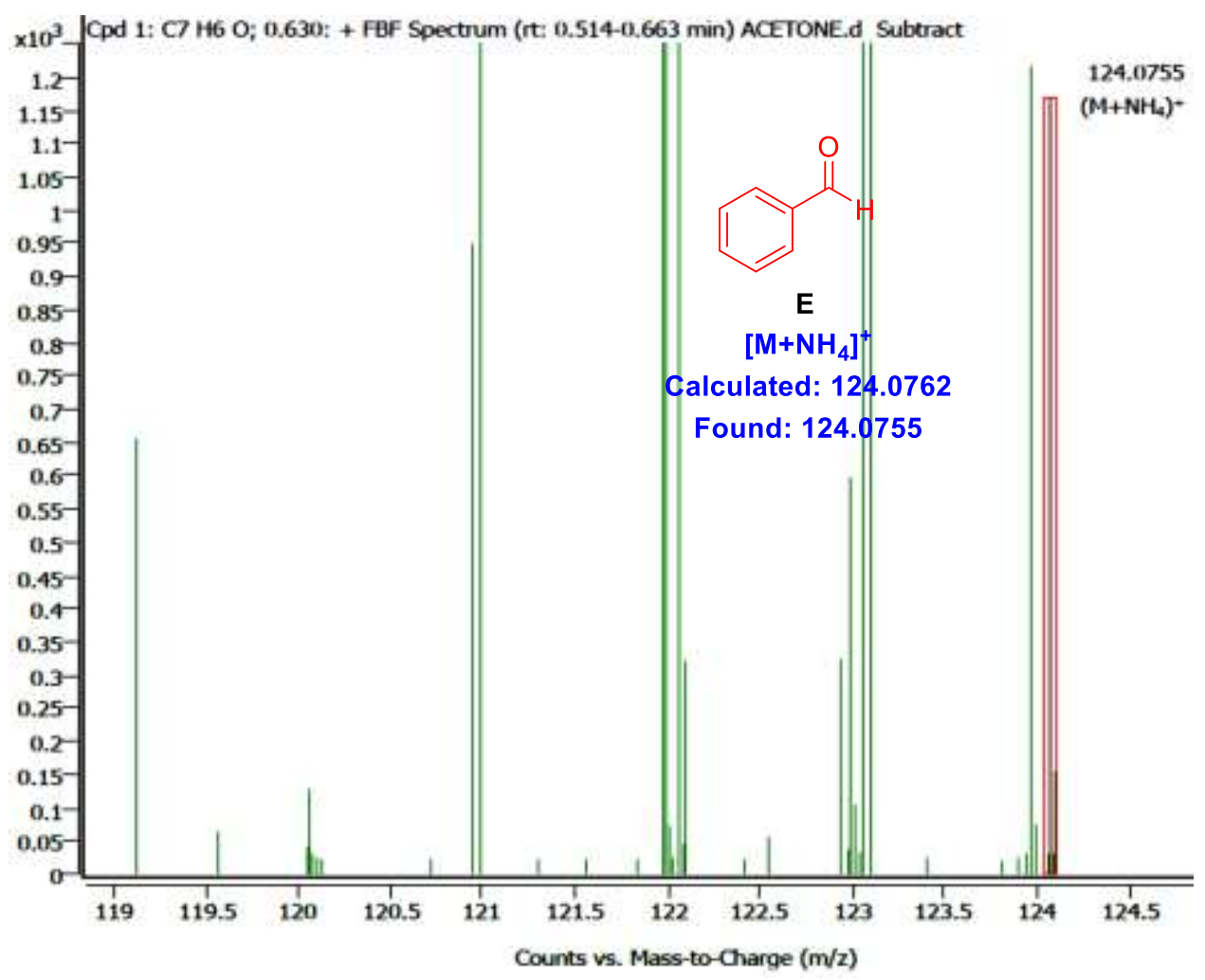

Figure S3. Analysis of reaction mixture by HRMS 


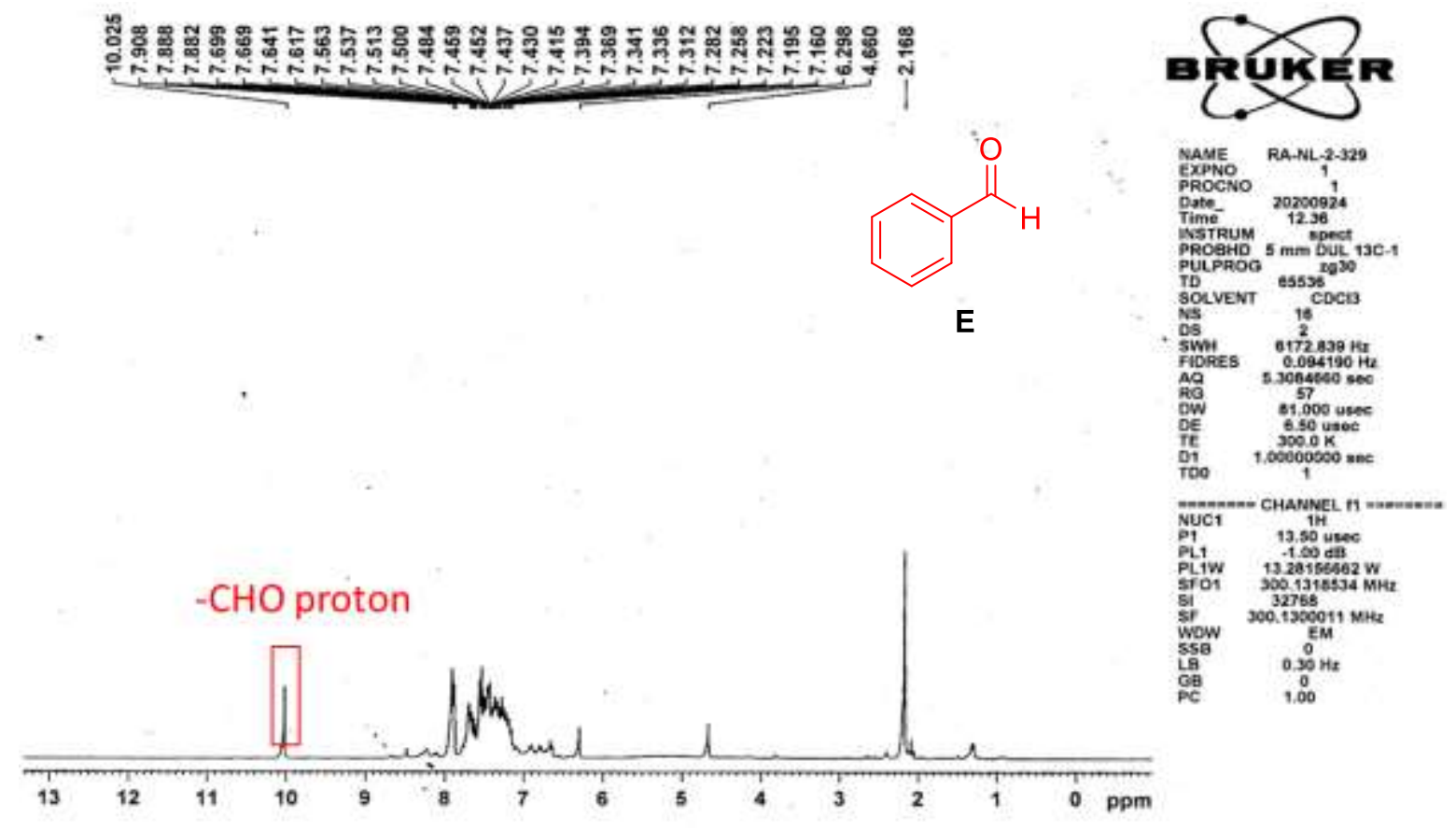

Figure S4. ${ }^{\mathbf{1}} \mathrm{H}$ NMR (300 MHz) spectrum of Compound $\mathbf{E}$

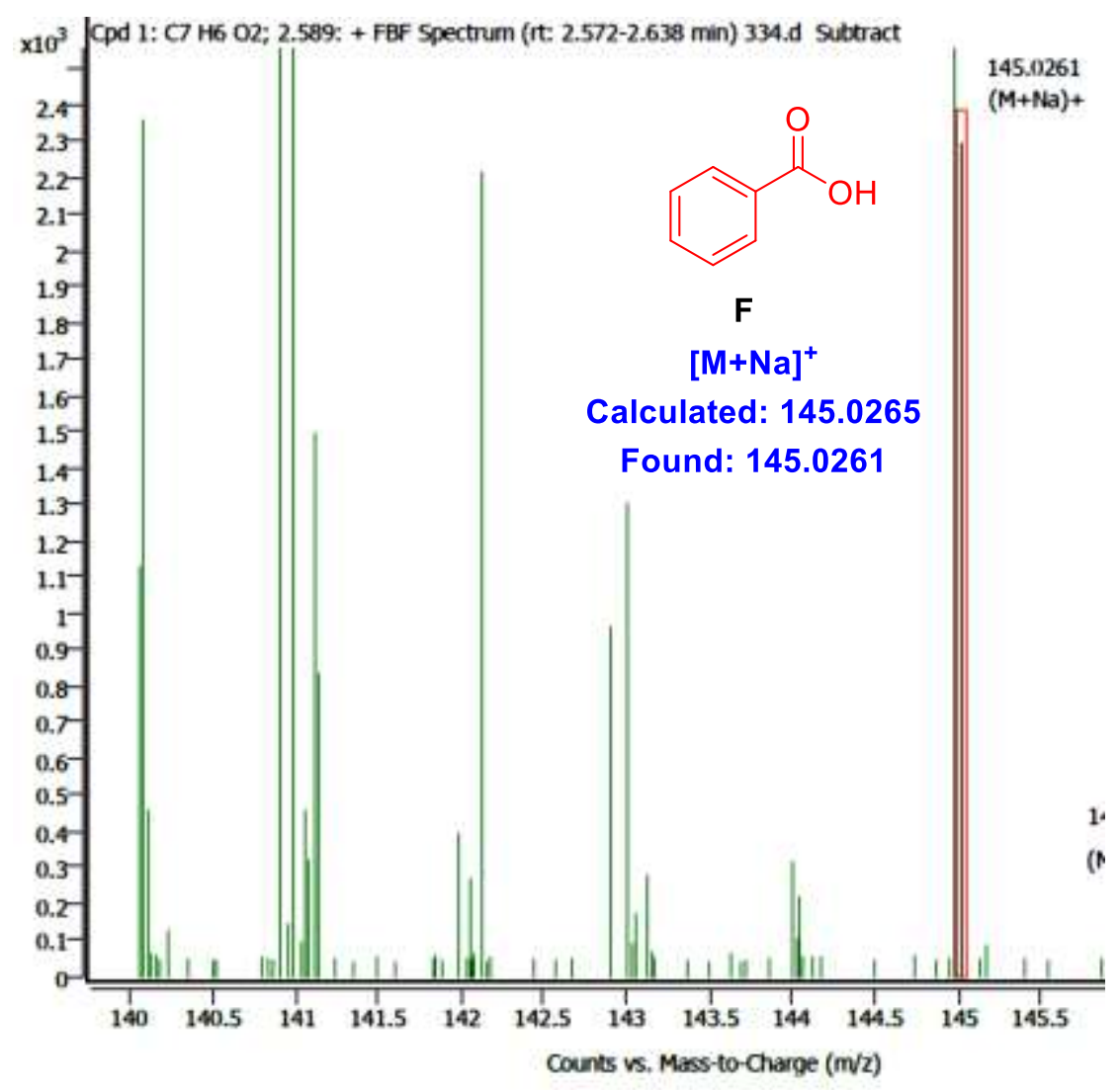

Figure S5. Analysis of reaction mixture by HRMS 


\section{2: Quenching experiments}

To understand the reactive oxygen species in our reaction, quenching experiments were carried out with several scavengers under optimized conditions as shown in Figure S6. No compound 2a was observed with the addition of 1.5 Equiv. of TEMPO as a radical scavenger. Also, a singlet oxygen quencher $\mathrm{NaN}_{3}$ and superoxide radical anion quencher benzoquinone (BQ) suppressed the yield of compound 2a to $20 \%$ and $5 \%$, respectively, which indicates that the involvement of radical, singlet oxygen $\left({ }^{1} \mathrm{O}_{2}\right)$, and superoxide radical anion $\left(\mathrm{O}_{2}^{-\cdot}\right)$ in our photocatalytic reaction.

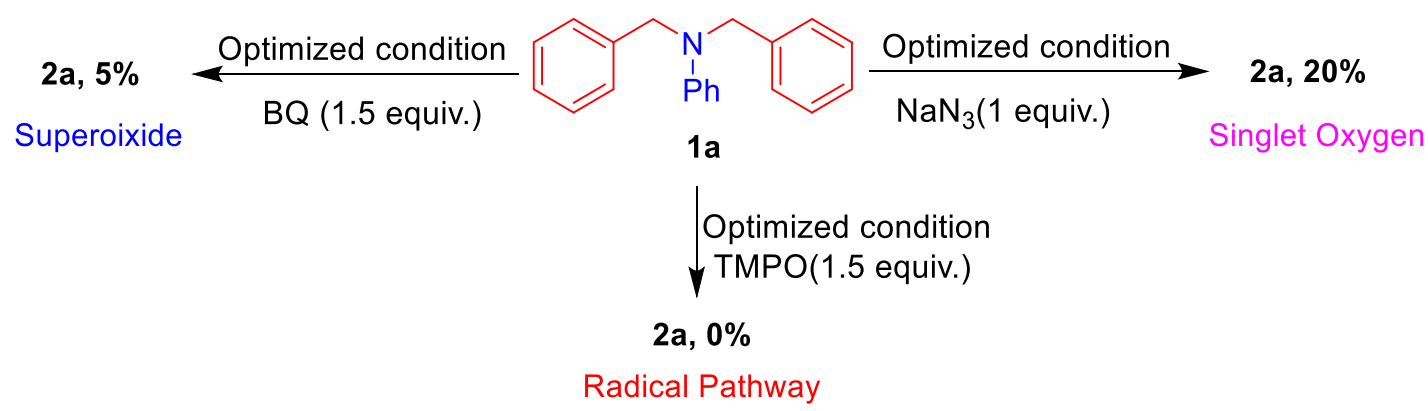

Figure S6: Quenching Experiments

\section{3: Studies on $\mathrm{C}-\mathrm{N}$ bond cleavage.}

To gain insight into $\mathrm{C}-\mathrm{N}$ bond cleavage, the $\mathrm{N}$-benzyl- $N$-(4-methylbenzyl)aniline $\mathbf{1 5}$ was performed under optimized conditions with different time intervals at $8 \mathrm{~h}, 16 \mathrm{~h}$, and $32 \mathrm{~h}$ which afforded the mixture of $\mathbf{2 a}$ and $\mathbf{2 c}$ in the 1:1 ratio (Table S1). It clearly implies that different electron donating substituents on benzyl do not influence the $\mathrm{C}-\mathrm{N}$ bond cleavage. 
Table S1: C-N bond cleavage at different time

\begin{tabular}{|c|c|c|c|c|c|}
\hline S.NO & Time & \multicolumn{2}{|c|}{ Mixture of 2a \& 2c (mg) } & $2 a^{a}$ & $2 c^{a}$ \\
\hline 1 & $8 \mathrm{~h}$ & & 17 & $11 \%$ & $13 \%$ \\
\hline 2 & $16 \mathrm{~h}$ & & 28 & $20 \%$ & $20 \%$ \\
\hline 3 & $32 \mathrm{~h}$ & & 45 & $31 \%$ & $29 \%$ \\
\hline
\end{tabular}

${ }^{\mathrm{a}}$ The $\%$ yield of the mixture was determined from ${ }^{1} \mathrm{H}$ NMR spectrum (Figure S7 and S8).

œ œ

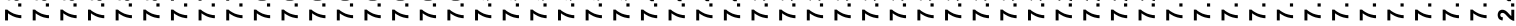

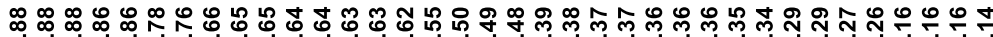

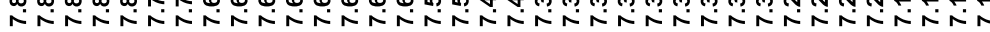

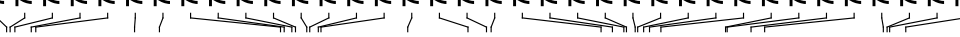<smiles>O=C(Nc1ccccc1)c1ccccc1</smiles>

$2 a$

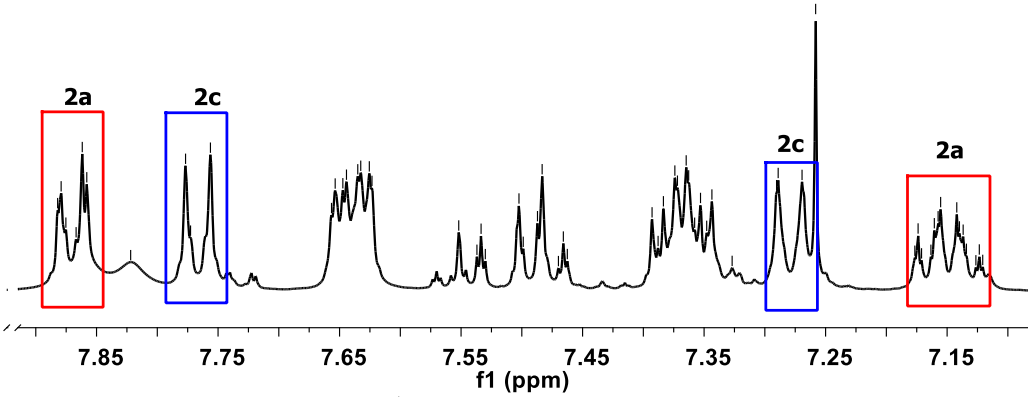<smiles>Cc1ccc(C(=O)Nc2ccccc2)cc1</smiles>

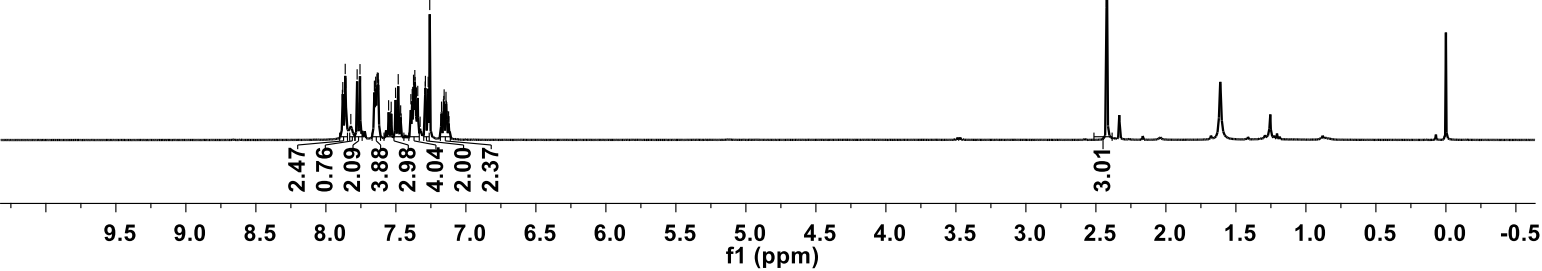

Figure S7. ${ }^{\mathbf{1}} \mathrm{H}$ NMR (400 MHz) spectrum of mixture of $\mathbf{2 a}$ and $\mathbf{2 c}$ compound 


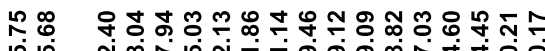

லั

$\stackrel{\text { ก }}{\stackrel{1}{\perp}}$

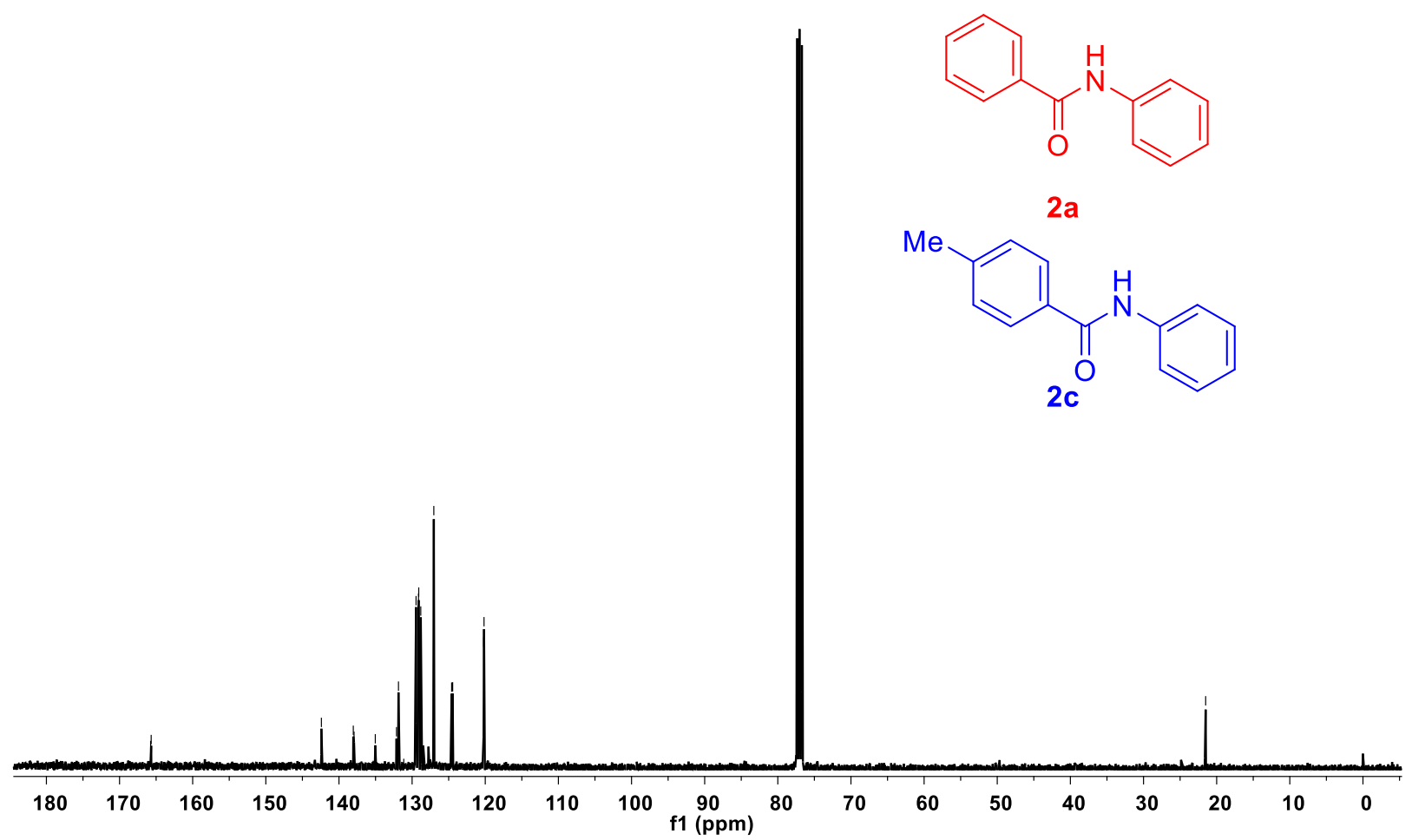

Figure S8. ${ }^{13} \mathrm{C}\left\{{ }^{1} \mathrm{H}\right\}$ NMR (101 MHz) spectrum of Mixture of 2a and 2c compound 


\section{4: Determination of singlet oxygen species:}

EPR spectra were recorded at room temperature on a JEOL Model JES FA200 instrument as shown in Figure S9. In order to identify the active species of singlet oxygen involved during the reaction, 2,2,6,6-tetramethylpiperidine (TEMP) was used to trap ${ }^{1} \mathrm{O}_{2}$. Reaction mixture of TEMP, $N, N$-dibenzylaniline and rose bengal in the presence of $\mathrm{O}_{2}$ atmosphere under blue LED $(456 \mathrm{~nm})$ irradiation resulted in the formation of a strong characteristic signal ${ }^{1} \mathrm{O}_{2}$ adduct with TEMP.

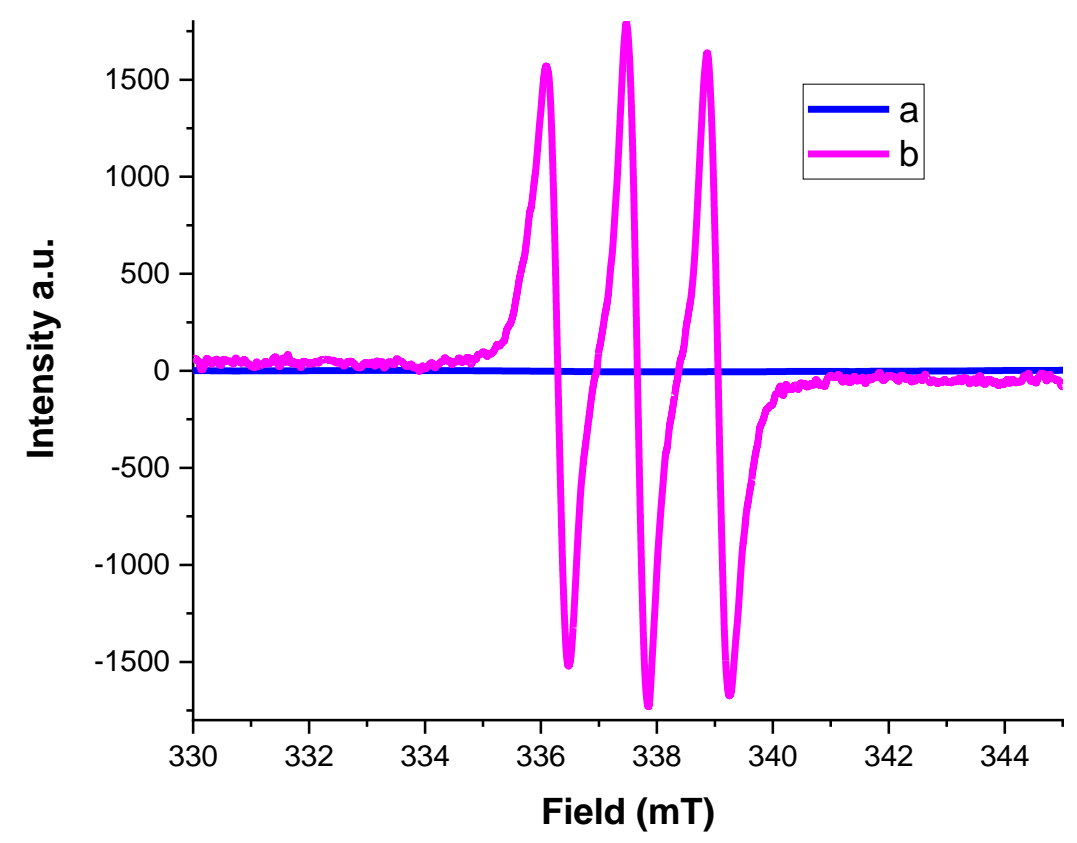

Figure S9. EPR spectra: A solution of TEMP $(0.02 \mathrm{~mL}), N, N$-dibenzylanilines $1 \mathrm{a}(0.36$ $\mathrm{mmol})$ and rose bengal $(5 \mathrm{~mol} \%)$ in acetone $(8 \mathrm{~mL})$ under $\mathrm{O}_{2}$ atmosphere. (a) Without blue LED irradiation; (b) with blue LED irradiation for 10 minutes. 


\section{5: UV-Visible Absorption spectra}

UV-Visible absorptions characterizations were done for the substrates $\mathbf{1 i}, \mathbf{4 e}, \mathbf{4 i}$ and 6e to under the absorption nature of the compound which is given in Figure S10-13. The molecules show absorption around in range of 360 to $390 \mathrm{~nm}$. These experiments disclose that the molecule can act as photosensitizer.

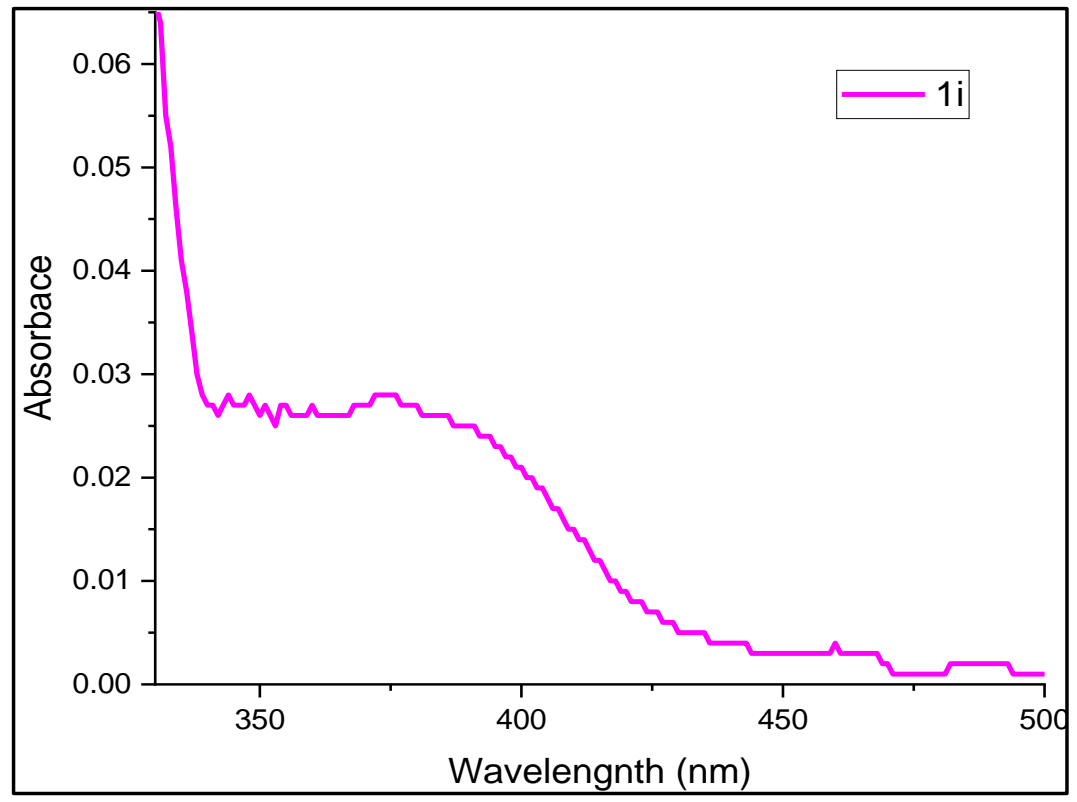

Figure S10. Absorption spectra of $N, N$-bis(4-chlorobenzyl)aniline (1i) in acetone 


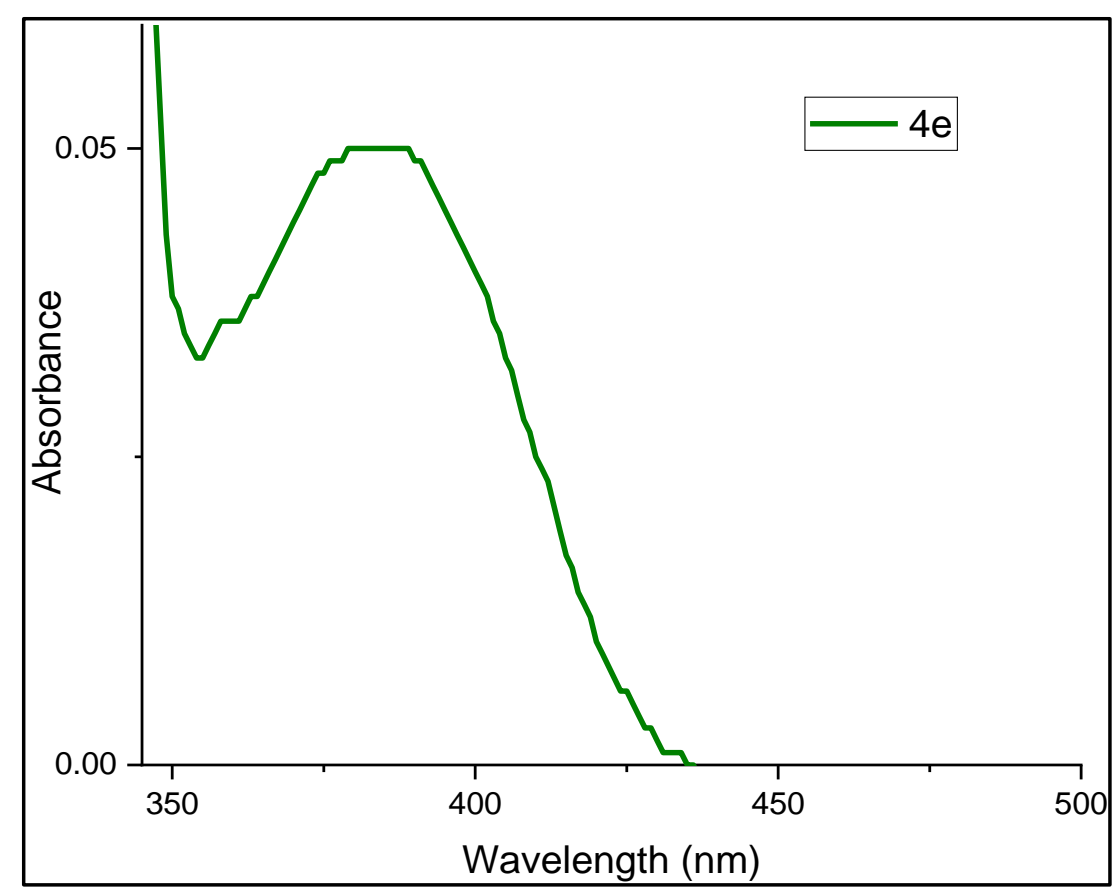

Figure S11. Absorption spectra of $N, N$-dibenzyl-4-chloroaniline (4e) in acetone

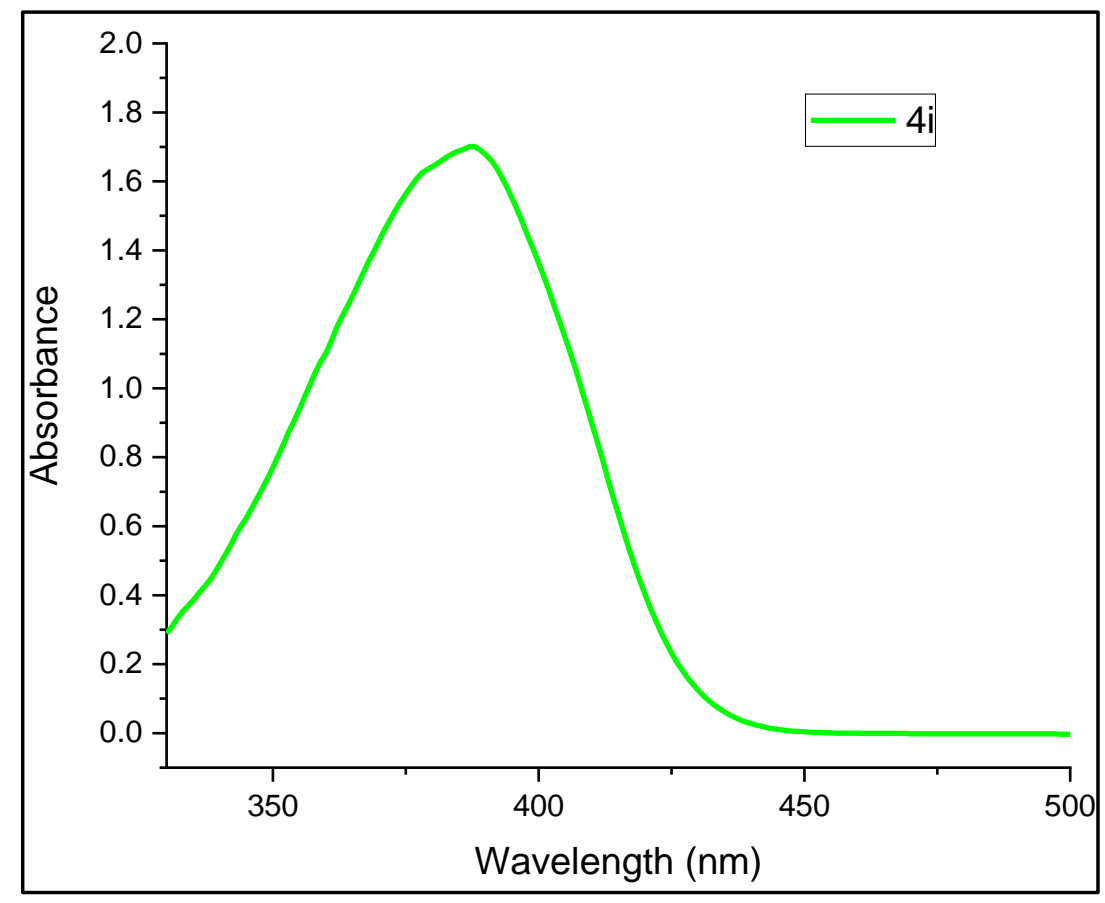

Figure S12. Absorption spectra of $N, N$-dibenzyl-4-nitroaniline (4i) in acetone 


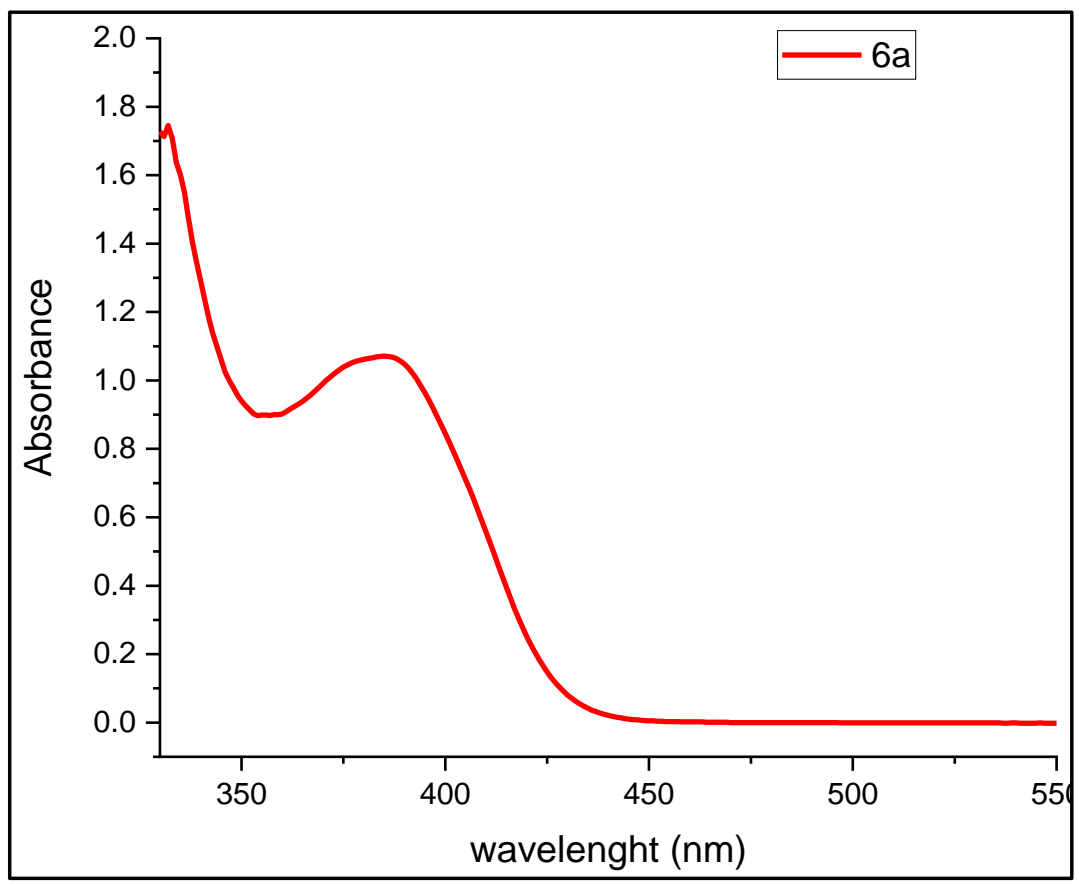

Figure S13. Absorption spectra of 2-(dibenzylamino)benzamide (6a) in acetone 


\section{6: Evaluation of green chemistry metrics for the synthesis of $2 a$}

We have evaluated the green chemistry metrics for the synthesis of $N$-phenylbenzamide $\mathbf{2 a}$

\subsection{1: Atom economy:}

Atom economy defined as "how much of the reactants remain in the final desired product"

$$
\text { Atom economy }(A E)(\%)=\frac{\text { Molecular mass of desired product }}{\text { Molecular mass of all reactant }} \times 100
$$

\subsection{2: Reaction mass efficiency:}

Reaction mass efficiency (RME) defined as "the percentage of the mass of the reactants that remain in the product"

$$
\text { Reaction mass efficiency }(\%)=\frac{\text { Mass of desired product }}{\text { Mass of all reactant }} \times 100
$$

\subsection{3: Reaction scheme for evaluation of green chemistry metrics}

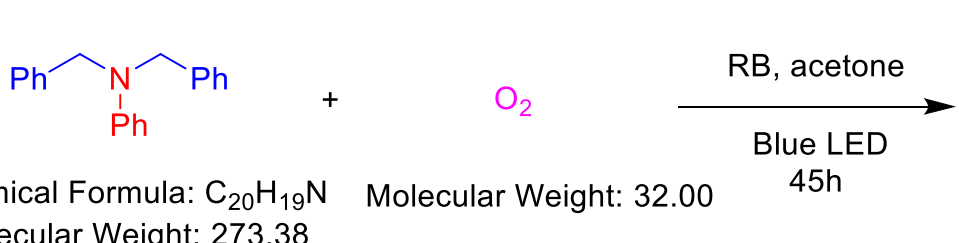

Molecular Weight: 273.38

$1 \mathrm{a}, 1.3 \mathrm{~g}$

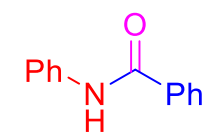

Chemical Formula: $\mathrm{C}_{13} \mathrm{H}_{11} \mathrm{NO}$ Molecular Weight: 197.24

$2 \mathrm{a}, 64 \%, 0.6 \mathrm{~g}$

Table S2: Evaluation of green chemistry metrics for the synthesis of $\mathbf{2 a}$

\begin{tabular}{|l|l|l|c|c|}
\hline Reactant & $N, N$-dibenzylaniline 1a & $1.3 \mathrm{~g}$ & $5 \mathrm{mmol}$ & FW 273.38 \\
\hline Solvent & Acetone & $25.51 \mathrm{~g}$ & - & \\
\hline Recycled solvent & Acetone & $6.37 \mathrm{~g}$ & - & - \\
\hline Product & $N$-phenylbenzamides 2a & $0.6 \mathrm{~g}$ & $3.04 \mathrm{mmol}$ & FW 197.24 \\
\hline
\end{tabular}

Product yield $=64 \%$

$\boldsymbol{E}-\boldsymbol{f a c t o r}=\frac{1.3 g+25.52 g-(0.6 g+6.37 g)}{0.6 g}=33.06 \mathrm{~kg}$ waste $/ 1 \mathrm{~kg}$ product

Atom economy $=\frac{197}{273+32} \times 100 \quad=64.5 \%$

Atom efficiency $=\frac{64.5 \% \times 64 \%}{100} \quad=\mathbf{4 1 . 3} \%$

Carbon efficiency $=\frac{13}{20} \times 100 \quad=65 \%$

Reaction mass efficiency $=\frac{0.6 g}{1.3 g} \times 100=46.2 \%$ 
4. Copies of ${ }^{1} \mathrm{H}$ and ${ }^{13} \mathrm{C}$ NMR and HRMS:

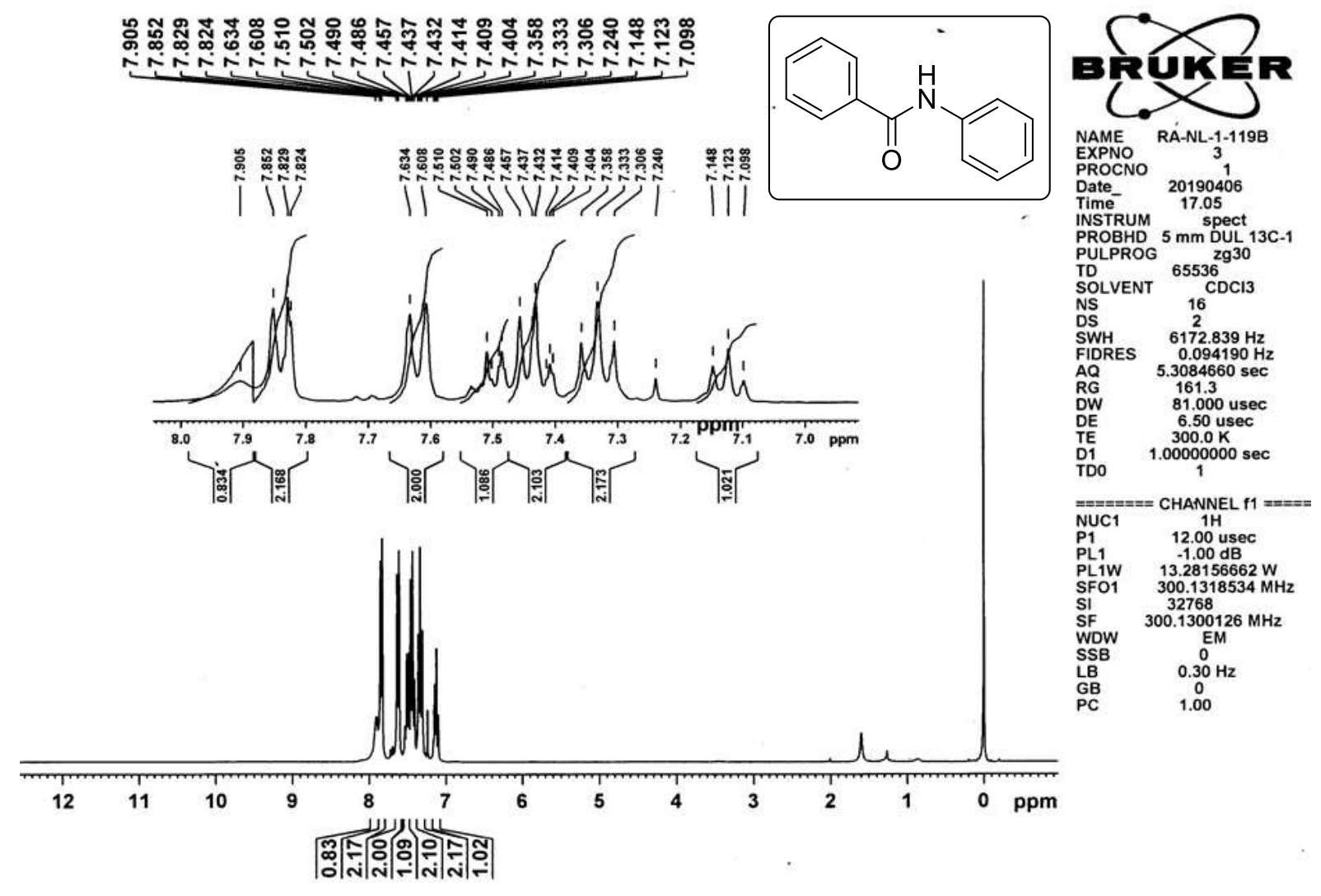

${ }^{1} \mathrm{H}$ NMR (300 MHz) spectra of compound 2a

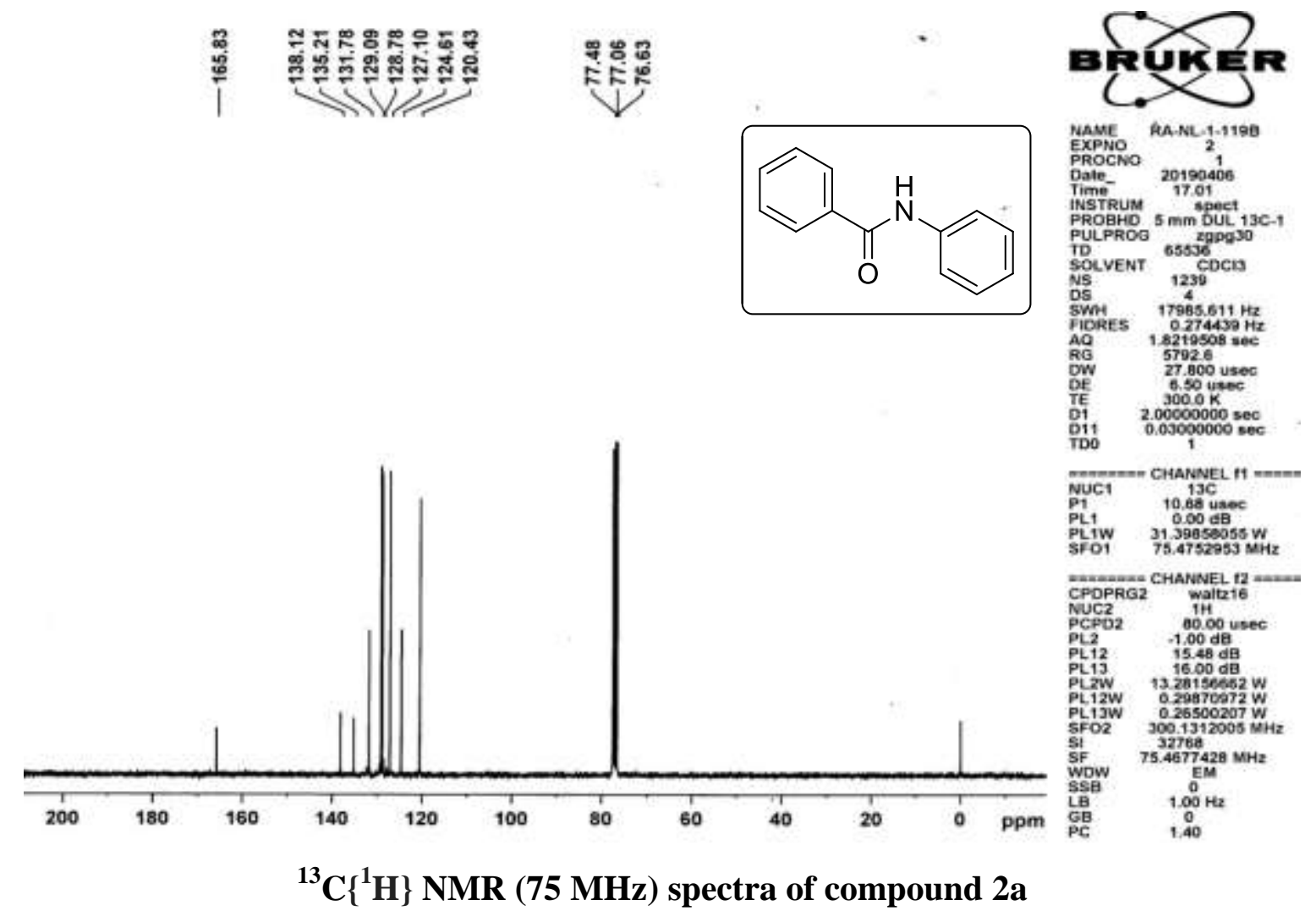




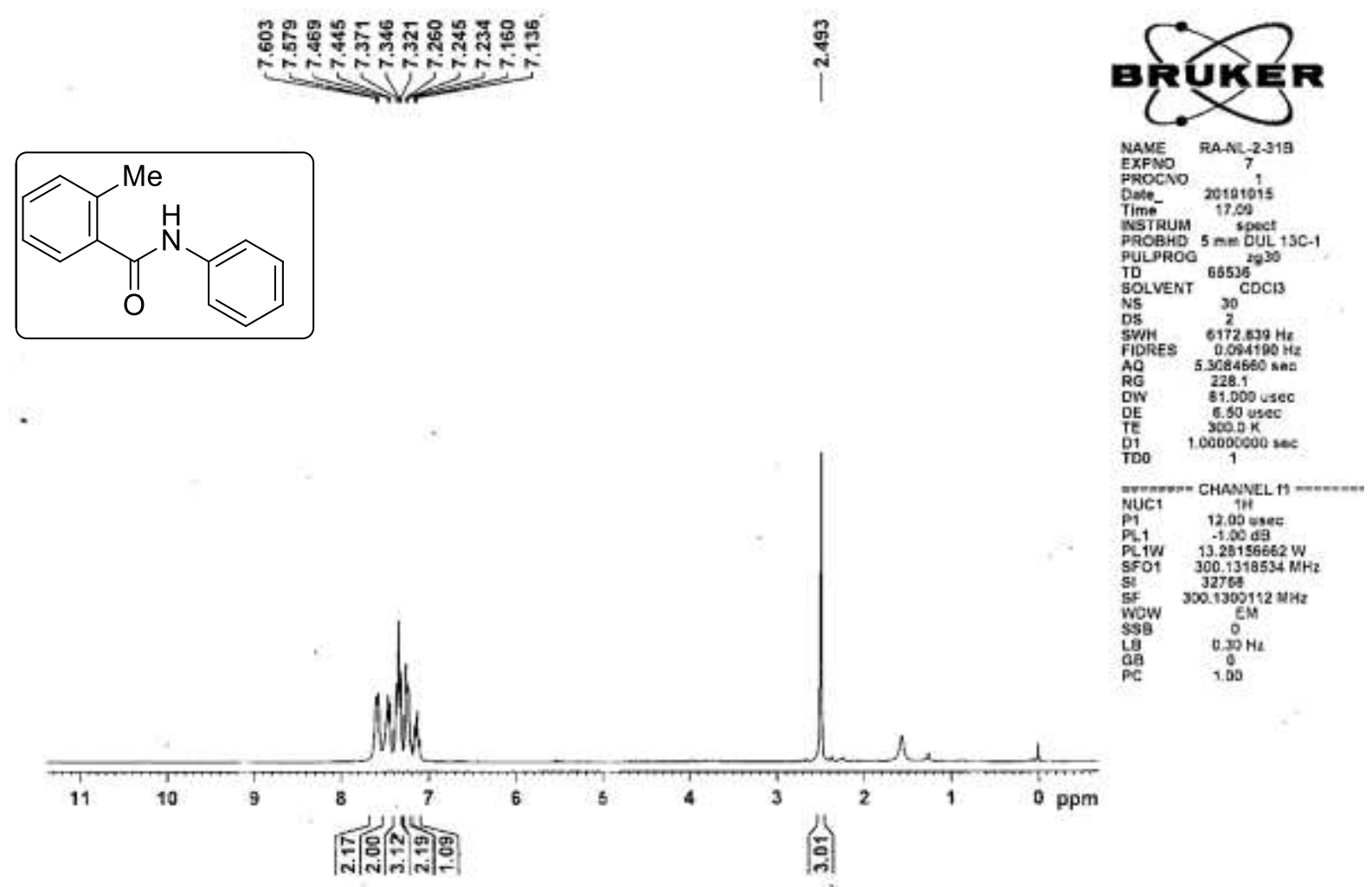

${ }^{1} \mathrm{H}$ NMR (300 MHz) spectra of compound $2 \mathrm{~b}$
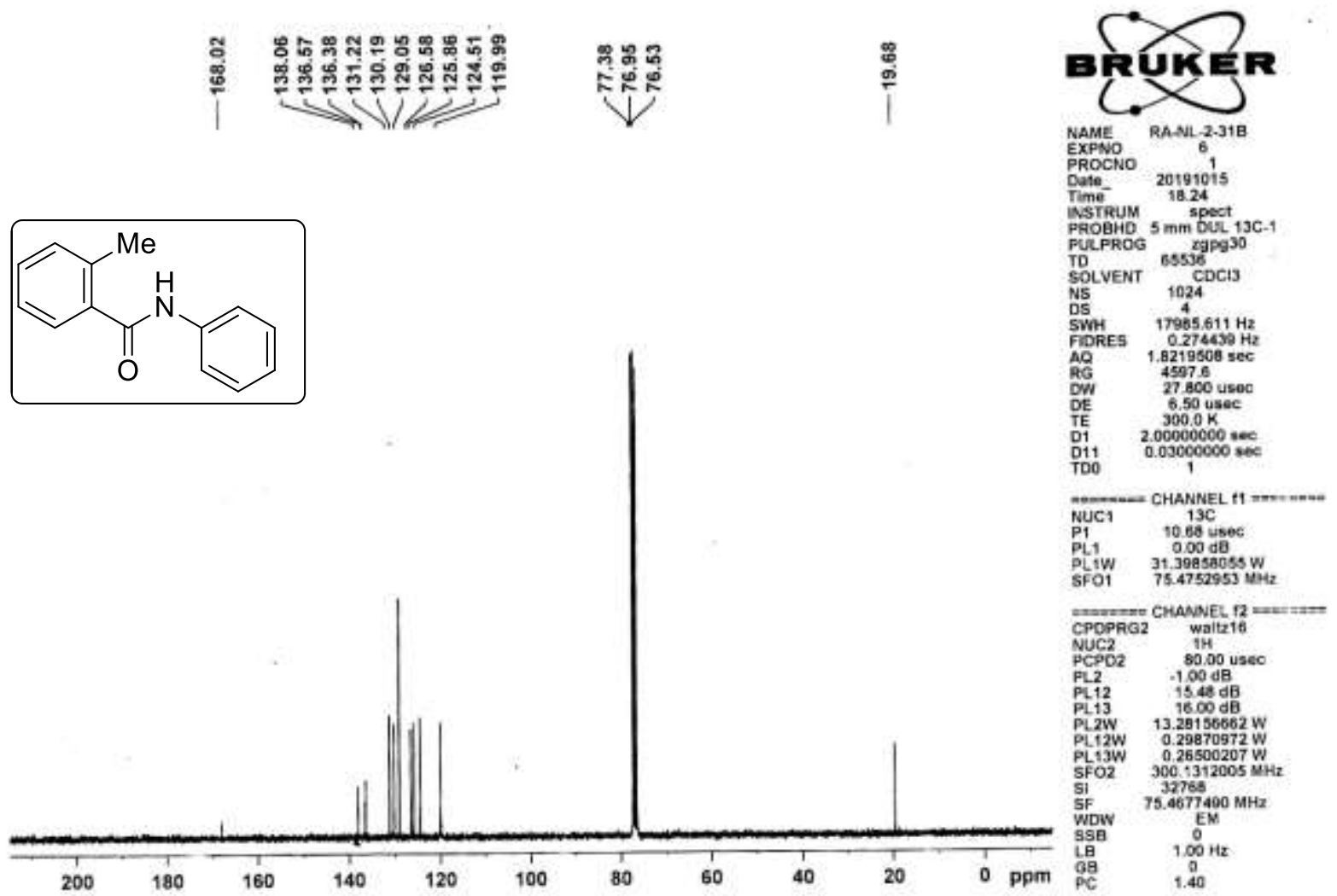

${ }^{13} \mathrm{C}\left\{{ }^{1} \mathrm{H}\right\}(75 \mathrm{MHz})$ spectra of compound $2 \mathrm{~b}$ 


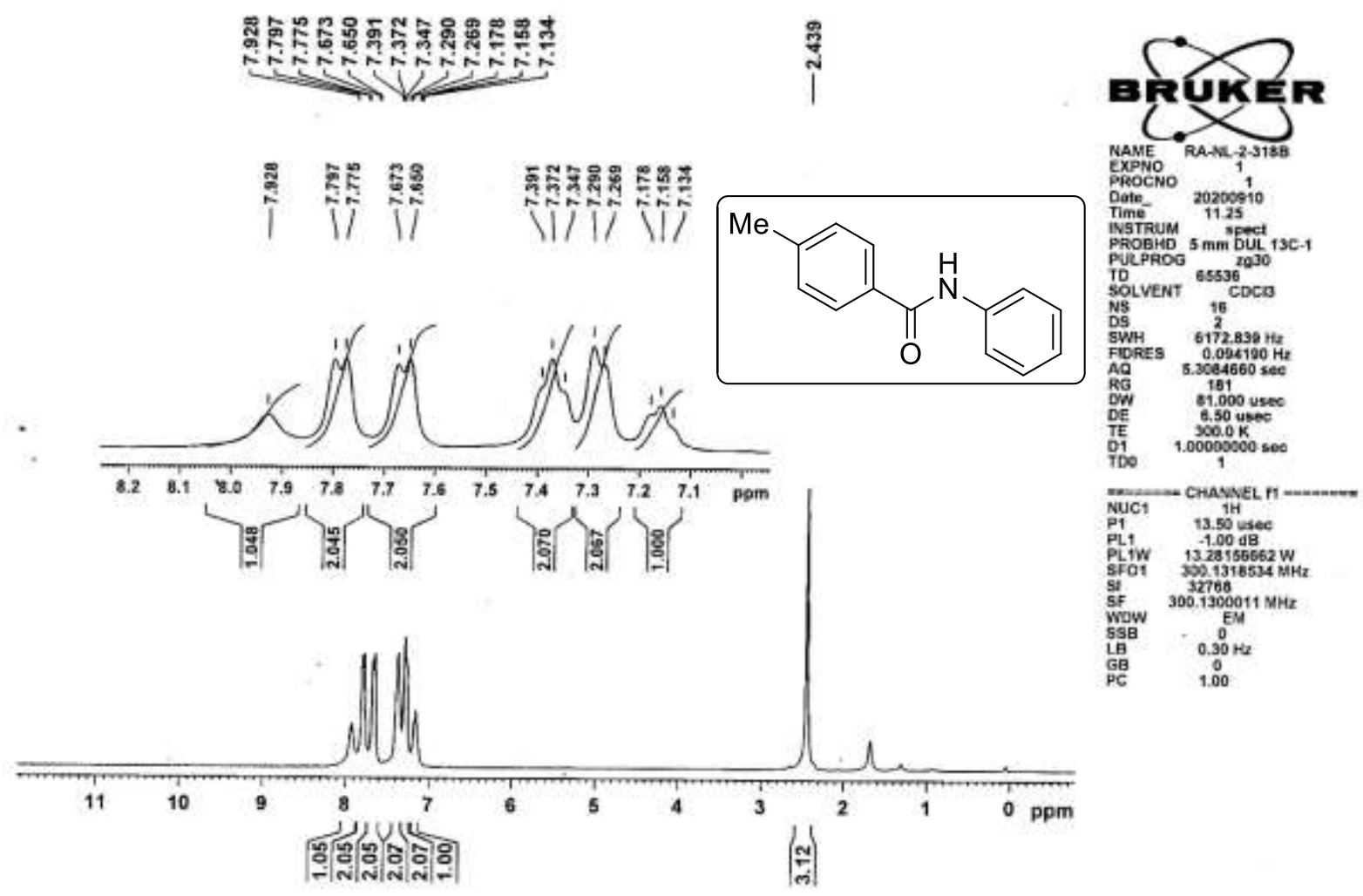

${ }^{1} \mathrm{H}$ NMR (300 MHz) spectra of compound 2c

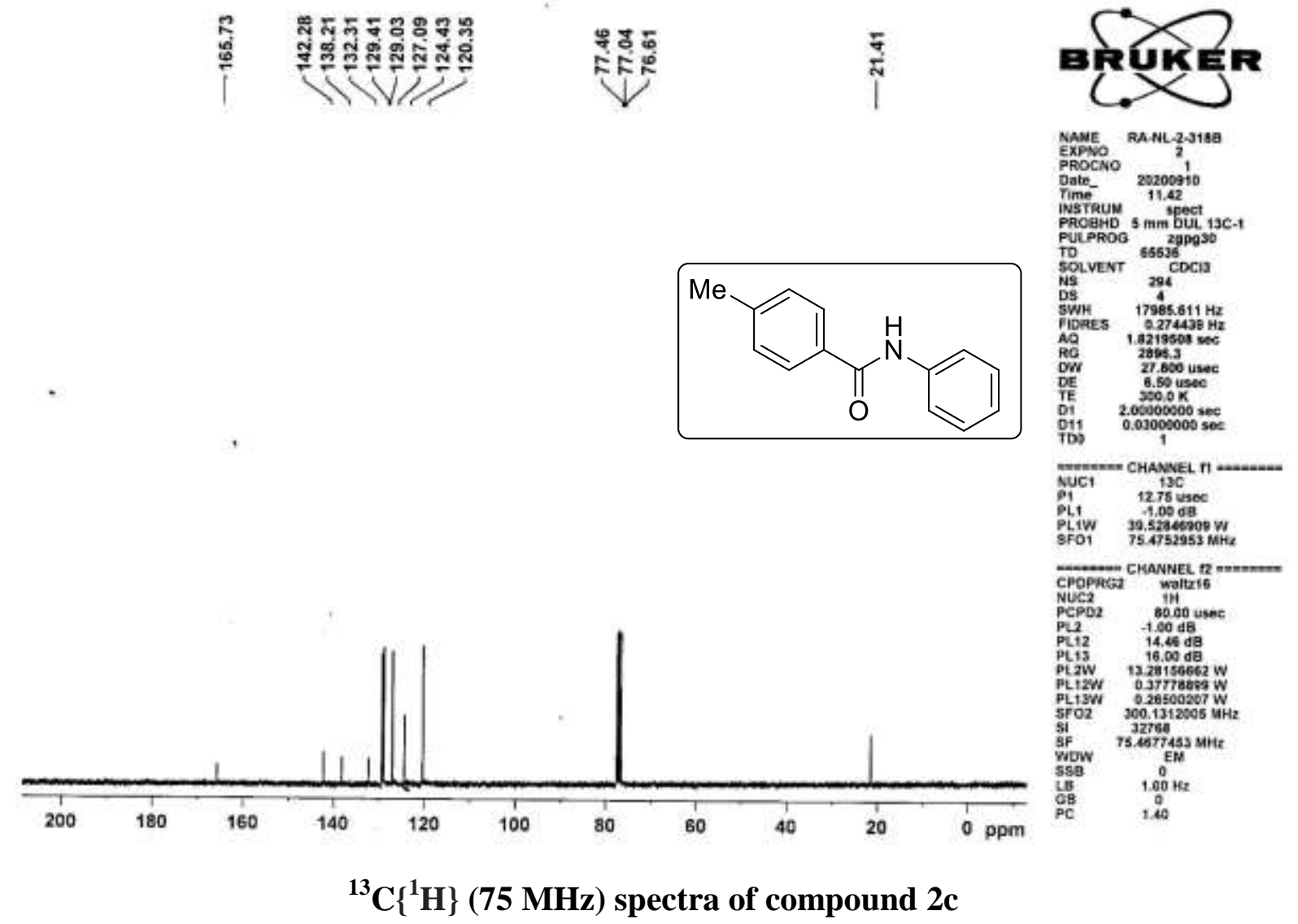




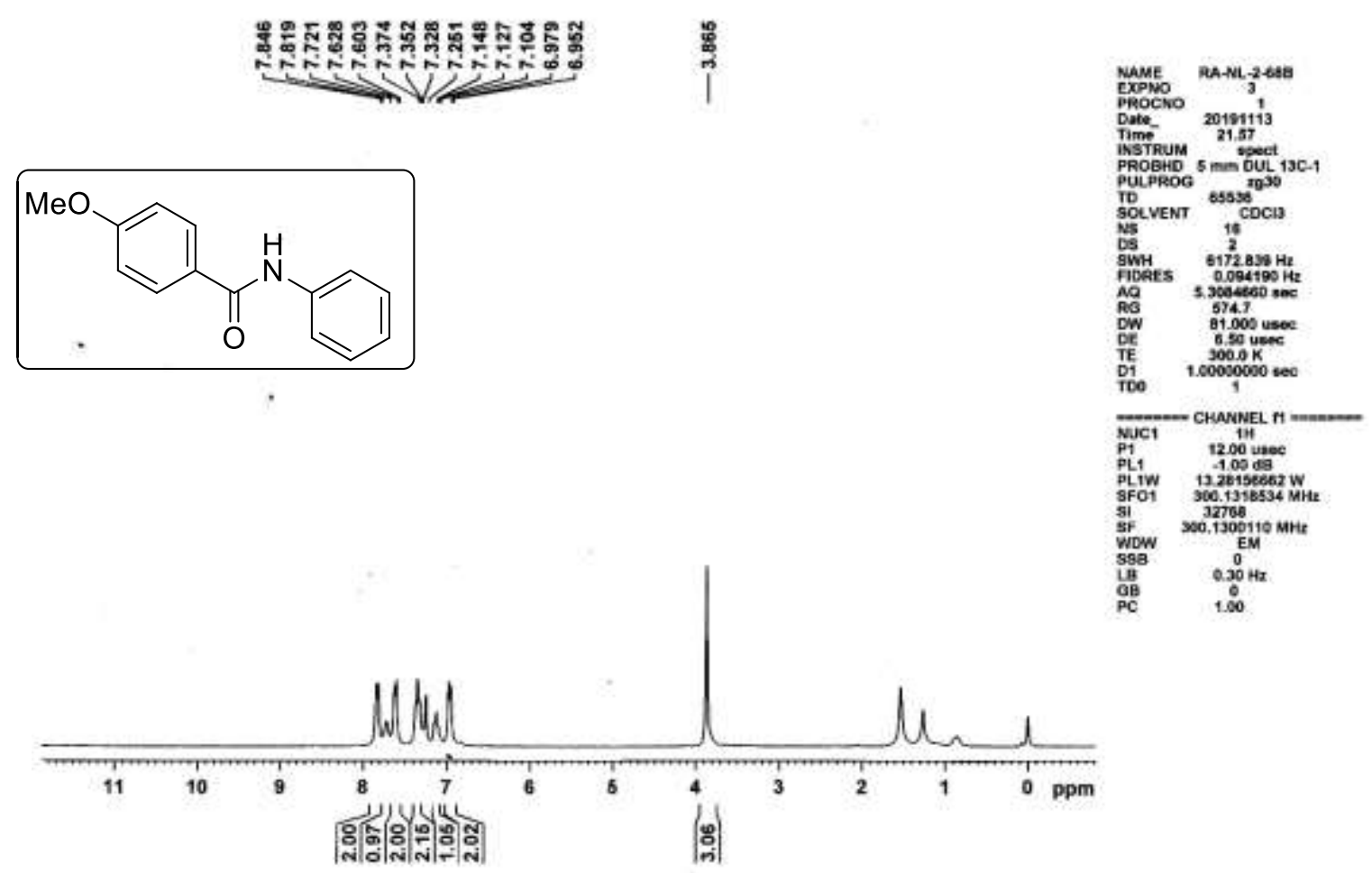

${ }^{1}$ H NMR (300 MHz) spectrum of compound 2d

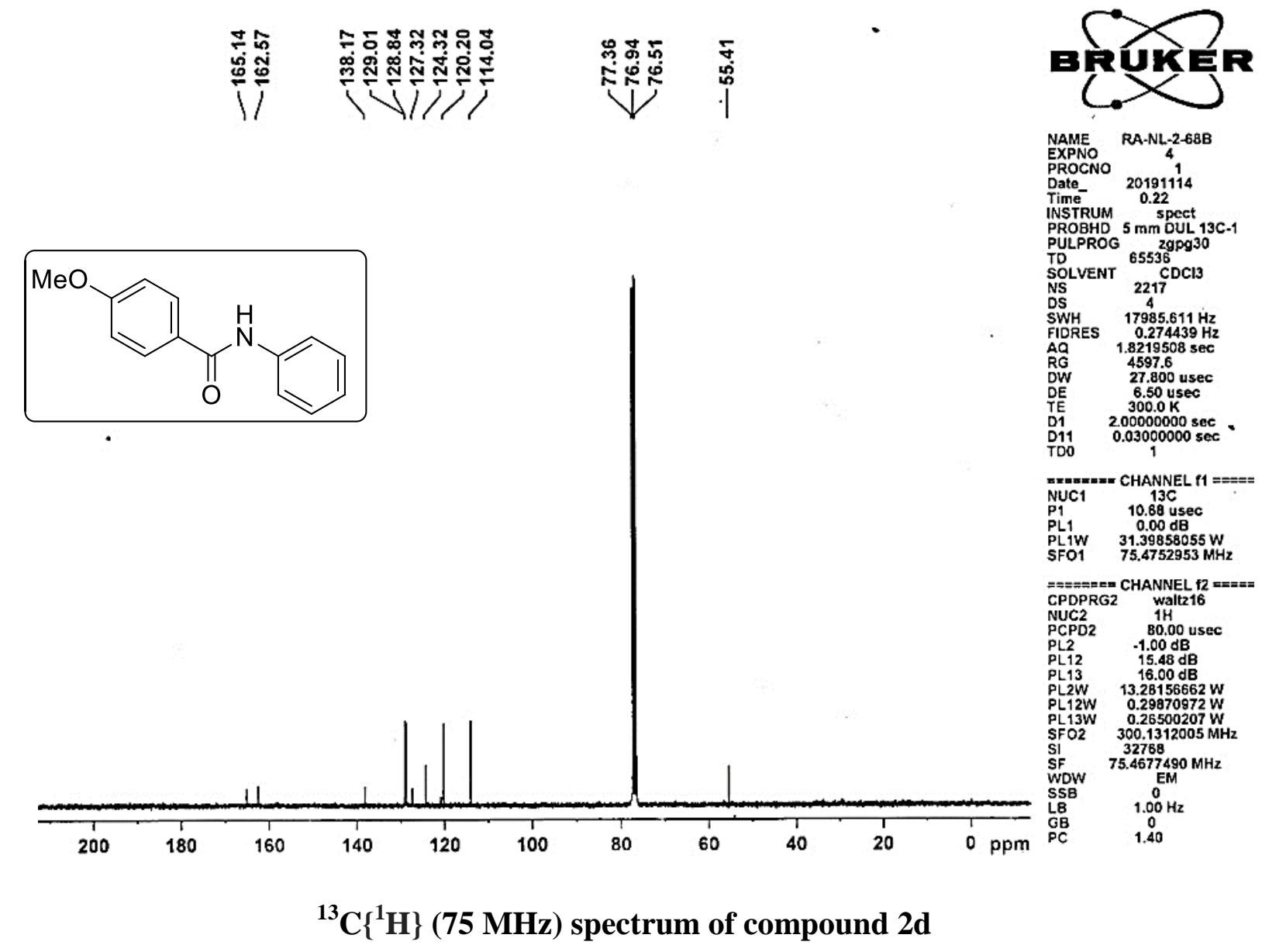




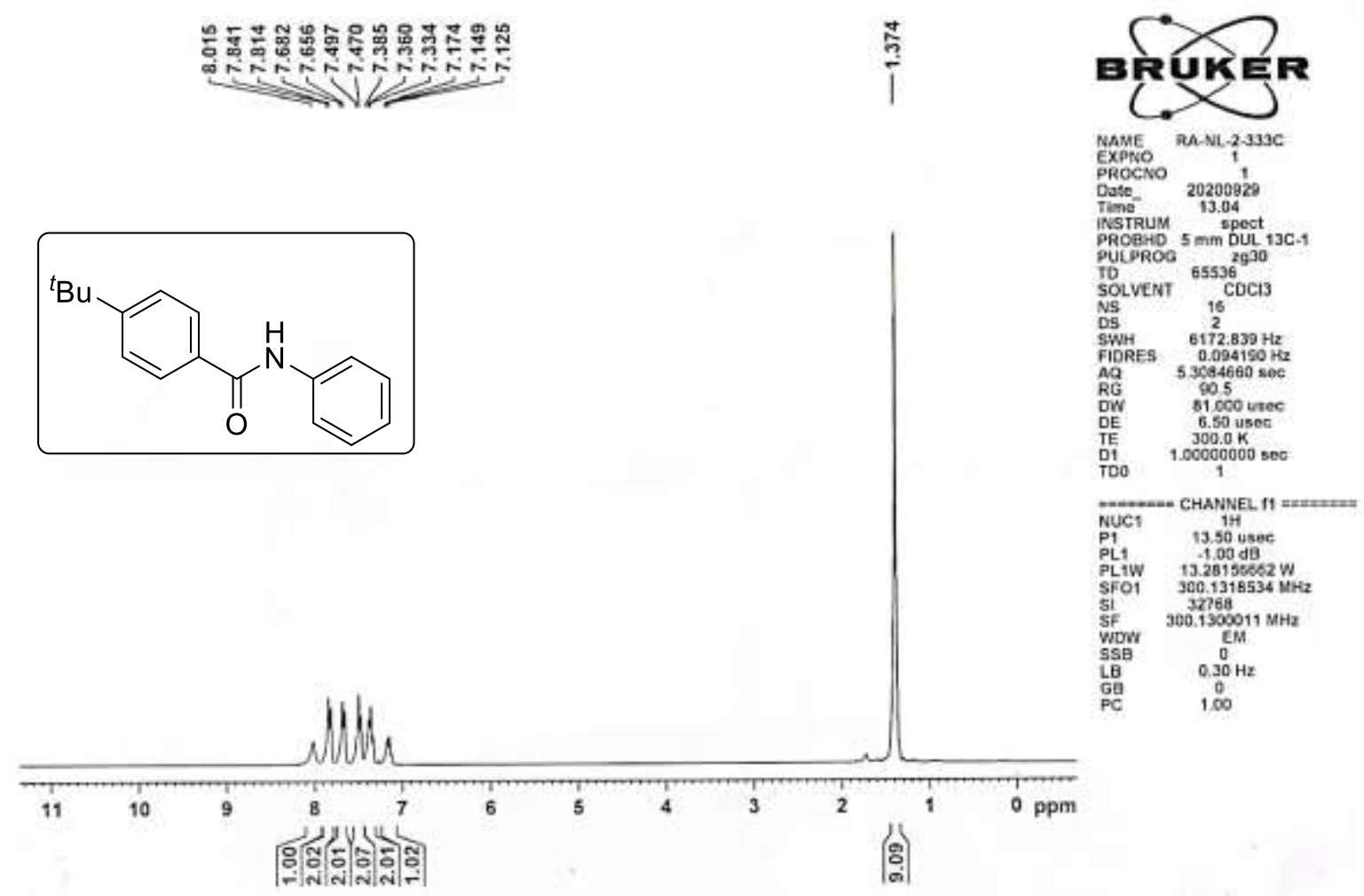

${ }^{1}$ H NMR (300 MHz) spectrum of compound $2 \mathrm{e}$

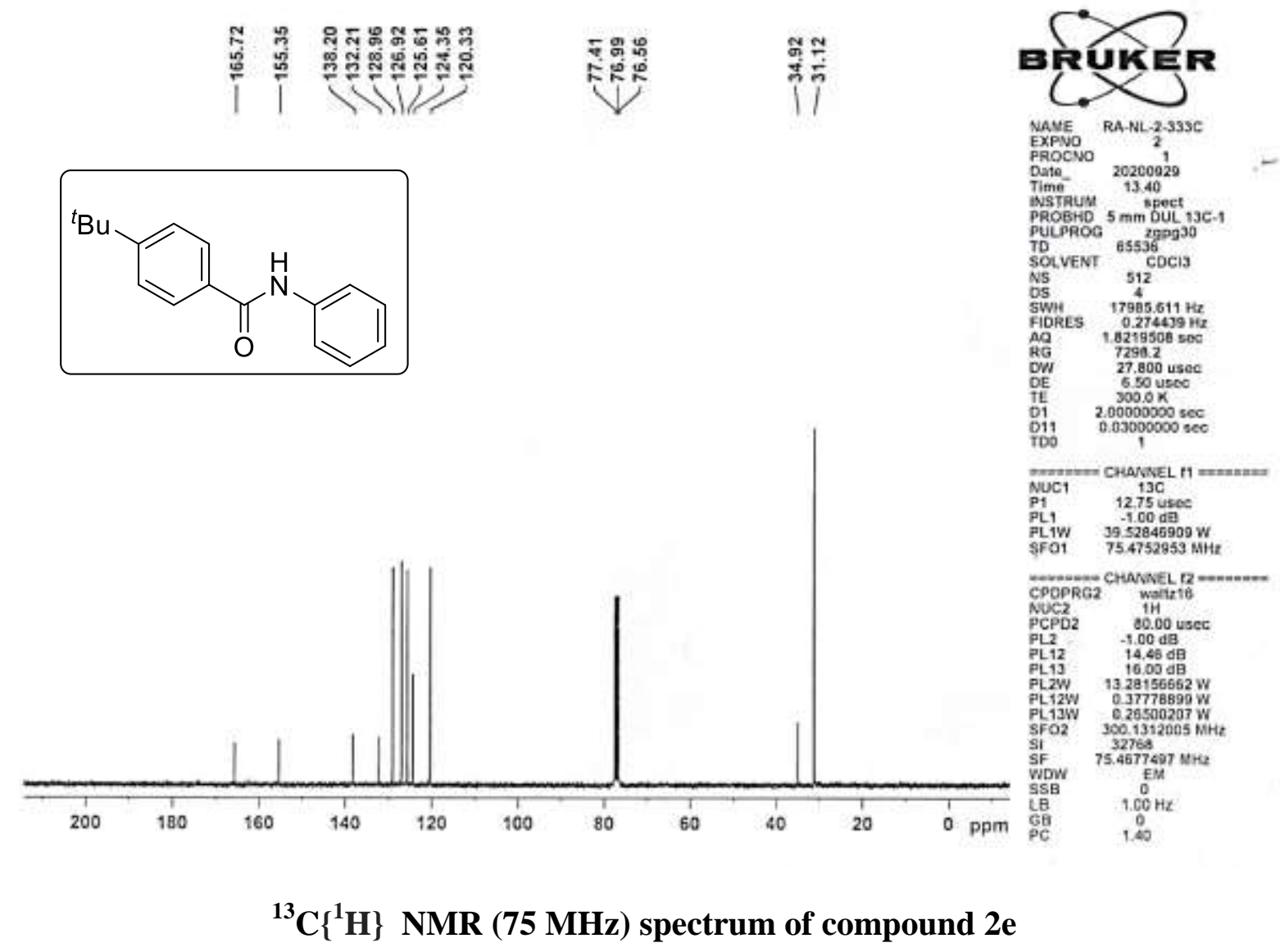




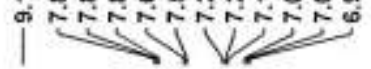

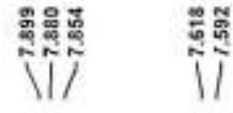
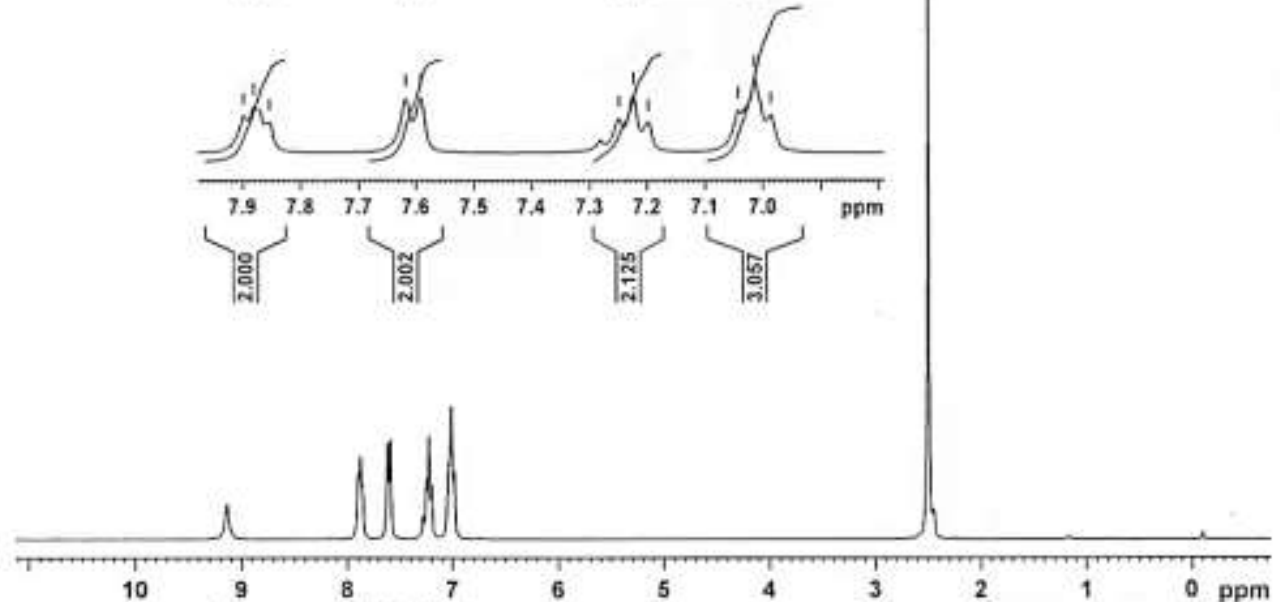

|ู่

\section{${ }^{1} \mathrm{H}$ NMR (300 MHz) spectrum of compound $2 \mathrm{f}$}

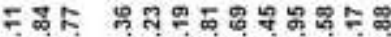

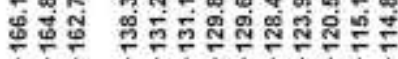

ำㅇํำ

KF!
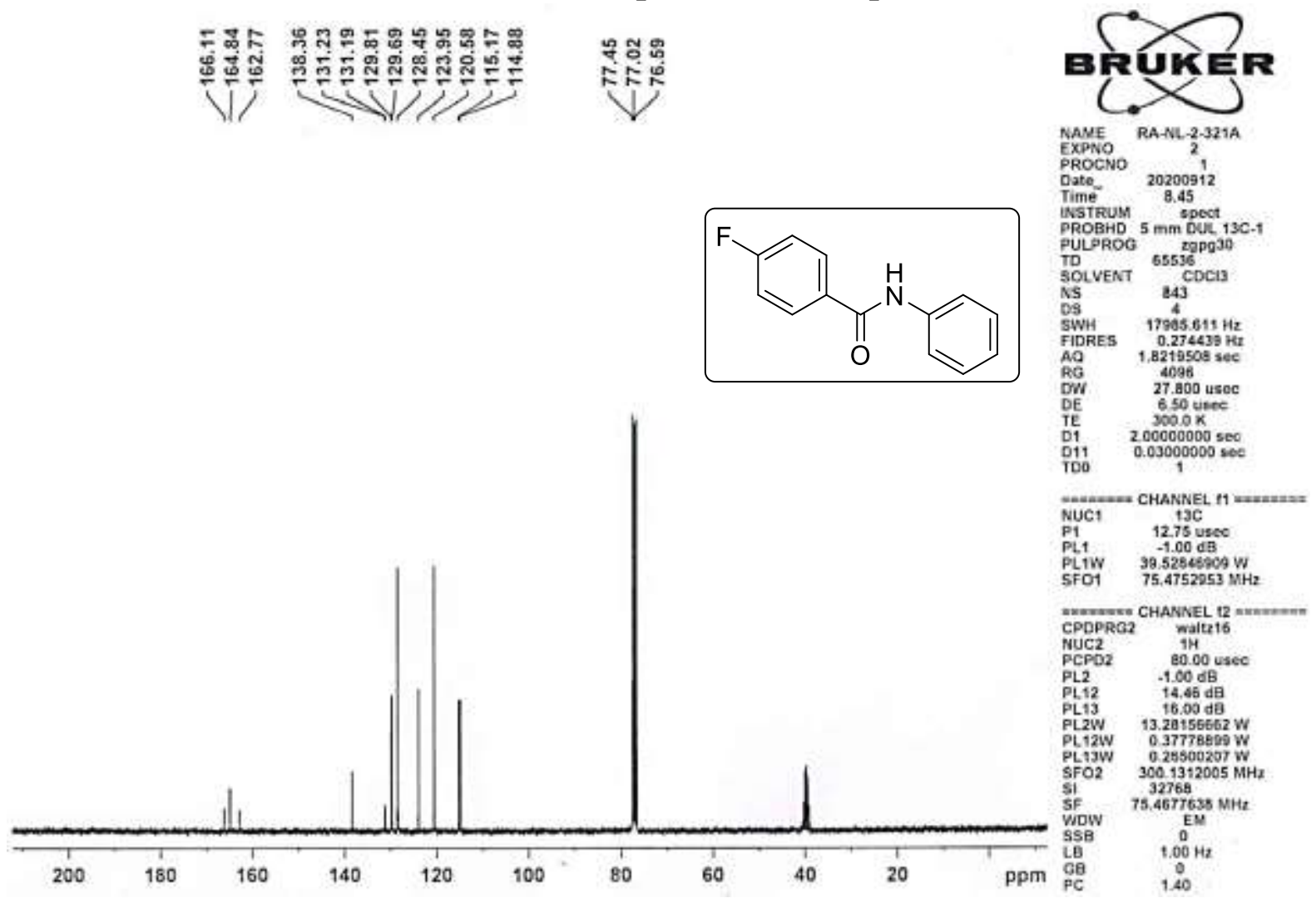

NANE RA-NL-2-321A

ERPNO

Time-

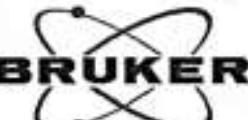

NANE RA-NL-2-321A

EXPNO RA-NL-2-32

time 20200912

PRSTRUM 5 spect

PULPROG 2930

TO $6553 \mathrm{CDCAB}^{29}$

NS 16 COCA

SSWH $\quad 611^{2} 2.839 \mathrm{~Hz}$

FIORES $\begin{aligned} 0.094190 \mathrm{Ft} \\ \mathrm{AQ}\end{aligned}$

ro

$\begin{array}{ll}81.000 \text { use } \\ \text { of } & 6.50 \text { usec }\end{array}$

$1300.0 \mathrm{~K}$

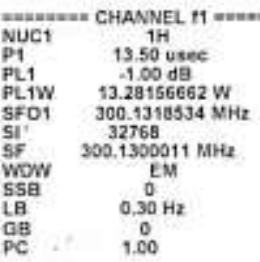

${ }^{13} \mathrm{C}\left\{{ }^{1} \mathrm{H}\right\}$ NMR (75 MHz) spectrum of compound $2 \mathrm{f}$ 


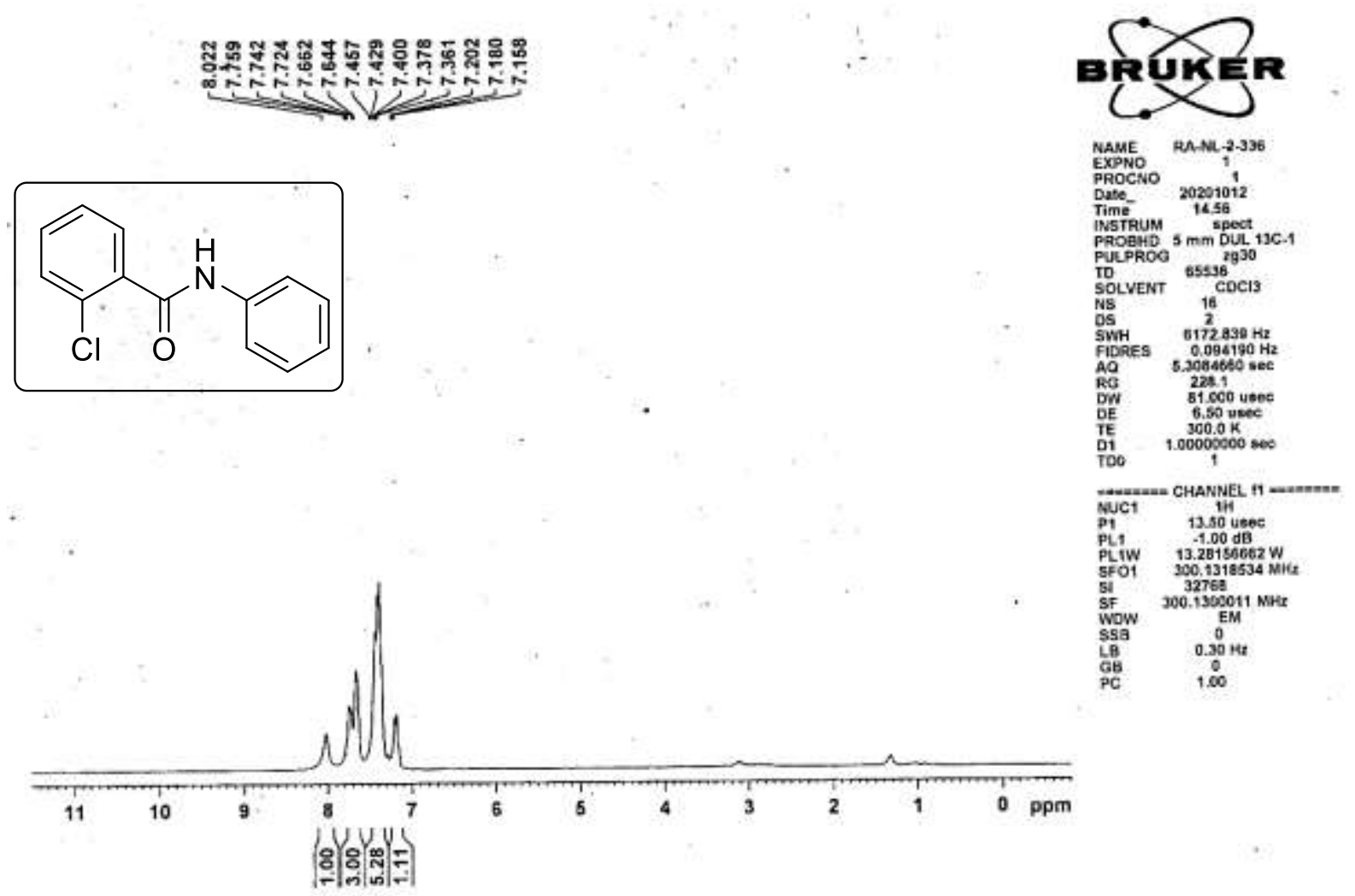

${ }^{1} \mathrm{H}$ NMR (300 MHz) spectrum of compound $2 \mathrm{~g}$

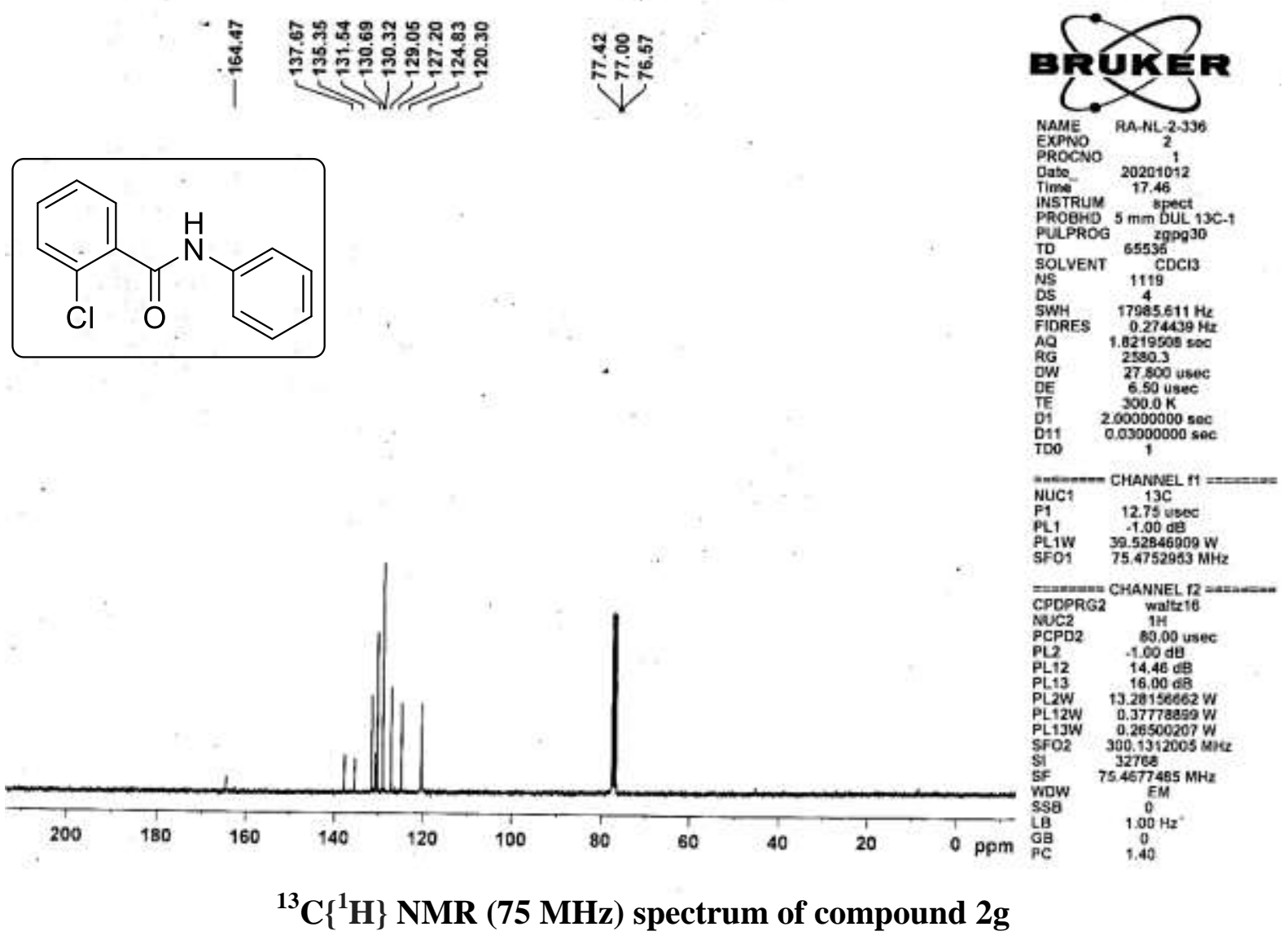




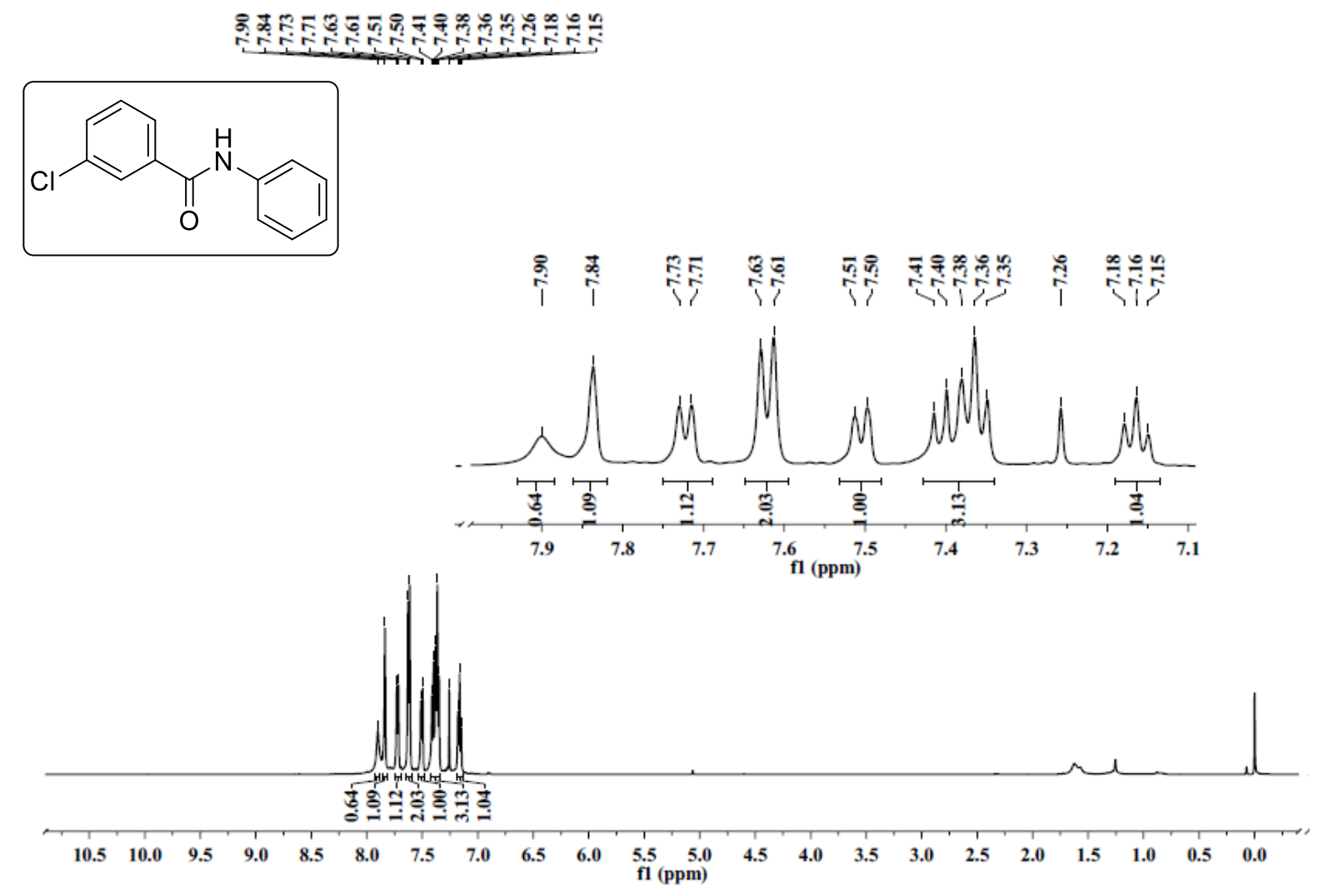

${ }^{1}$ H NMR (500 MHz) spectrum of compound $2 \mathrm{~h}$
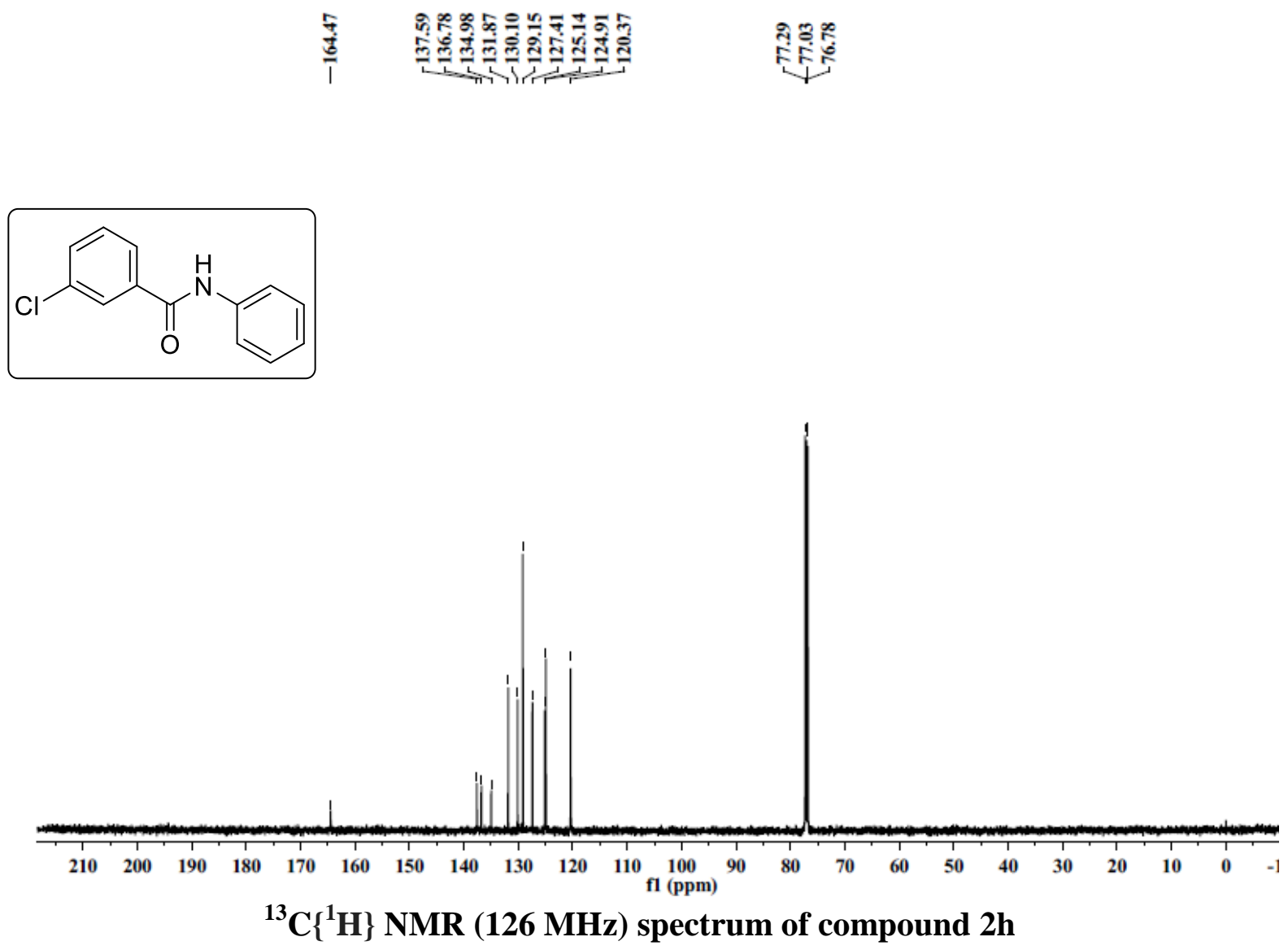


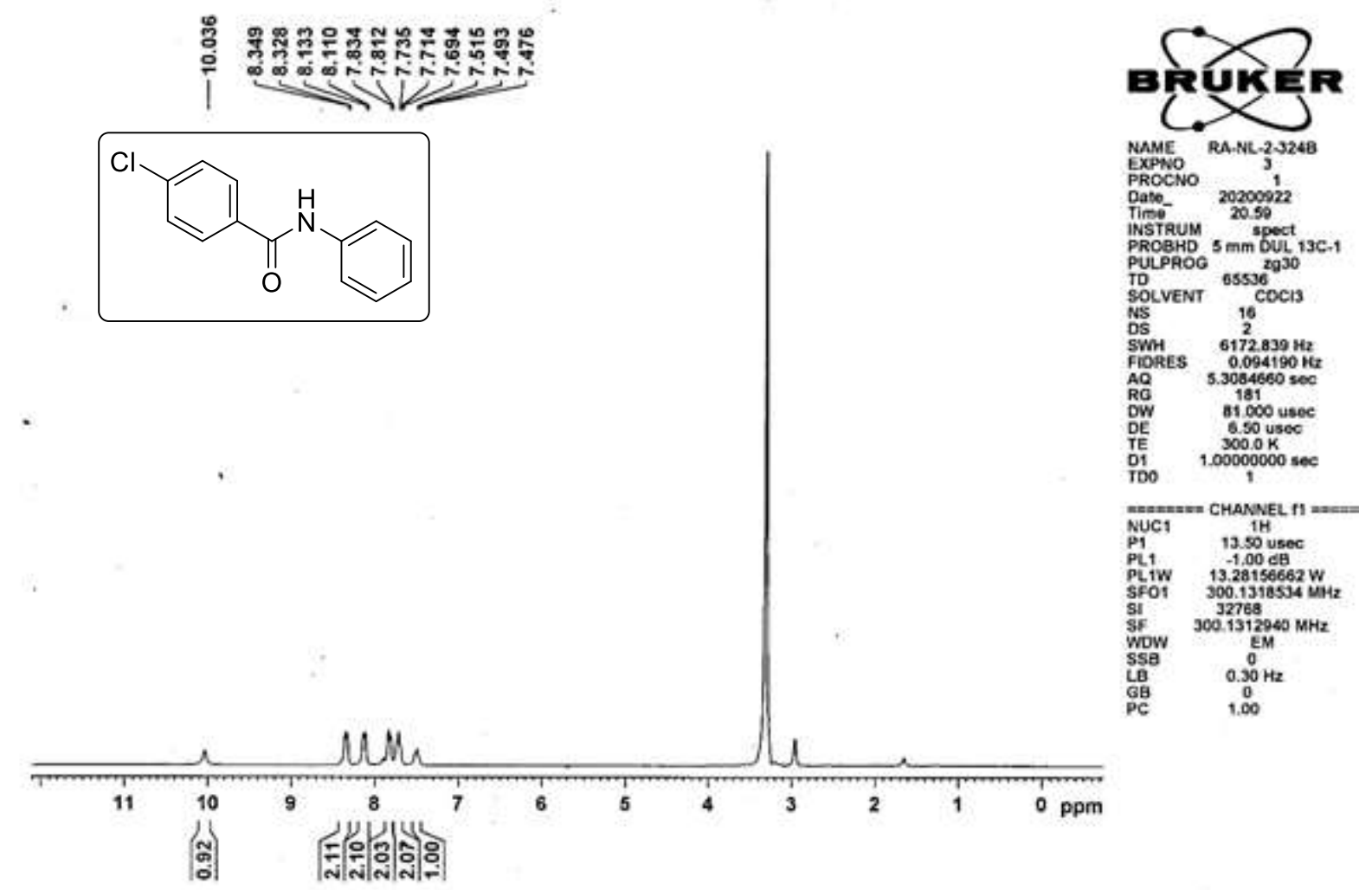

${ }^{1} \mathrm{H}$ NMR (300 MHz) spectrum of compound 2i

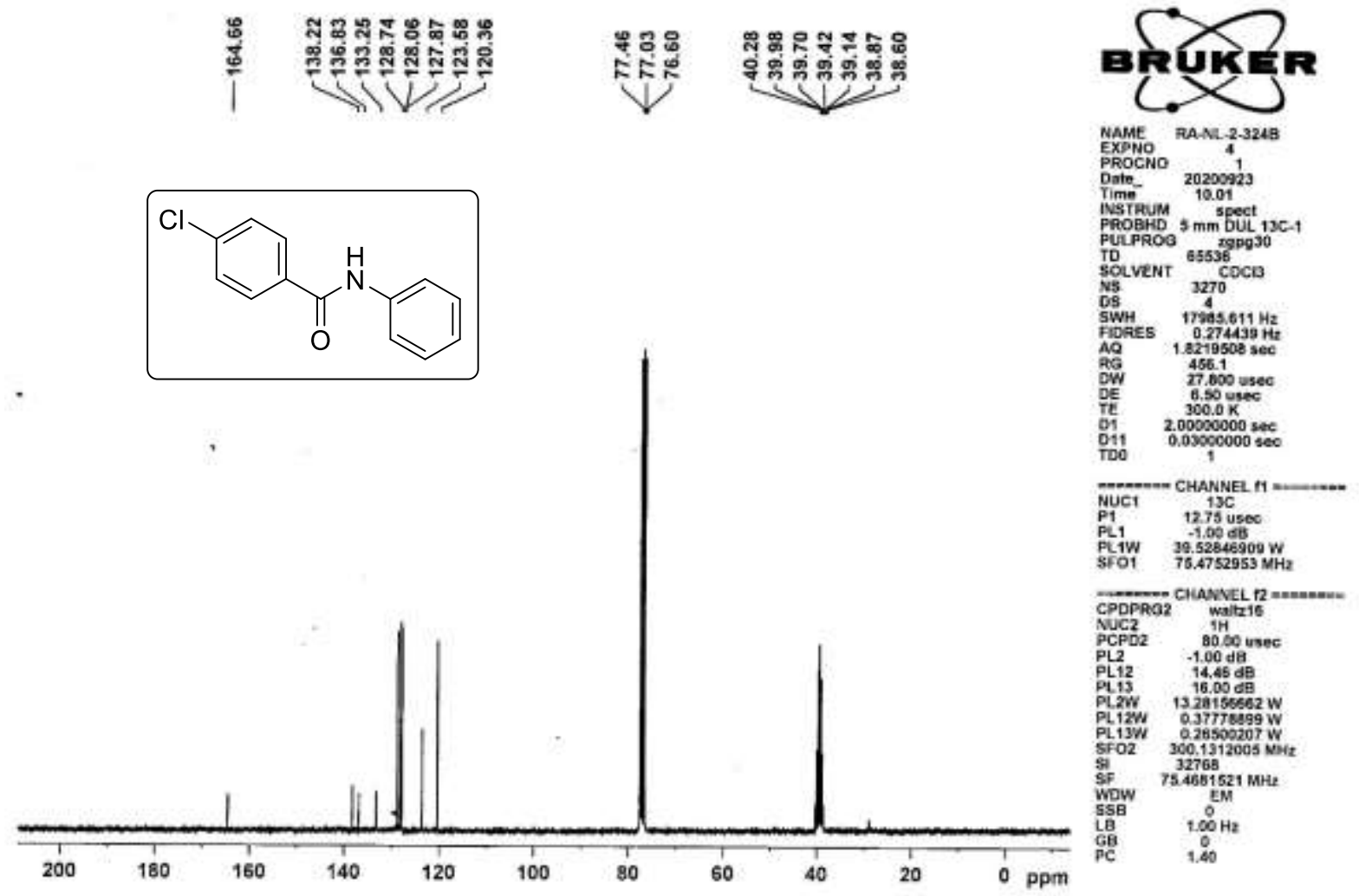

${ }^{13} \mathrm{C}\left\{{ }^{1} \mathrm{H}\right\}$ NMR (75 MHz) spectrum of compound $2 \mathrm{i}$ 


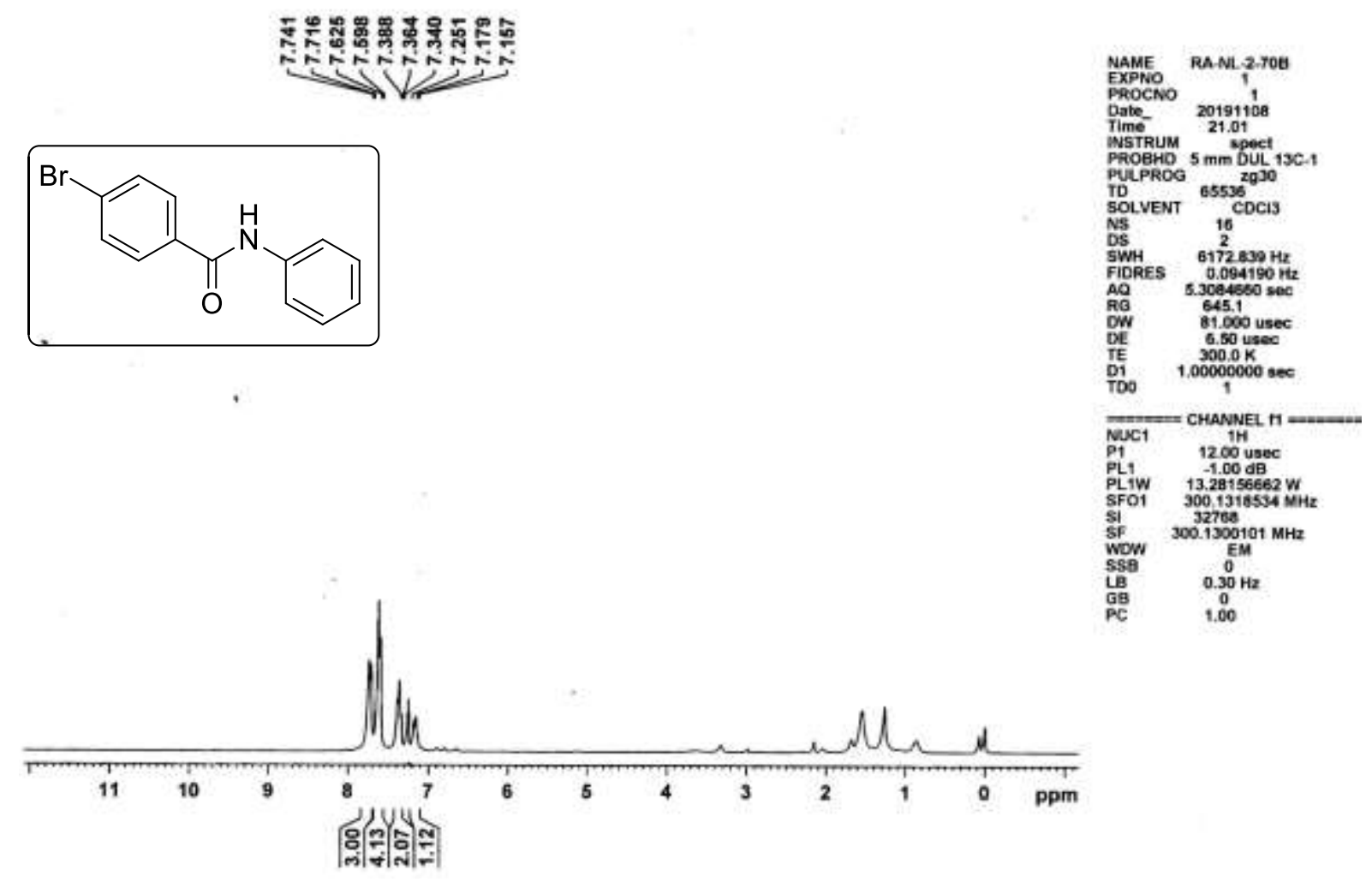

${ }^{1} \mathrm{H}$ NMR (300 MHz) spectrum of compound $2 \mathrm{j}$

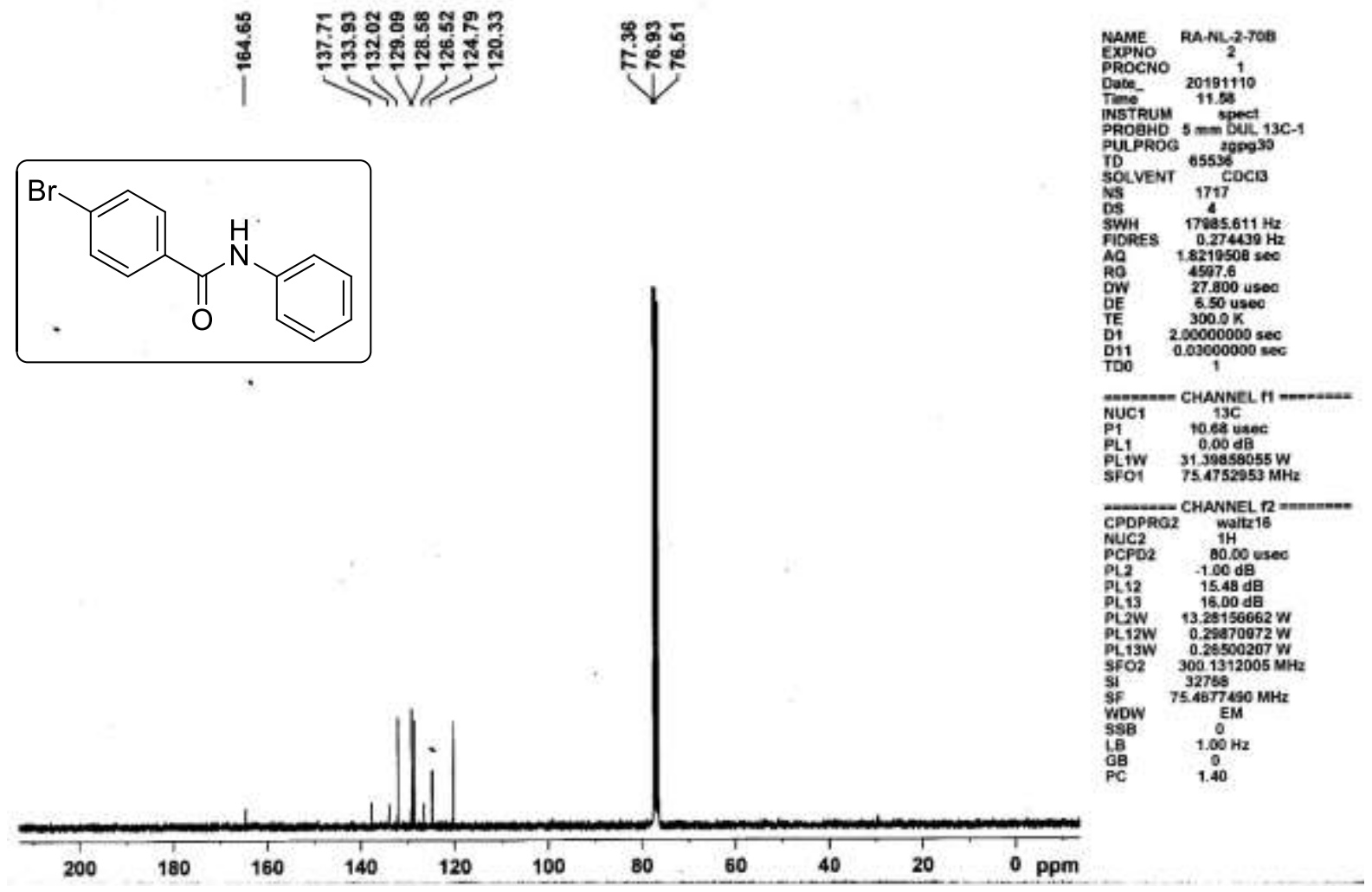

${ }^{13} \mathrm{C}\left\{{ }^{1} \mathrm{H}\right\}$ NMR (75 MHz) spectrum of compound $2 \mathrm{j}$ 


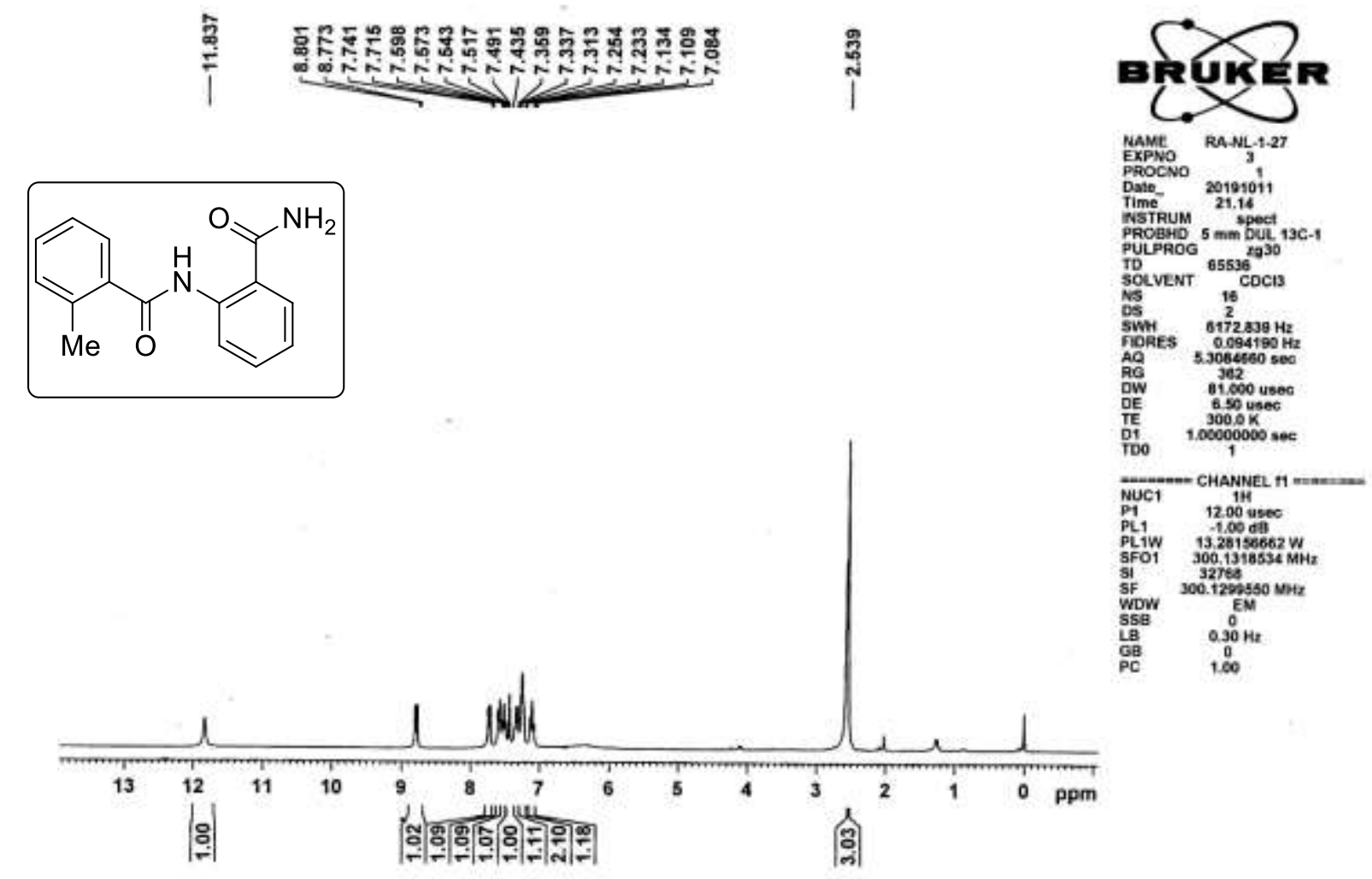

${ }^{1} \mathrm{H}$ NMR (300 MHz) spectrum of compound 2k

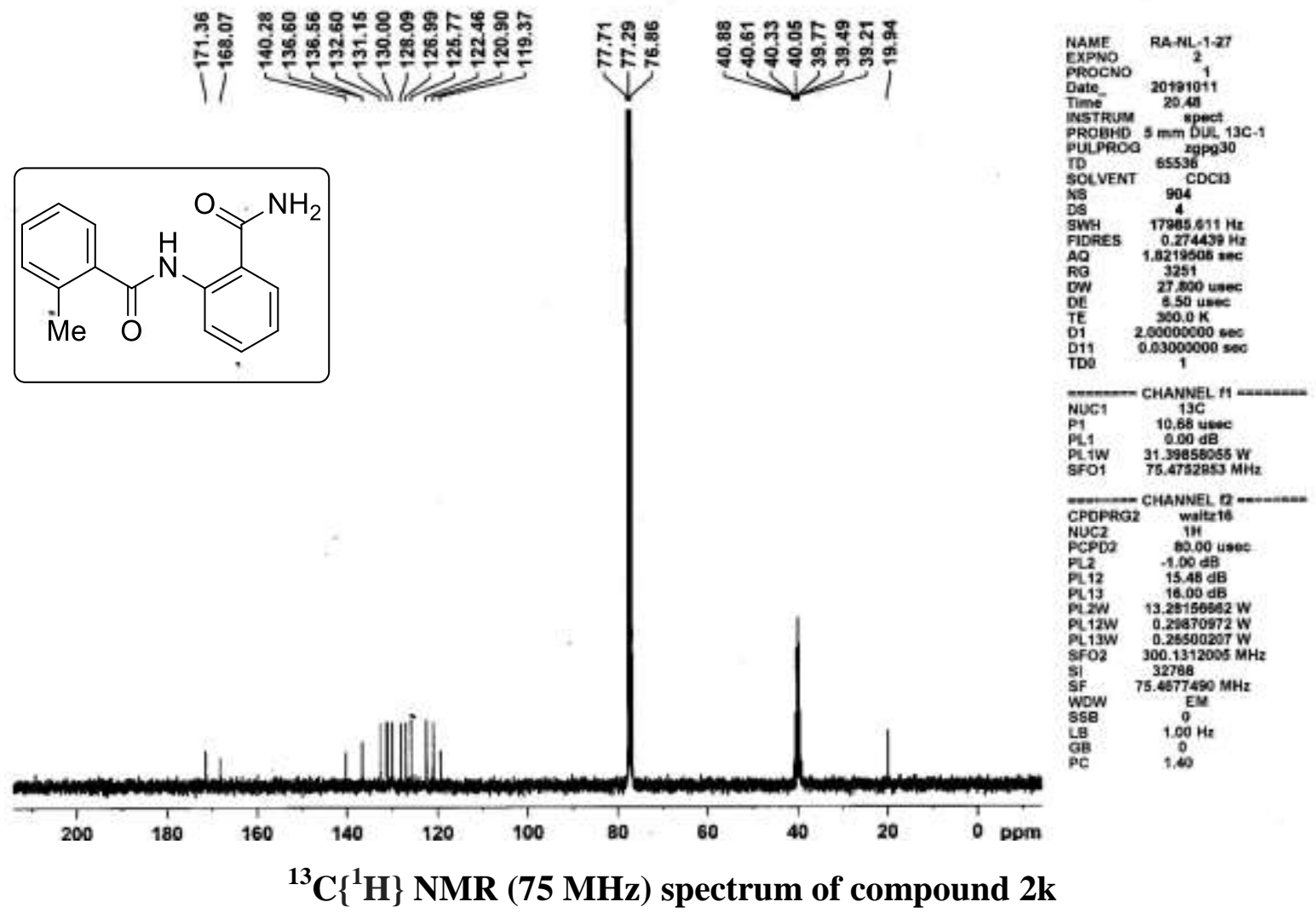




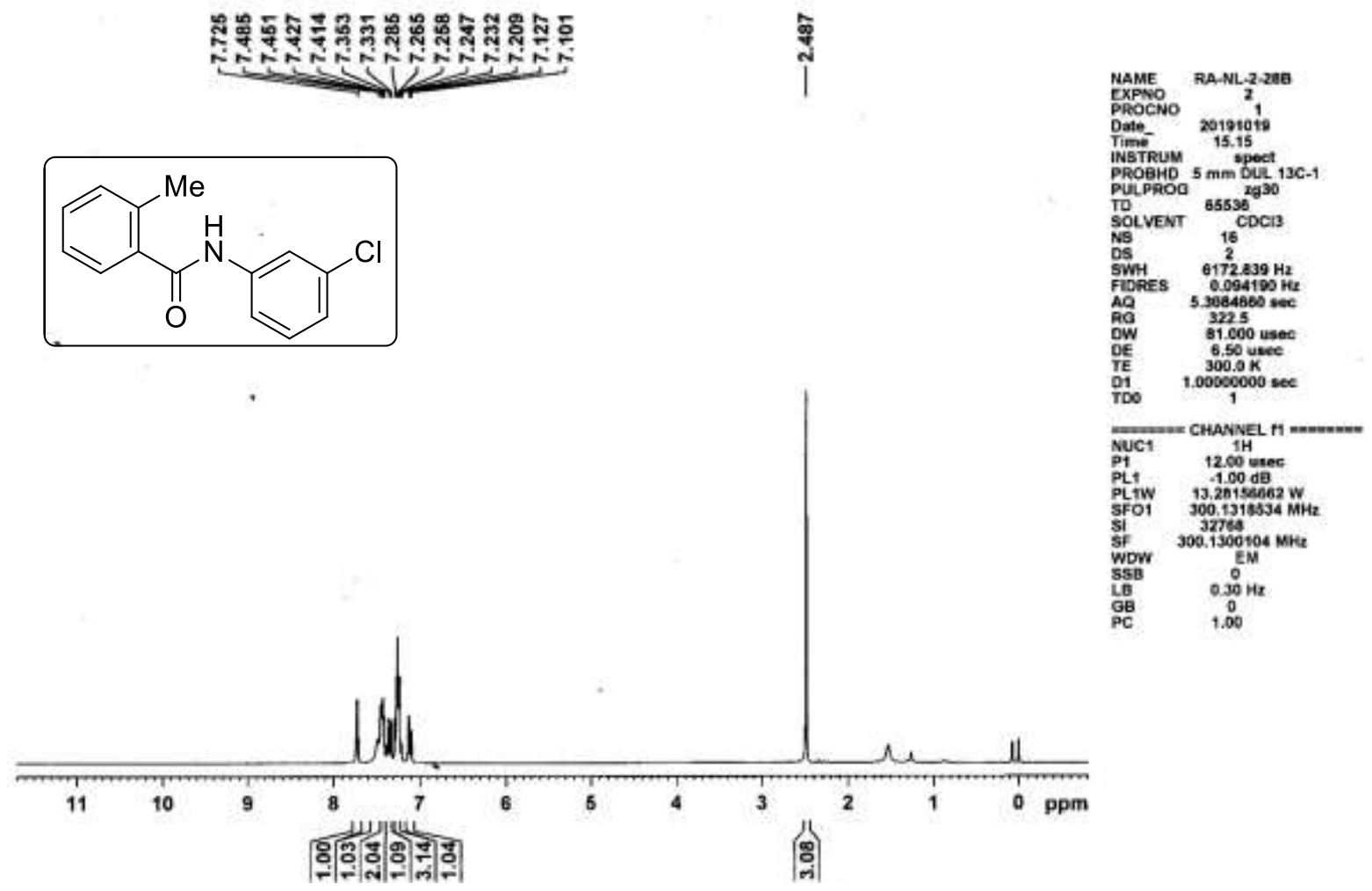

${ }^{1}$ H NMR (300 MHz) spectrum of compound 2 I
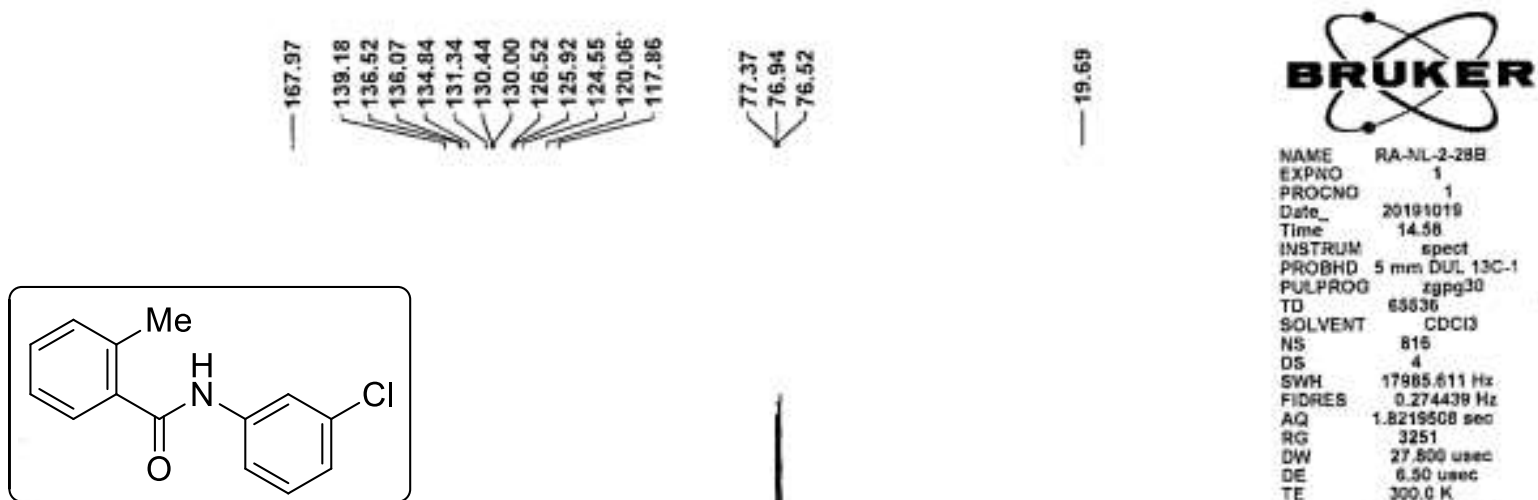

NAME RANL-2-28

Expio

PROCN

Date- 20195018

Time

PROBHD 5 mm DULL $13 \mathrm{C}$.

PUCPROO $x_{3 \mathrm{pg}} 30$

TDLVENT CS536 CDCI3

NS

SWH $17965.611 \mathrm{Hx}$

AQ 1.8215500 se

$\begin{array}{ll}\text { RG } & 3251 \\ \text { OW } & 27.500 \text { usec } \\ \text { DE } & 6.50 \text { usec }\end{array}$

TE 200000000 .

Di1 $20.030000000 \mathrm{sec}$

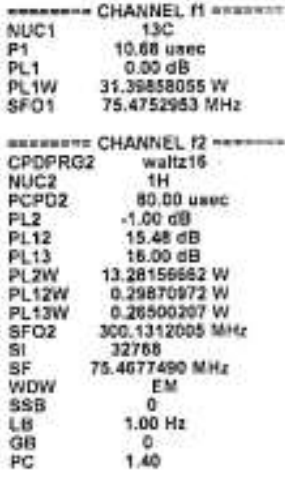

${ }^{13} \mathrm{C}\left\{{ }^{1} \mathrm{H}\right\}(75 \mathrm{MHz})$ spectrum of compound $2 \mathrm{I}$ 


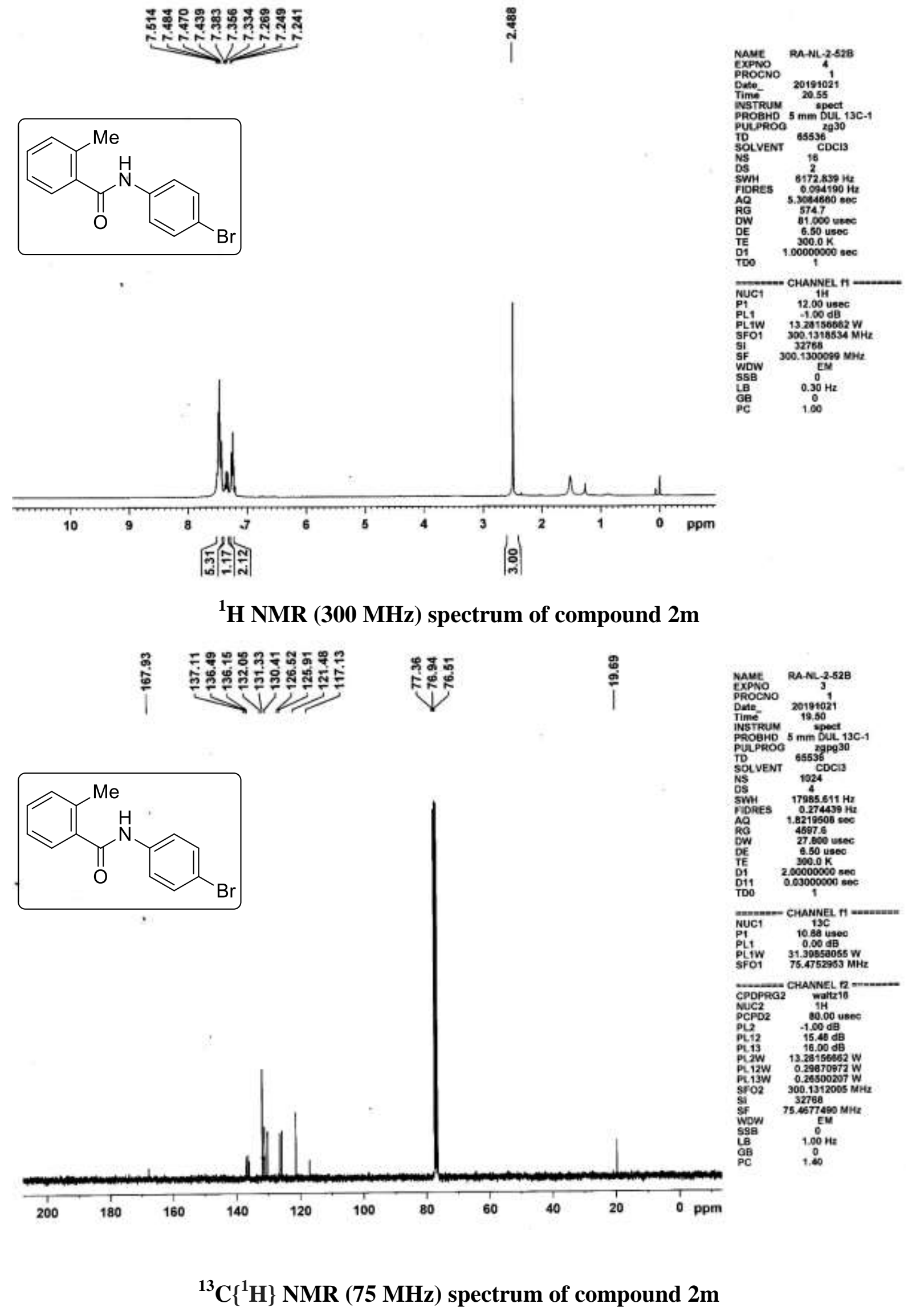




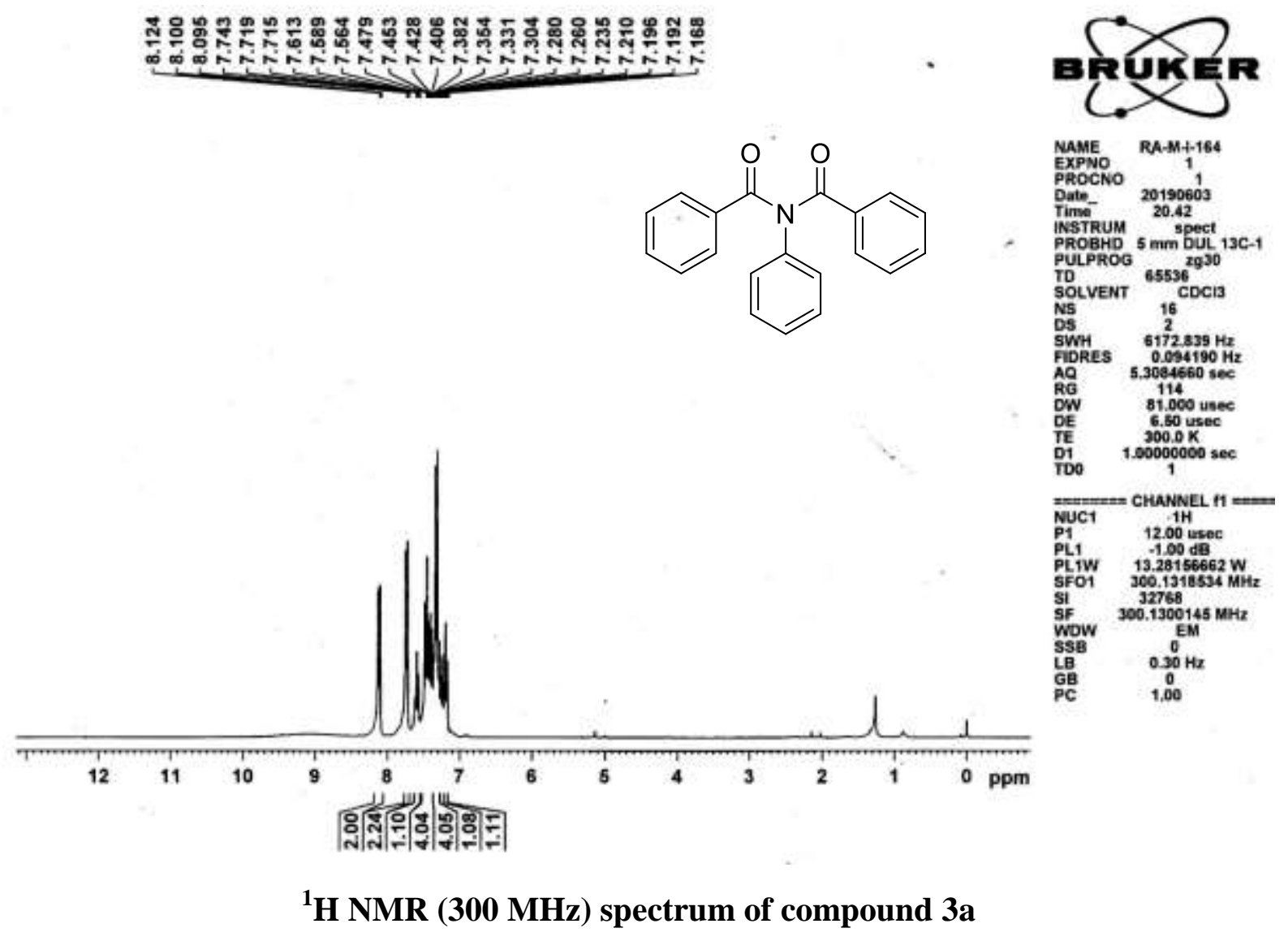




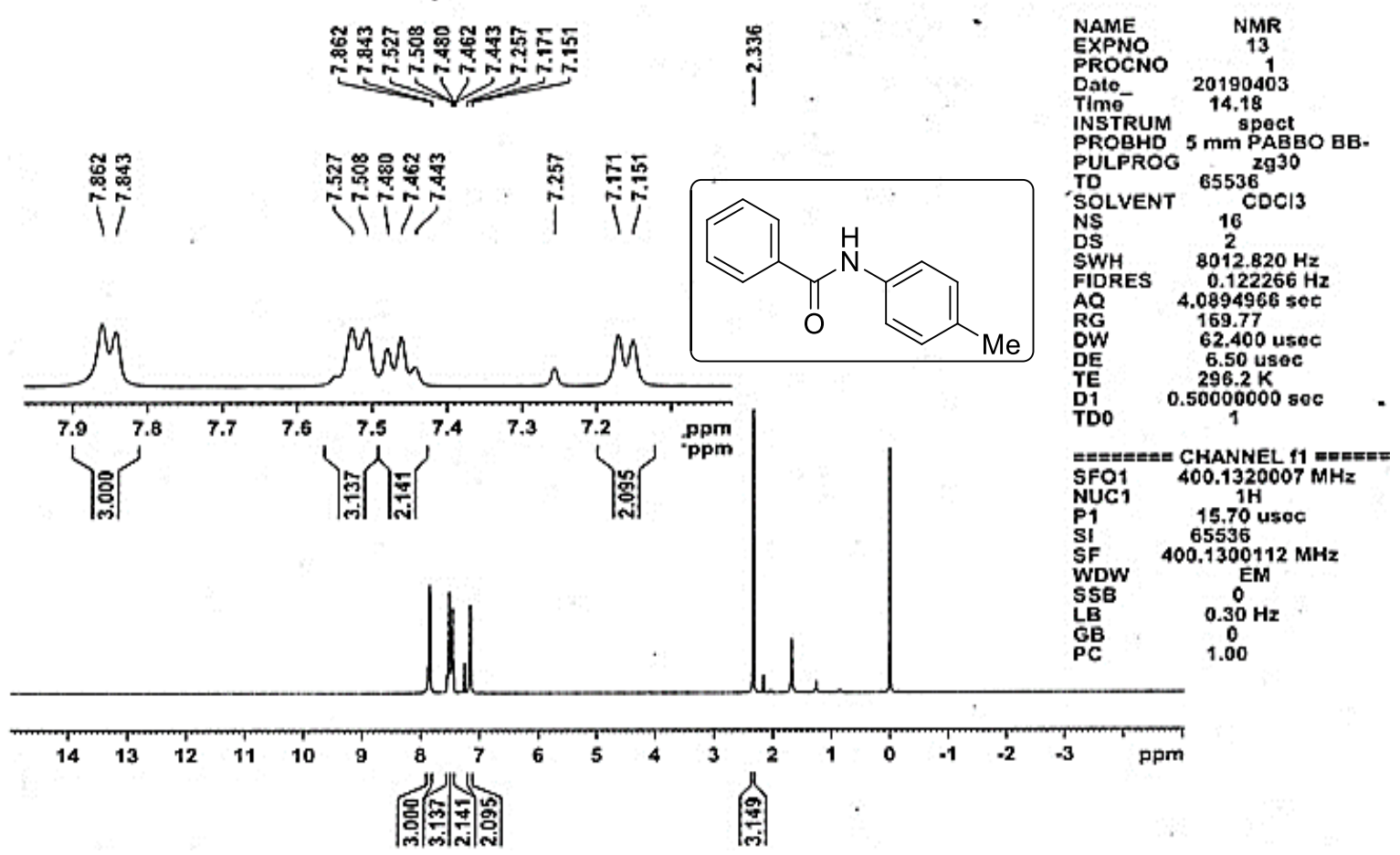

${ }^{1}$ H NMR (300 MHz) spectrum of compound $5 \mathrm{a}$

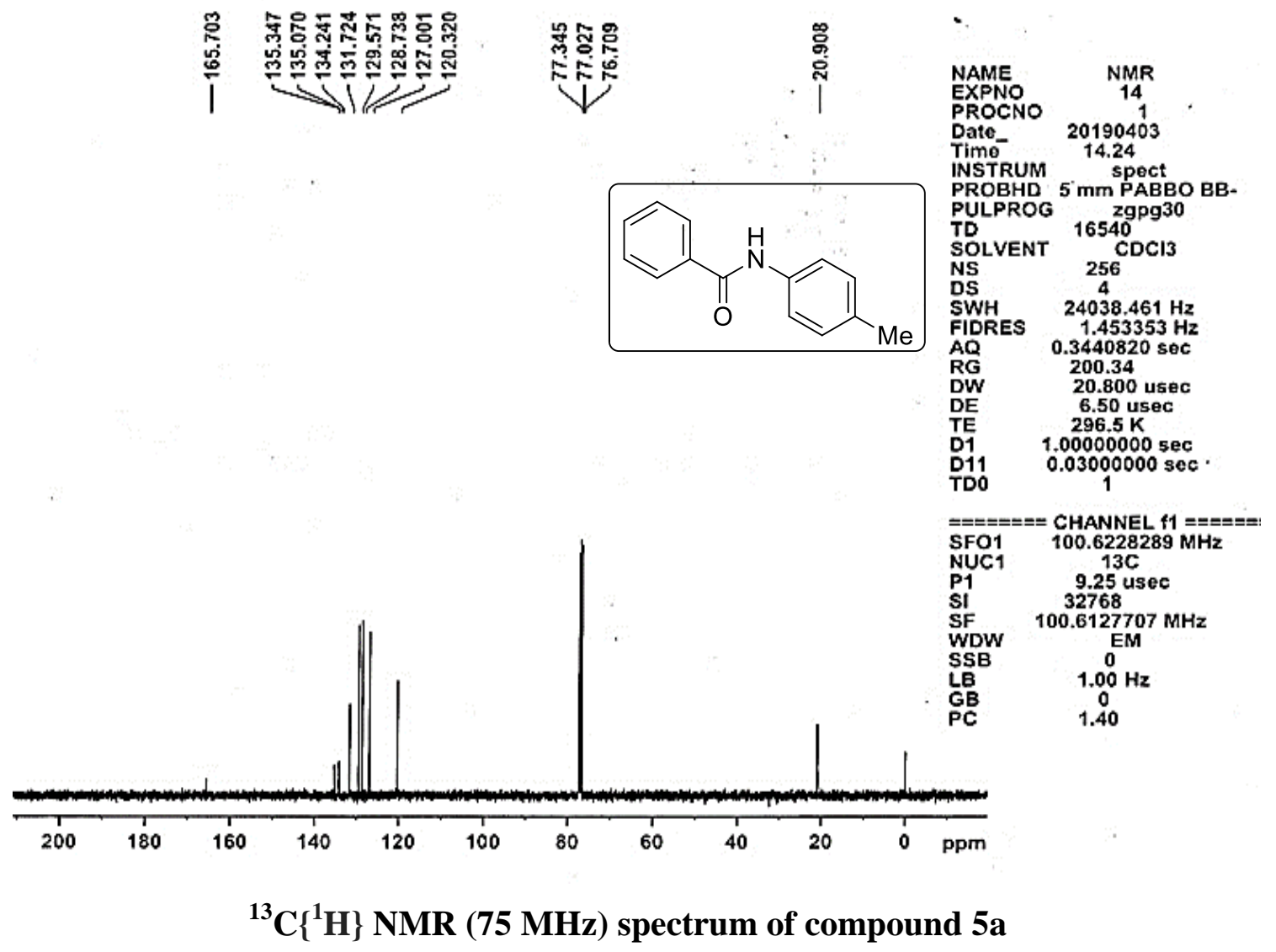




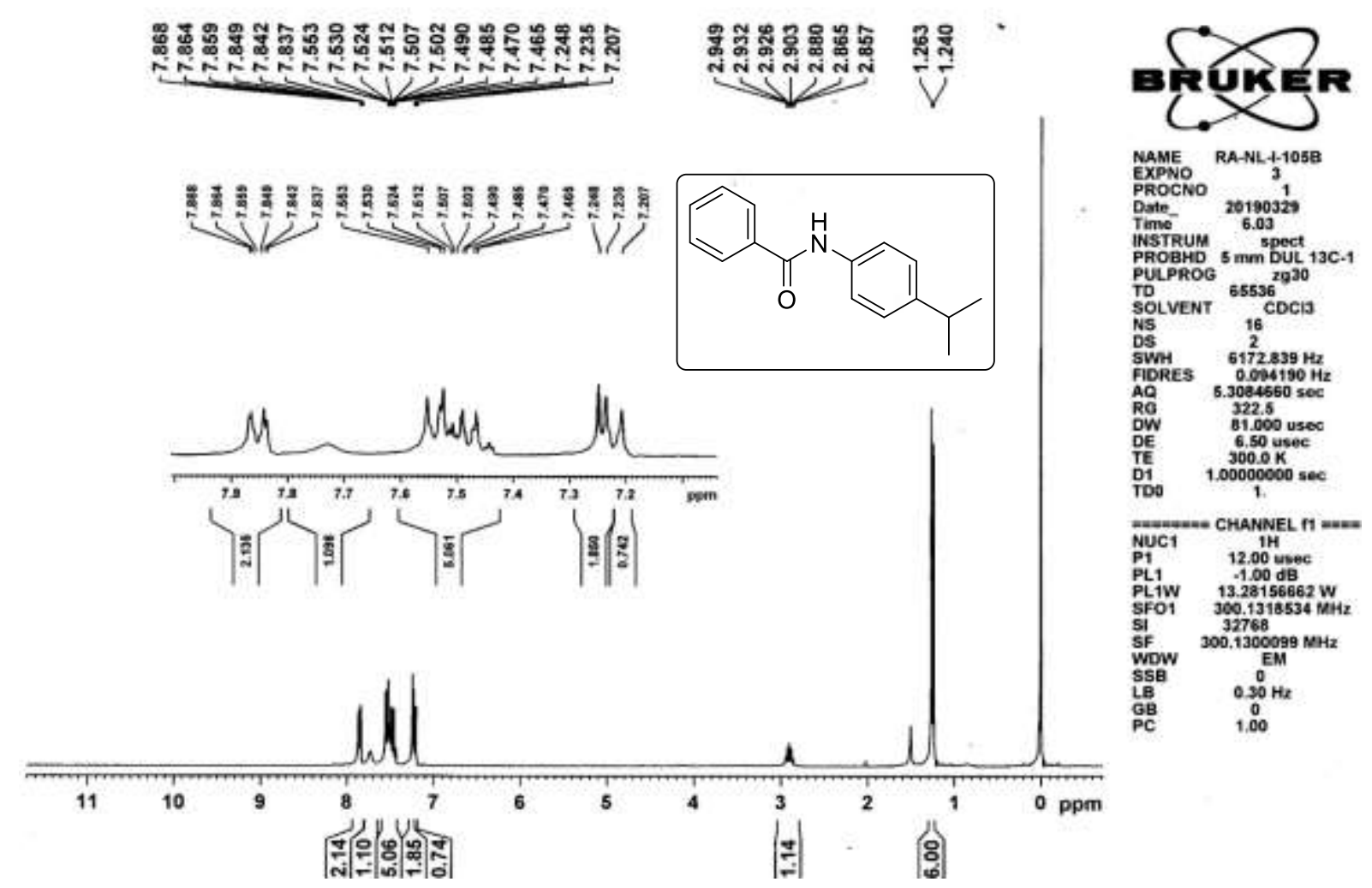

${ }^{1} \mathrm{H}$ NMR (300 MHz) spectrum of compound 5b

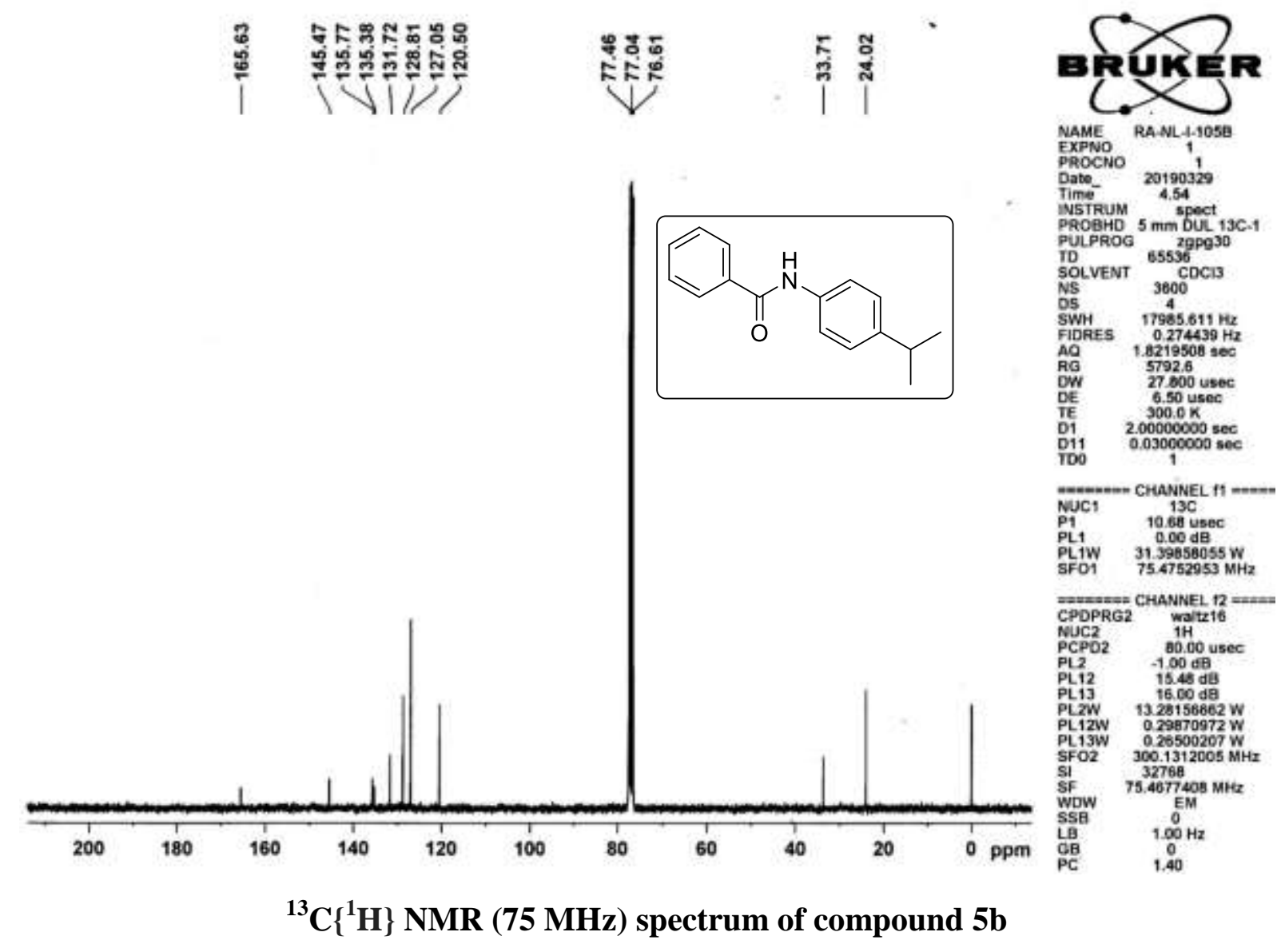




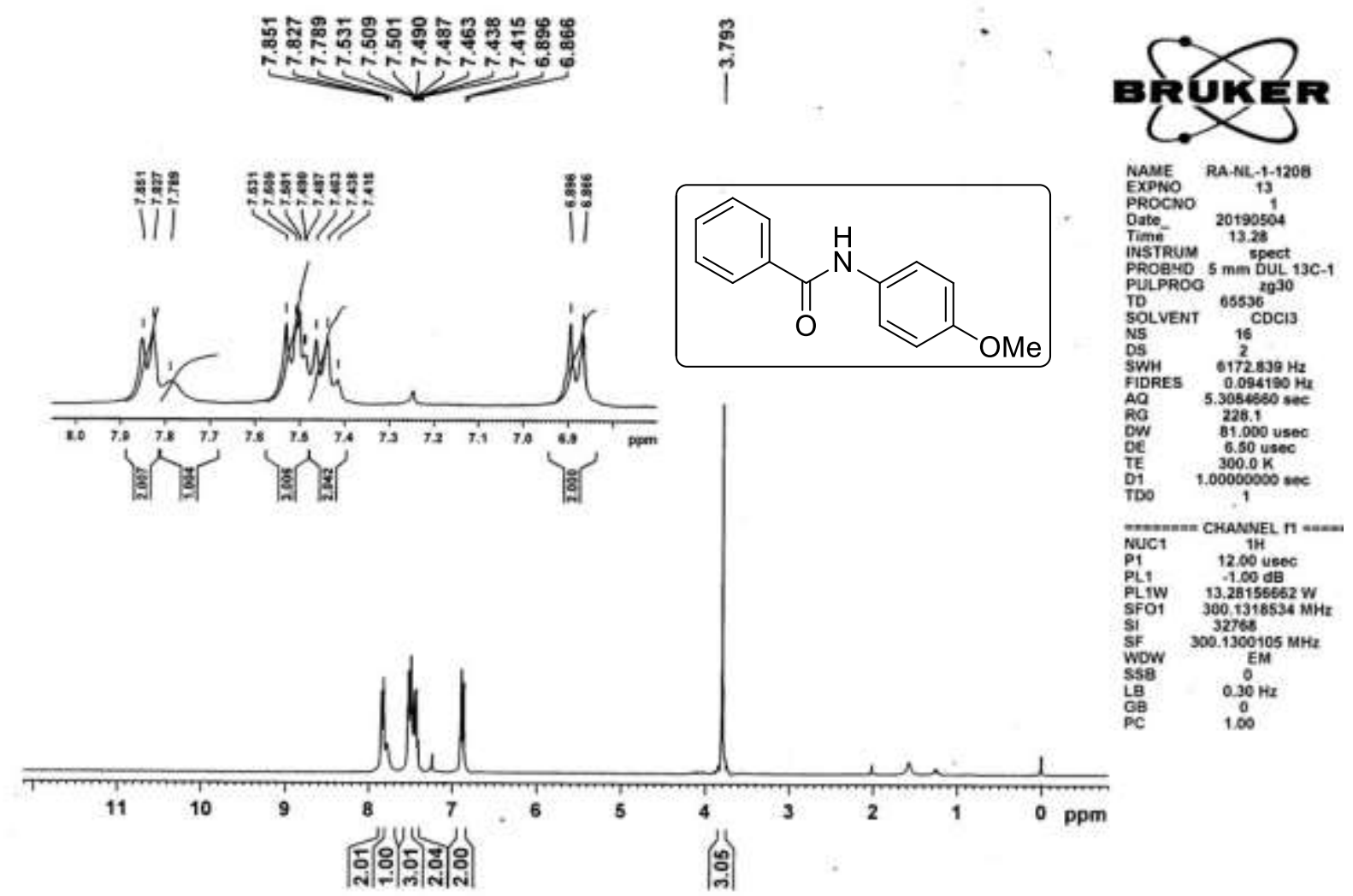

${ }^{1} \mathrm{H}$ NMR (300 MHz) spectrum of compound 5c

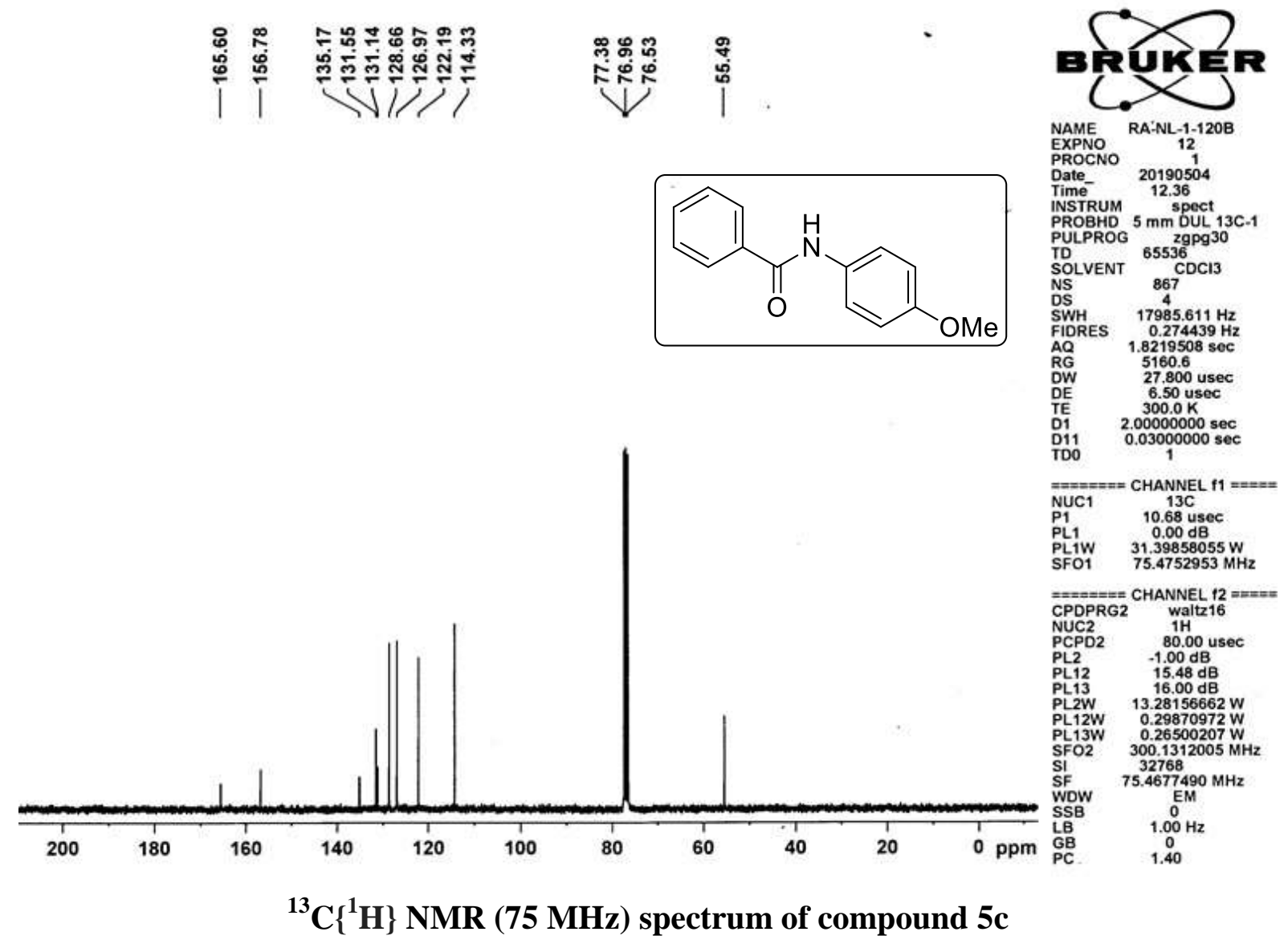




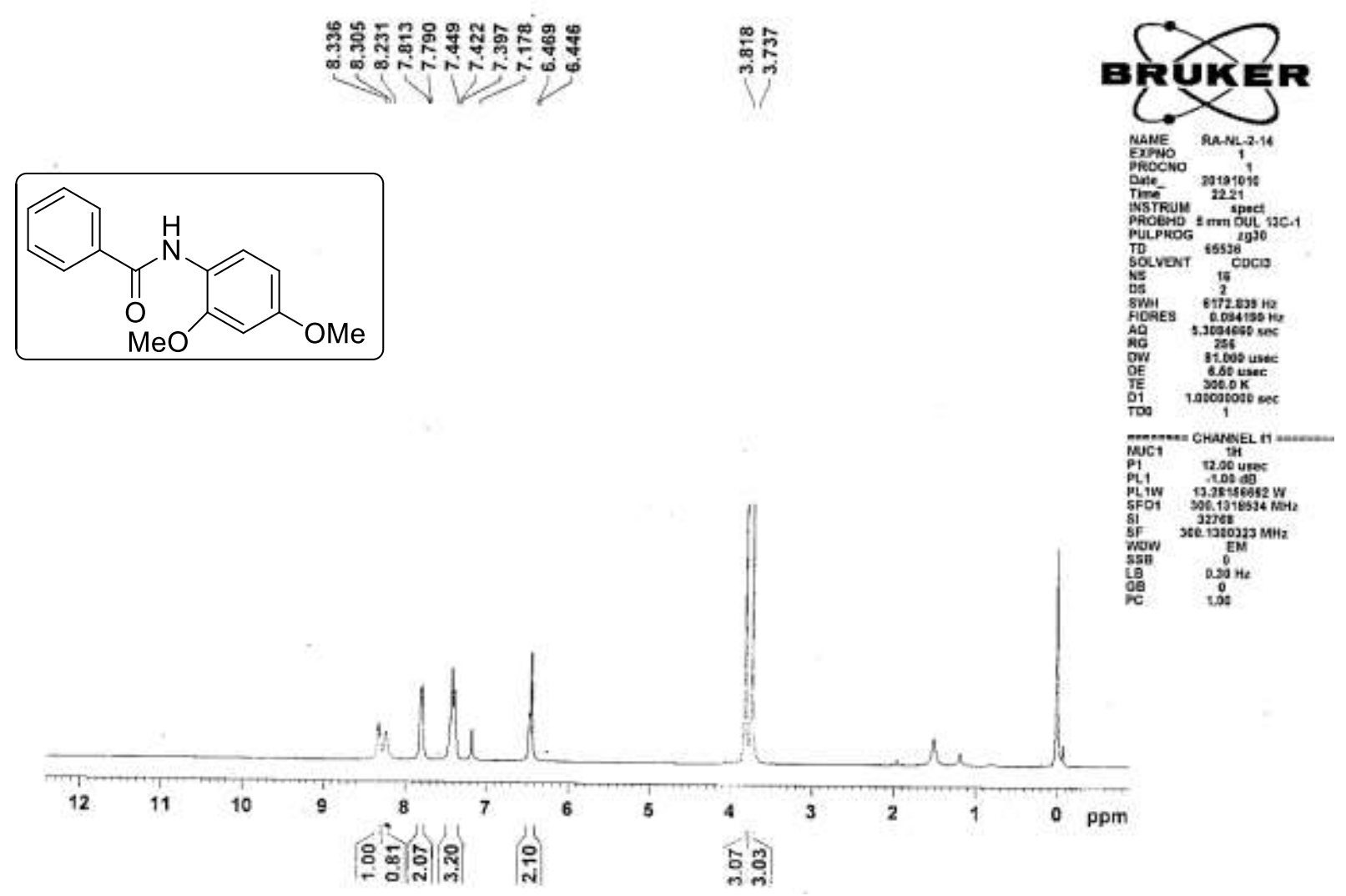

${ }^{1} \mathrm{H}$ NMR (300 MHz) spectrum of compound $5 \mathrm{~d}$
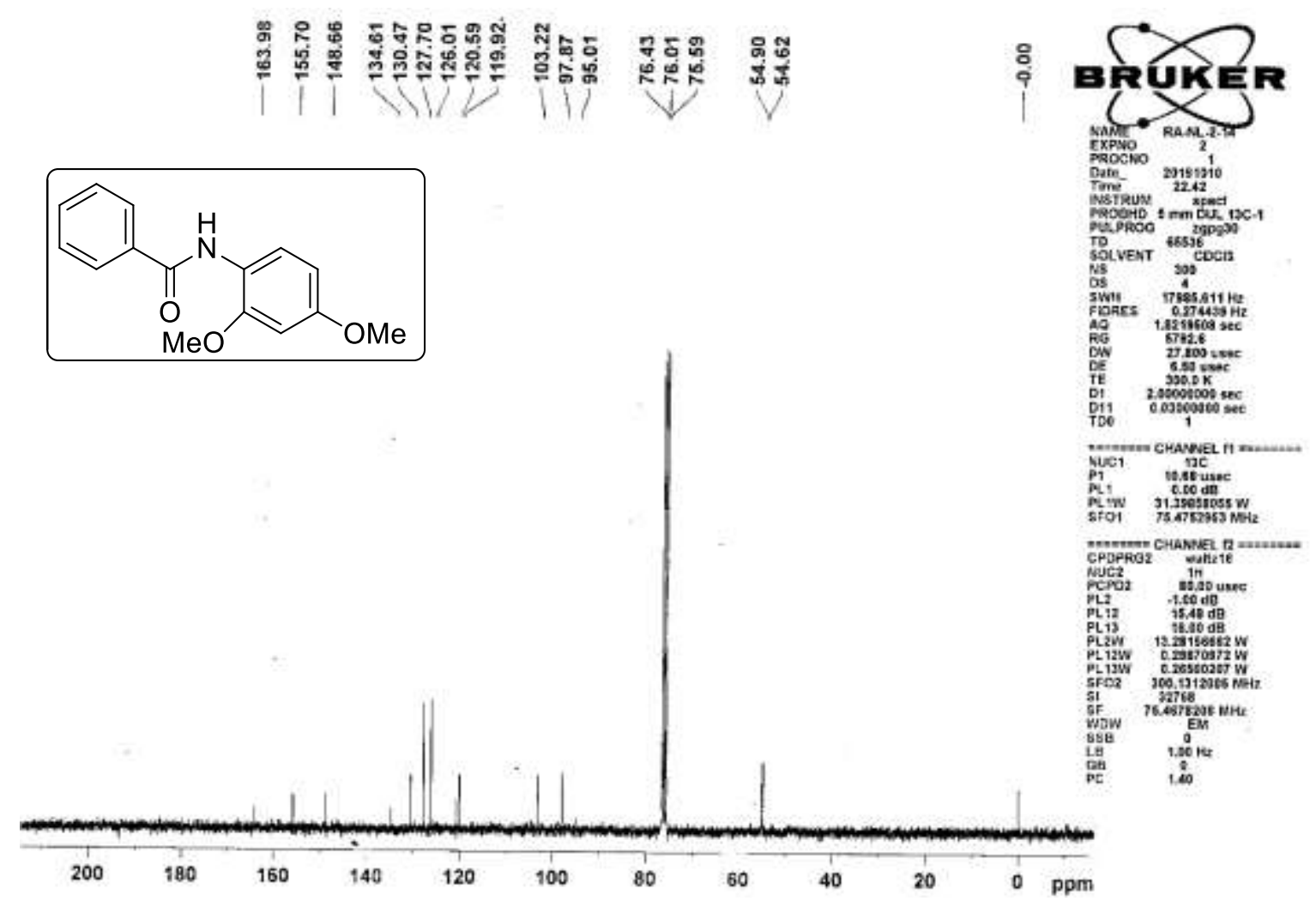

${ }^{13} \mathrm{C}\left\{{ }^{1} \mathrm{H}\right\}$ NMR (75 MHz) spectrum of compound $5 \mathrm{~d}$ 


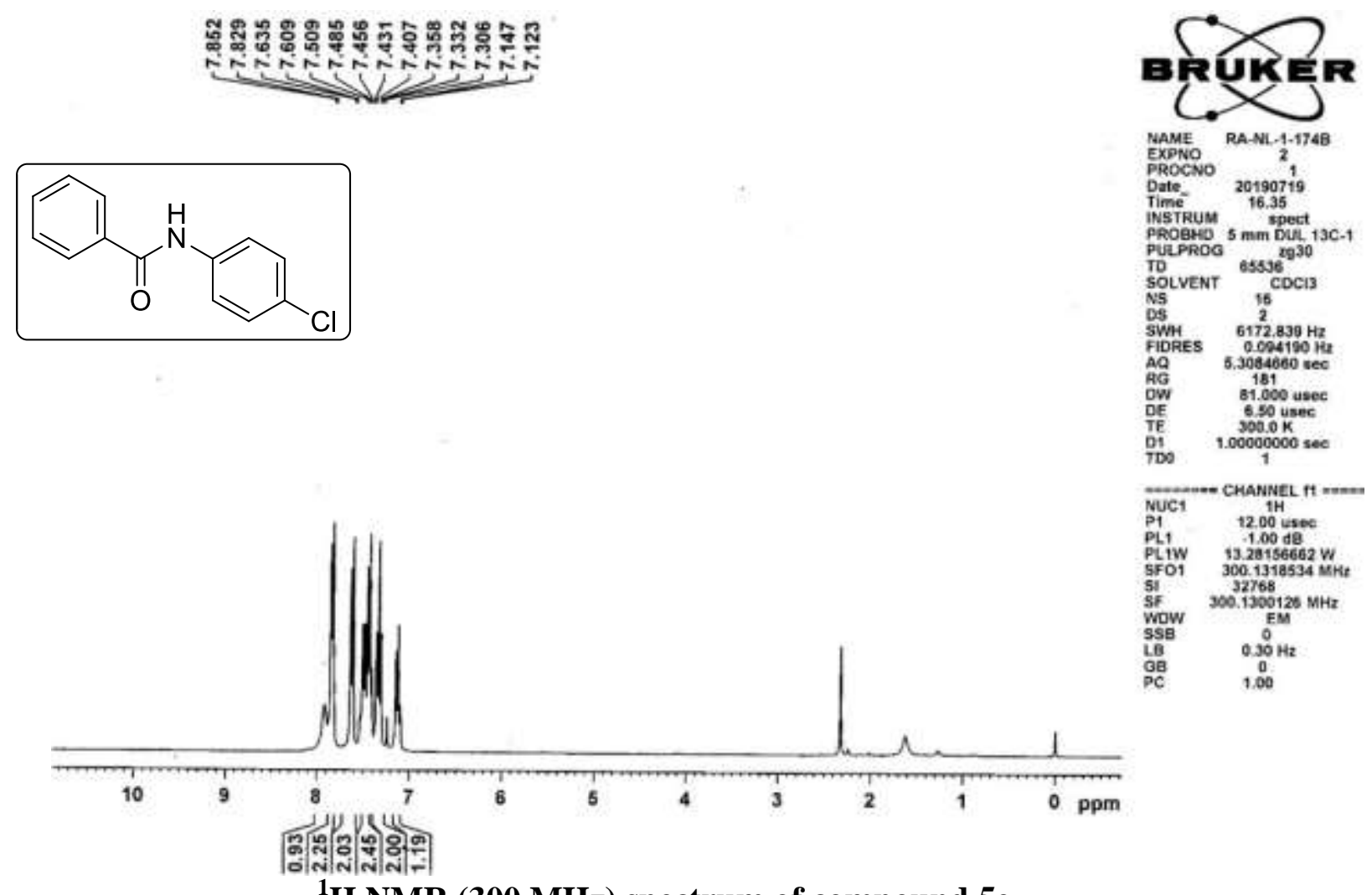

${ }^{1}$ H NMR (300 MHz) spectrum of compound 5e

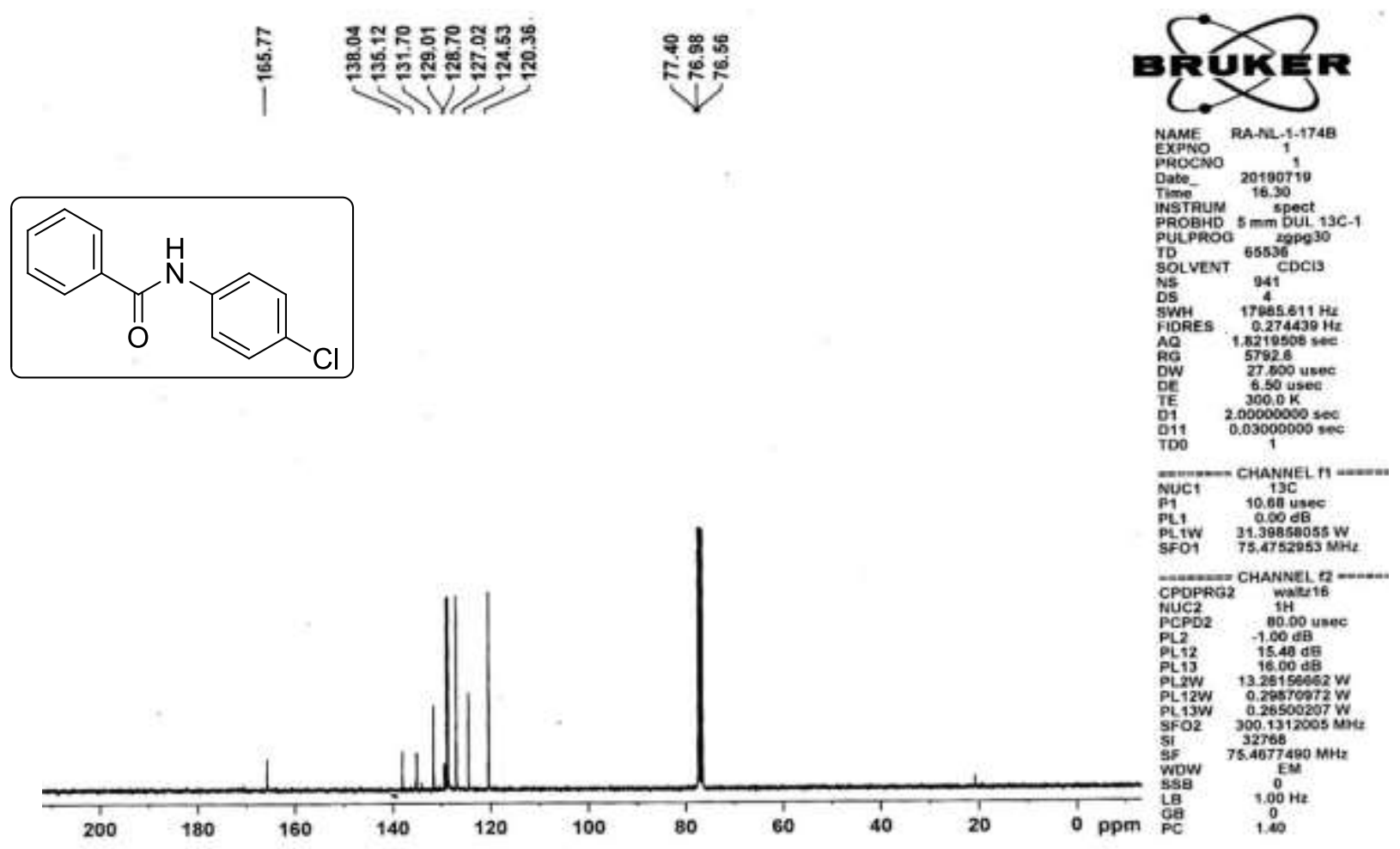

${ }^{13} \mathrm{C}\left\{{ }^{1} \mathrm{H}\right\}$ NMR (75 MHz) spectrum of compound $5 e$ 


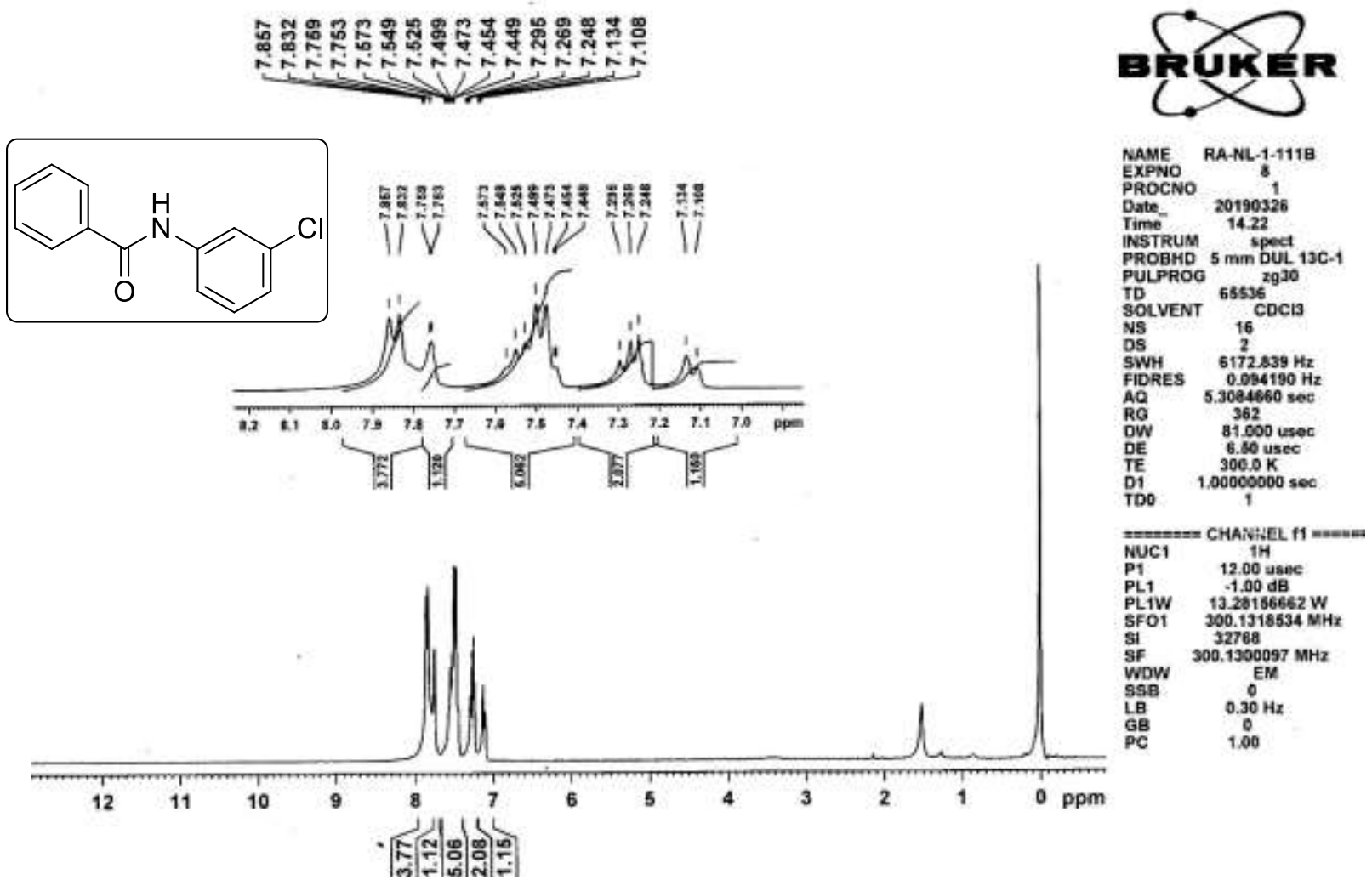

${ }^{1}$ H NMR (300 MHz) spectrum of compound $5 f$

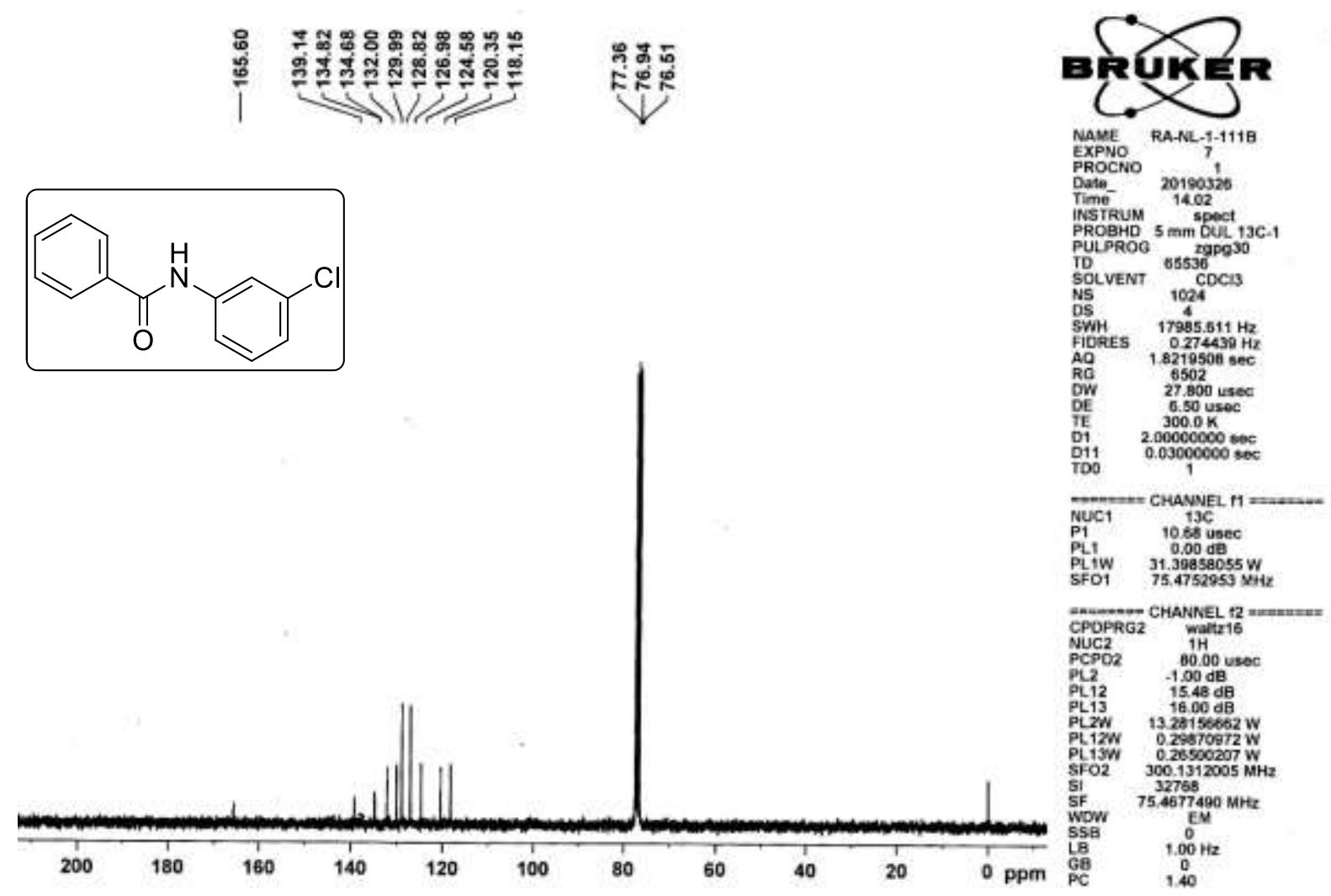

${ }^{13} \mathrm{C}\left\{{ }^{1} \mathrm{H}\right\}$ NMR (75 MHz) spectrum of compound $5 f$ 


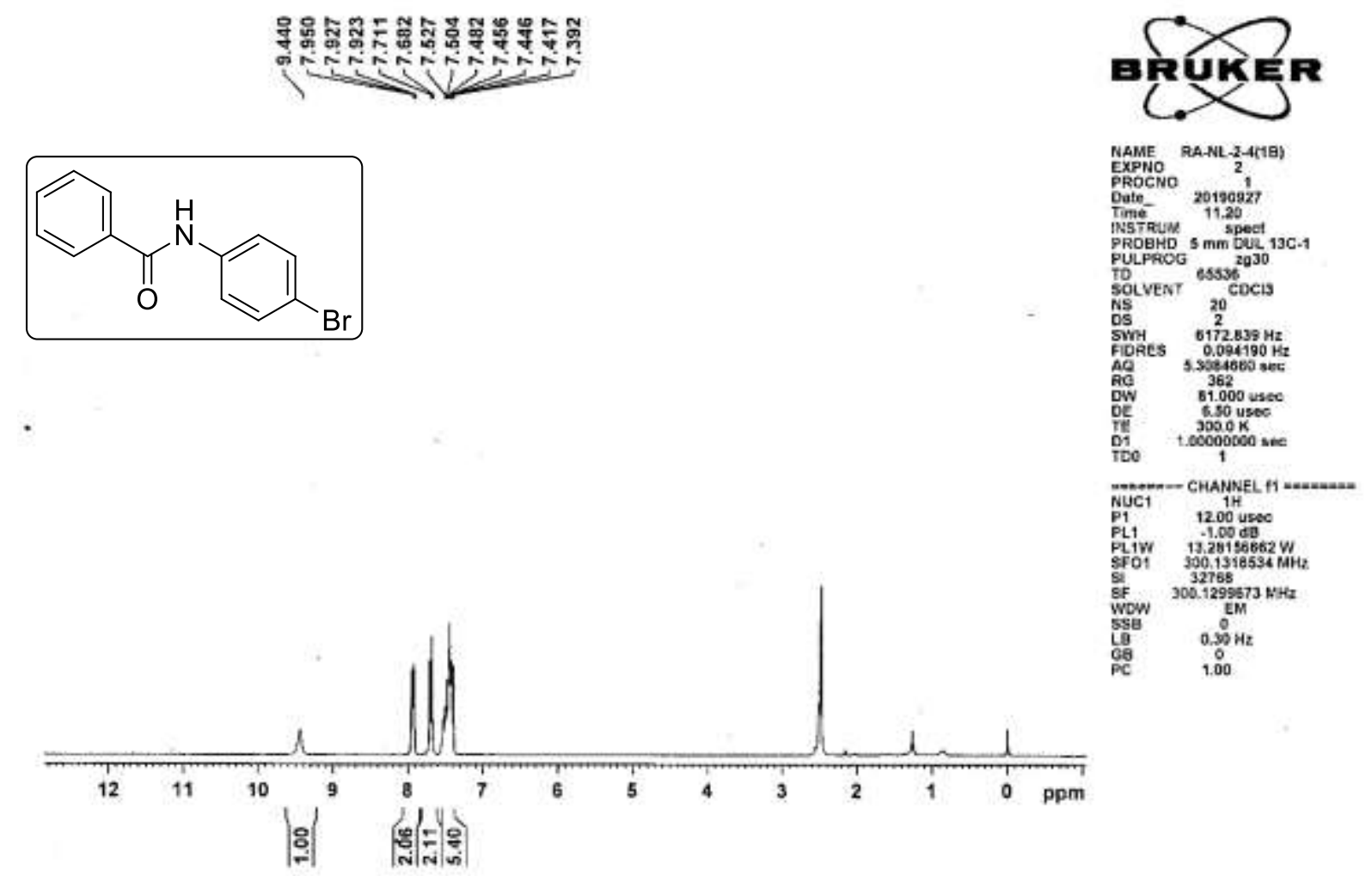

${ }^{1} \mathrm{H}$ NMR (300 MHz) spectrum of compound $5 \mathrm{~g}$

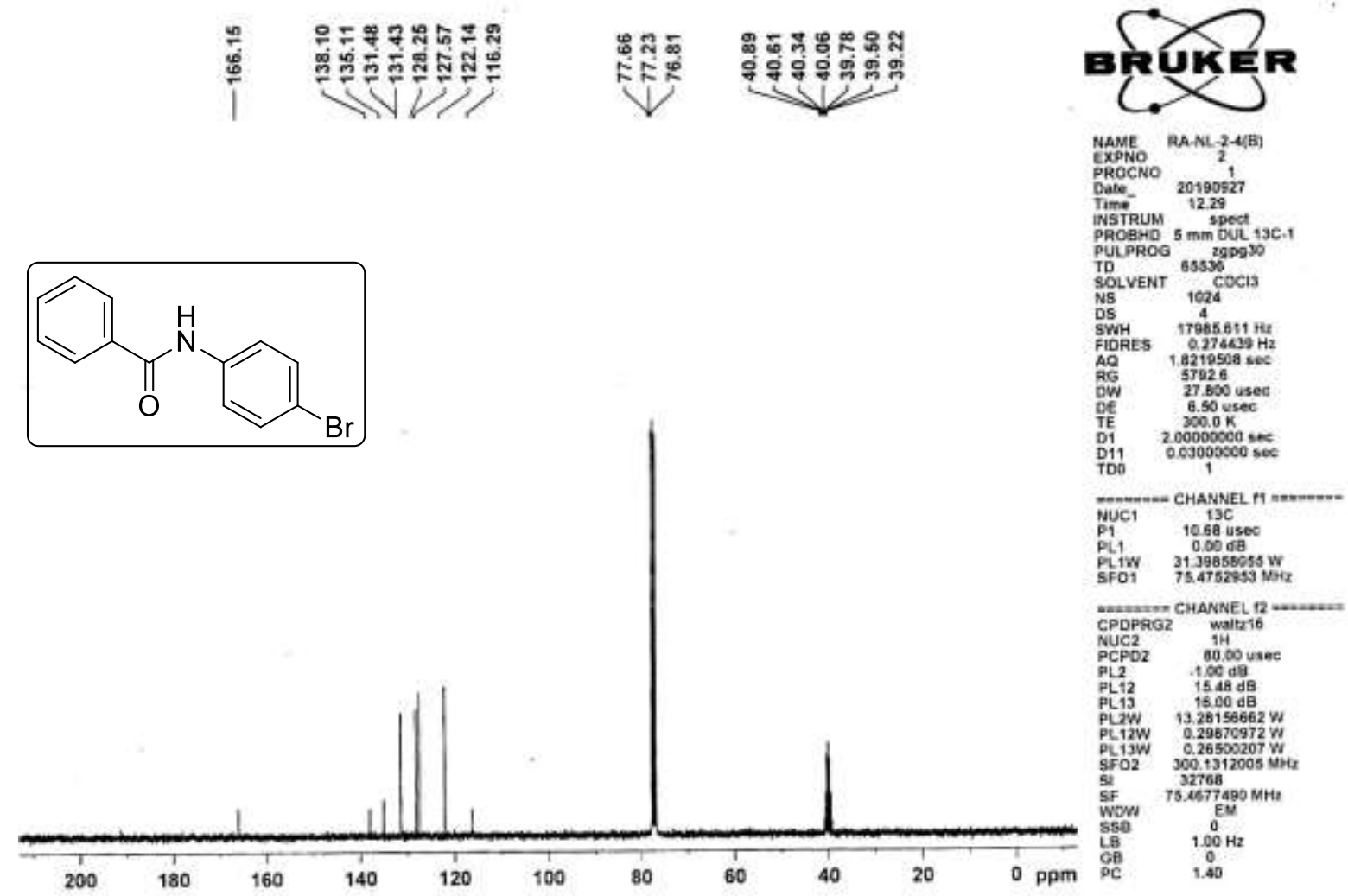

${ }^{13} \mathrm{C}\left\{{ }^{1} \mathrm{H}\right\}$ NMR (75 MHz) spectrum of compound $5 \mathrm{~g}$ 


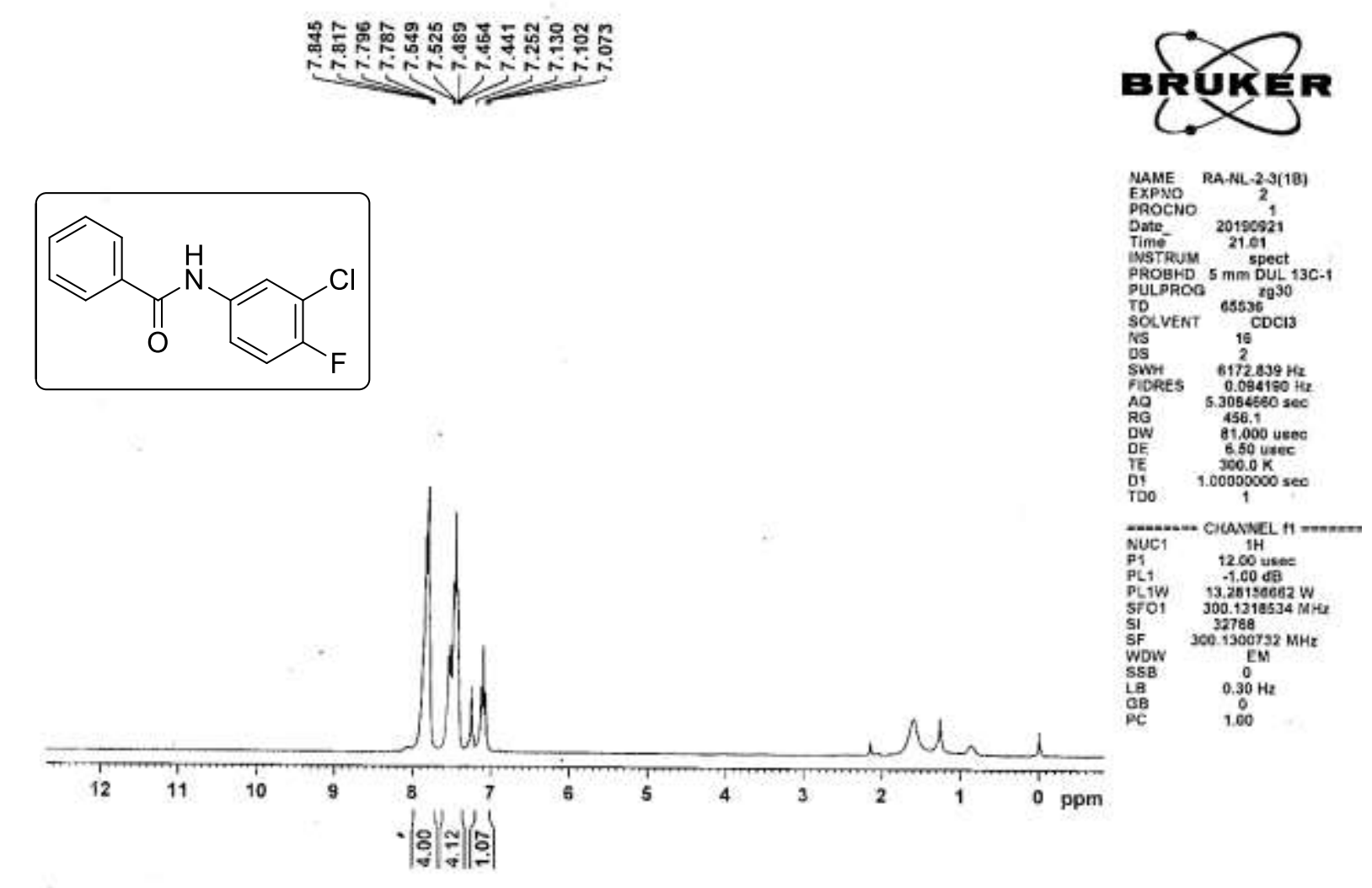

${ }^{1} \mathrm{H}$ NMR (300 MHz) spectrum of compound $5 \mathrm{~h}$

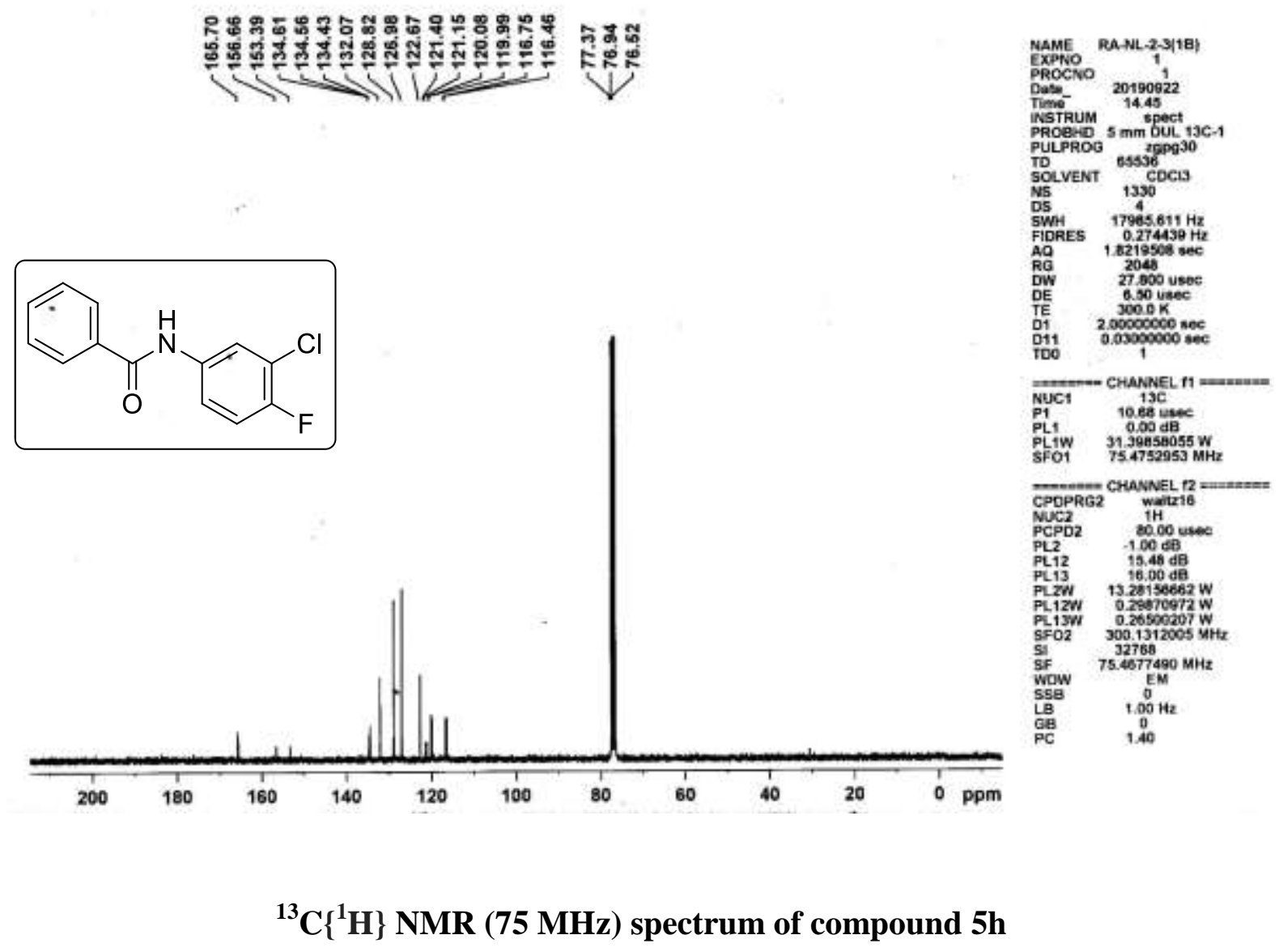




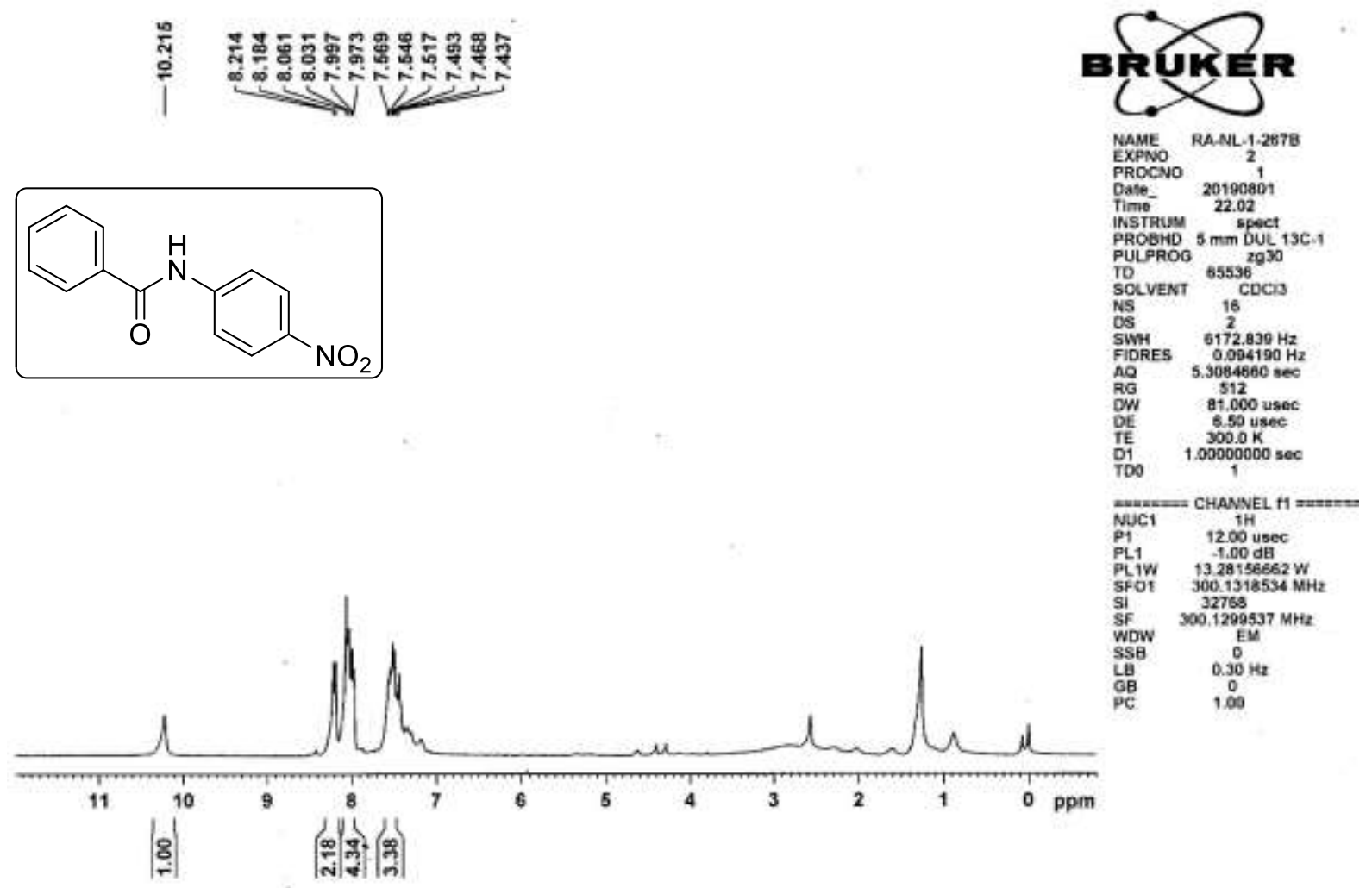

${ }^{1} \mathrm{H}$ NMR (300 MHz) spectrum of compound $5 \mathrm{i}$

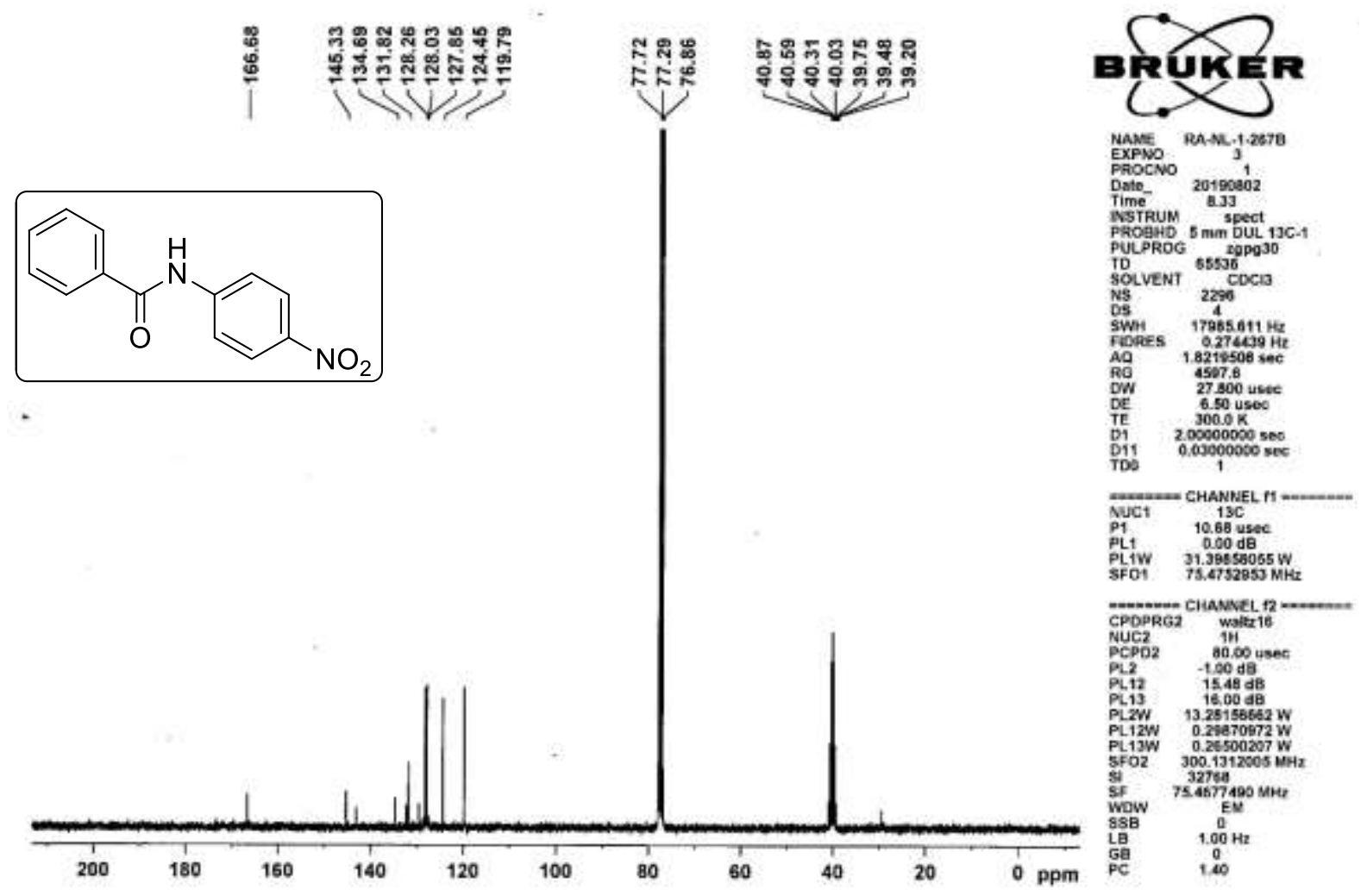

${ }^{13} \mathrm{C}\left\{{ }^{1} \mathrm{H}\right\}$ NMR (75 MHz) spectrum of compound $5 \mathrm{i}$ 


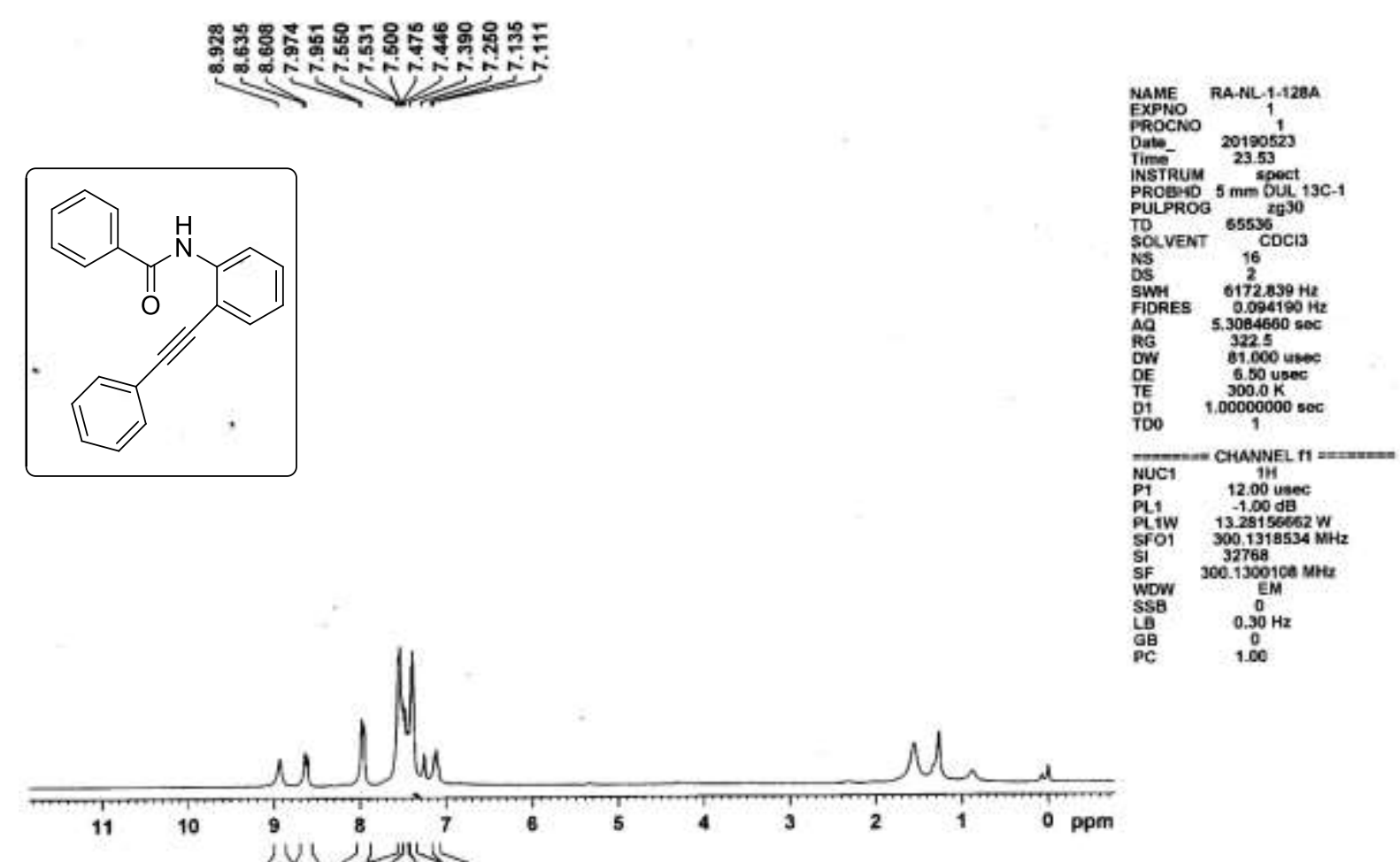

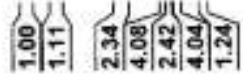

${ }^{1}$ H NMR (300 MHz) spectrum of compound $5 \mathbf{j}$

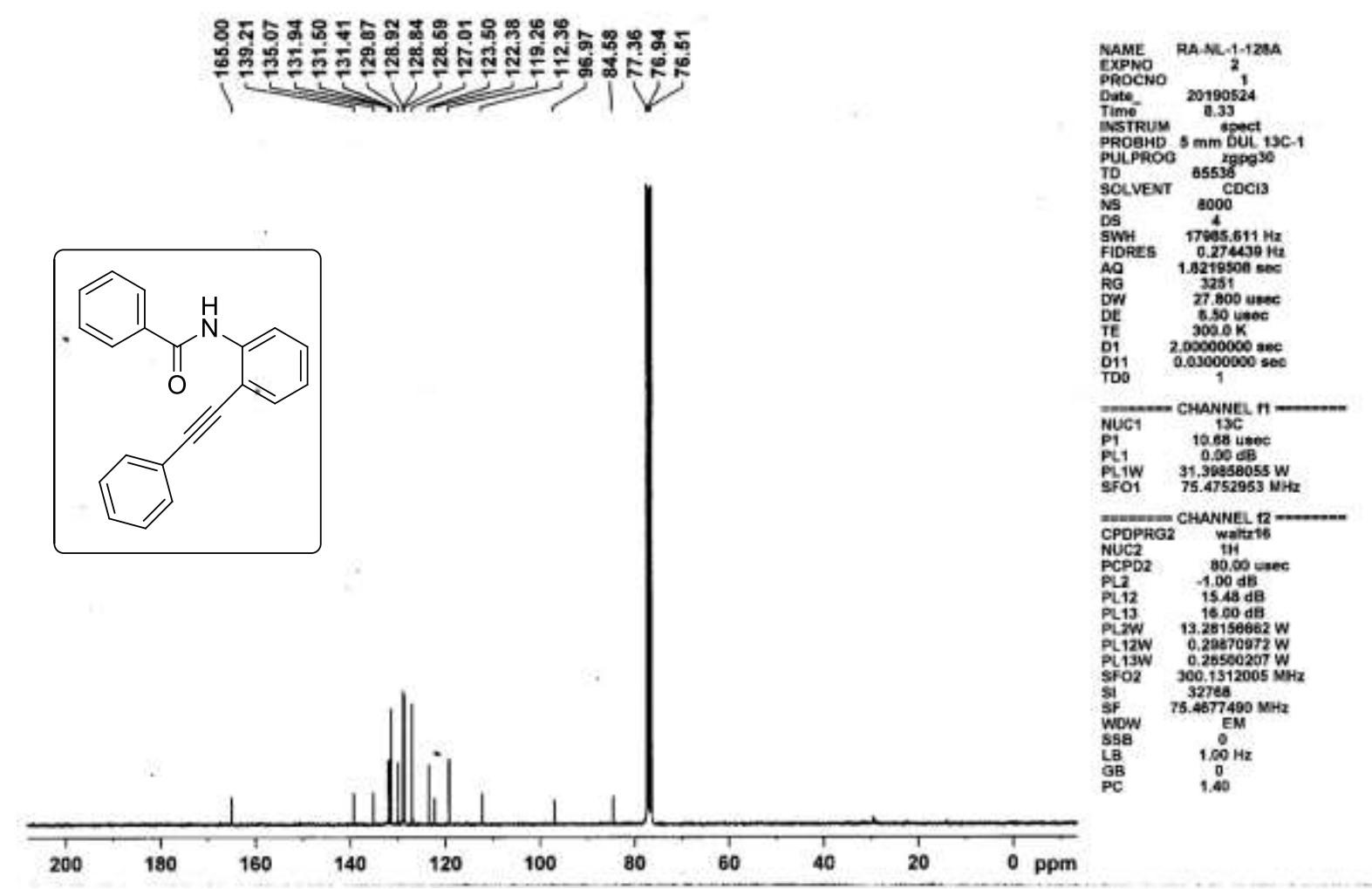

${ }^{13} \mathrm{C}\left\{{ }^{1} \mathrm{H}\right\}$ NMR (75 MHz) spectrum of compound $5 \mathrm{j}$ 


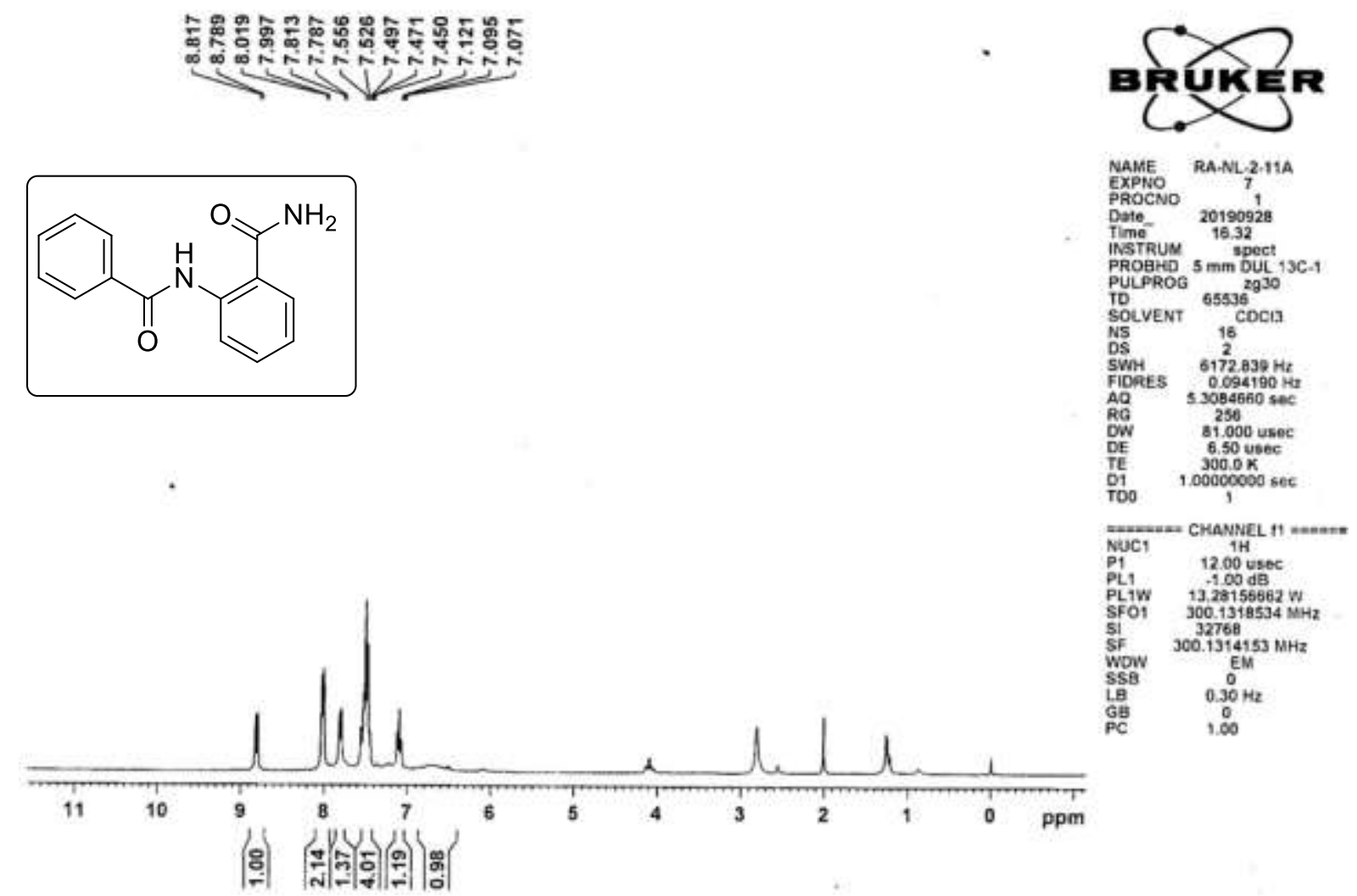

${ }^{1} \mathrm{H}$ NMR (300 MHz) spectrum of compound $5 \mathrm{k}$
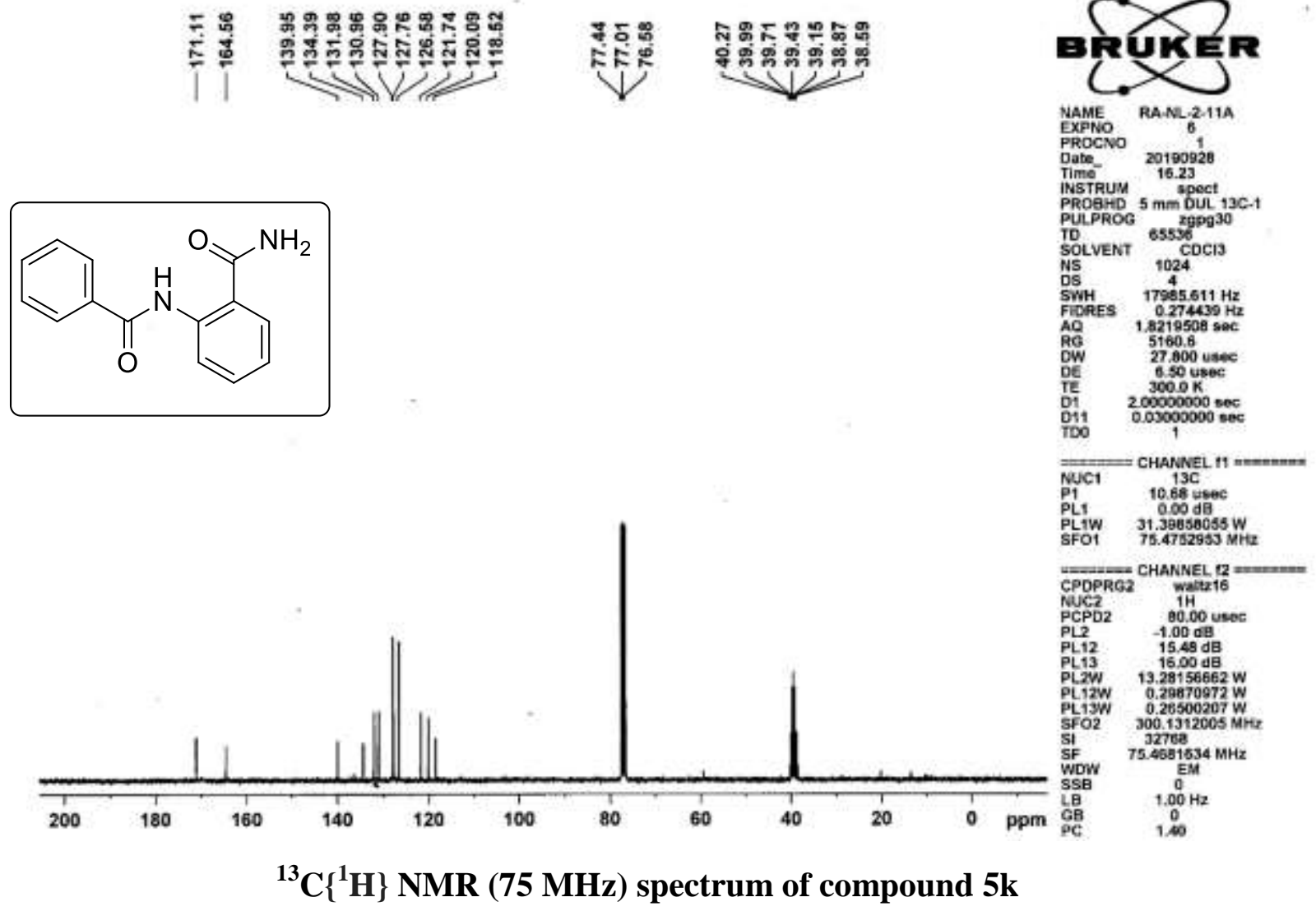
<smiles>O=C(NC1CCCCC1)c1ccccc1</smiles>

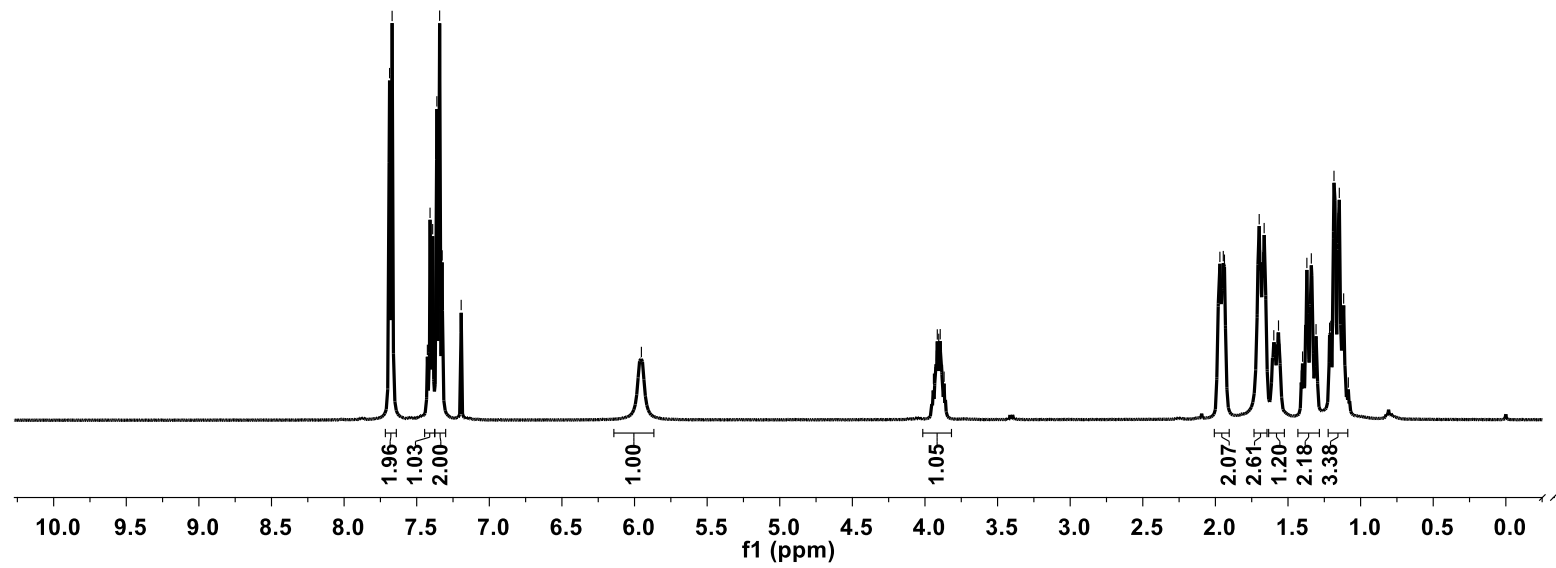

${ }^{1} \mathrm{H}$ NMR (400 MHz) spectrum of compound 51

NL $\quad \begin{aligned} & : \\ & \stackrel{0}{0} \\ & \end{aligned}$

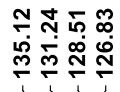

लำ

hKi

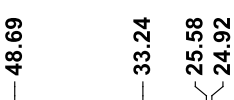<smiles>O=C(NC1CCCCC1)c1ccccc1</smiles>

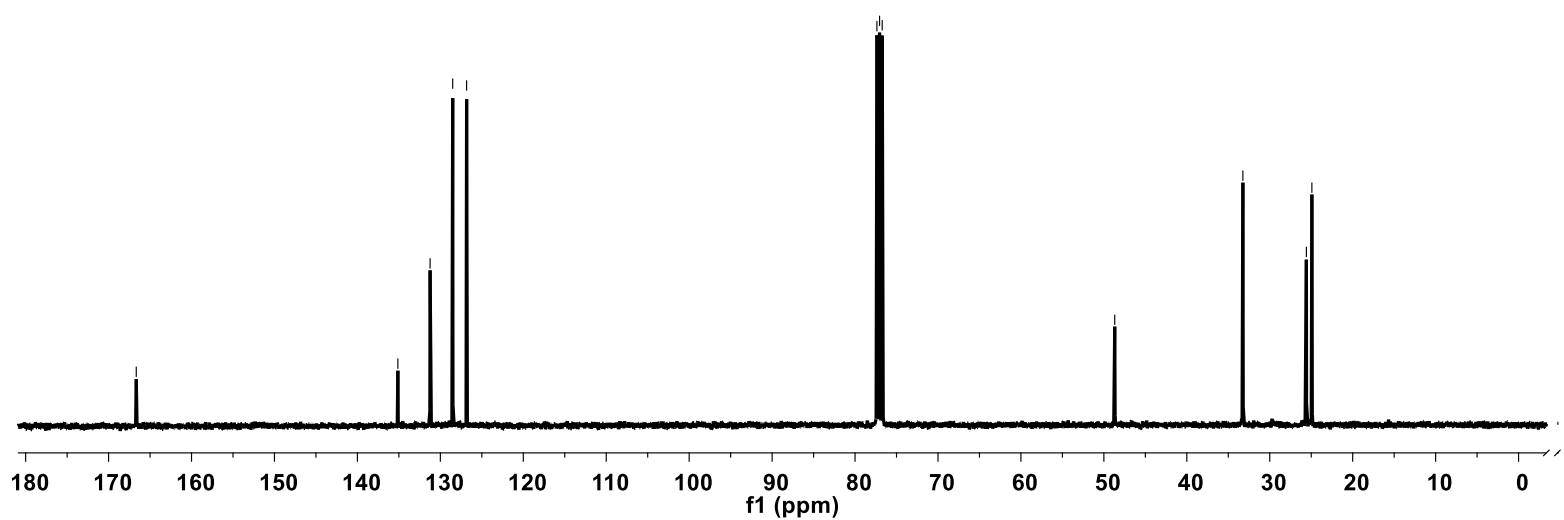

${ }^{13} \mathrm{C}\left\{{ }^{1} \mathrm{H}\right\}$ NMR (101 MHz) spectrum of compound 51 


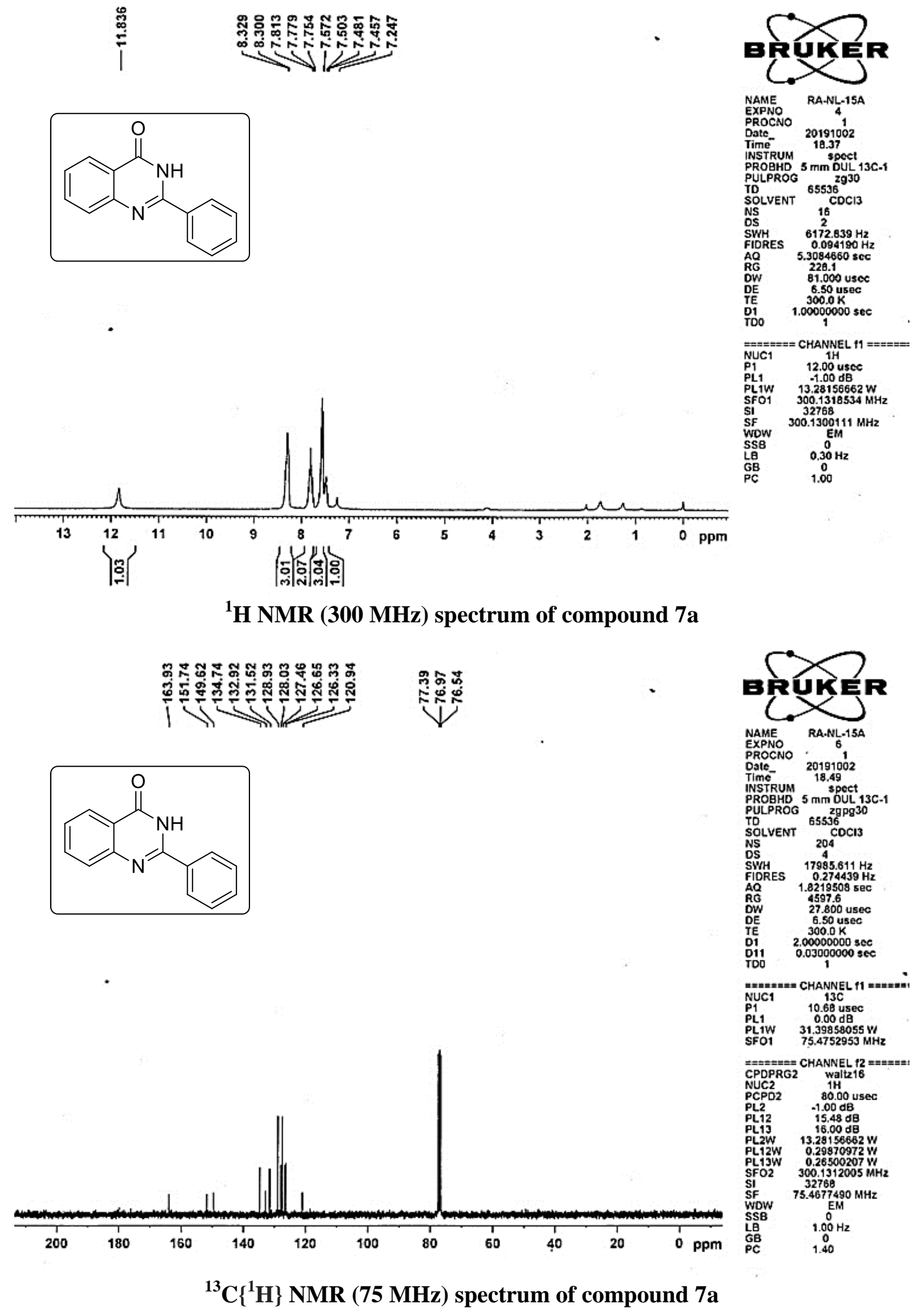




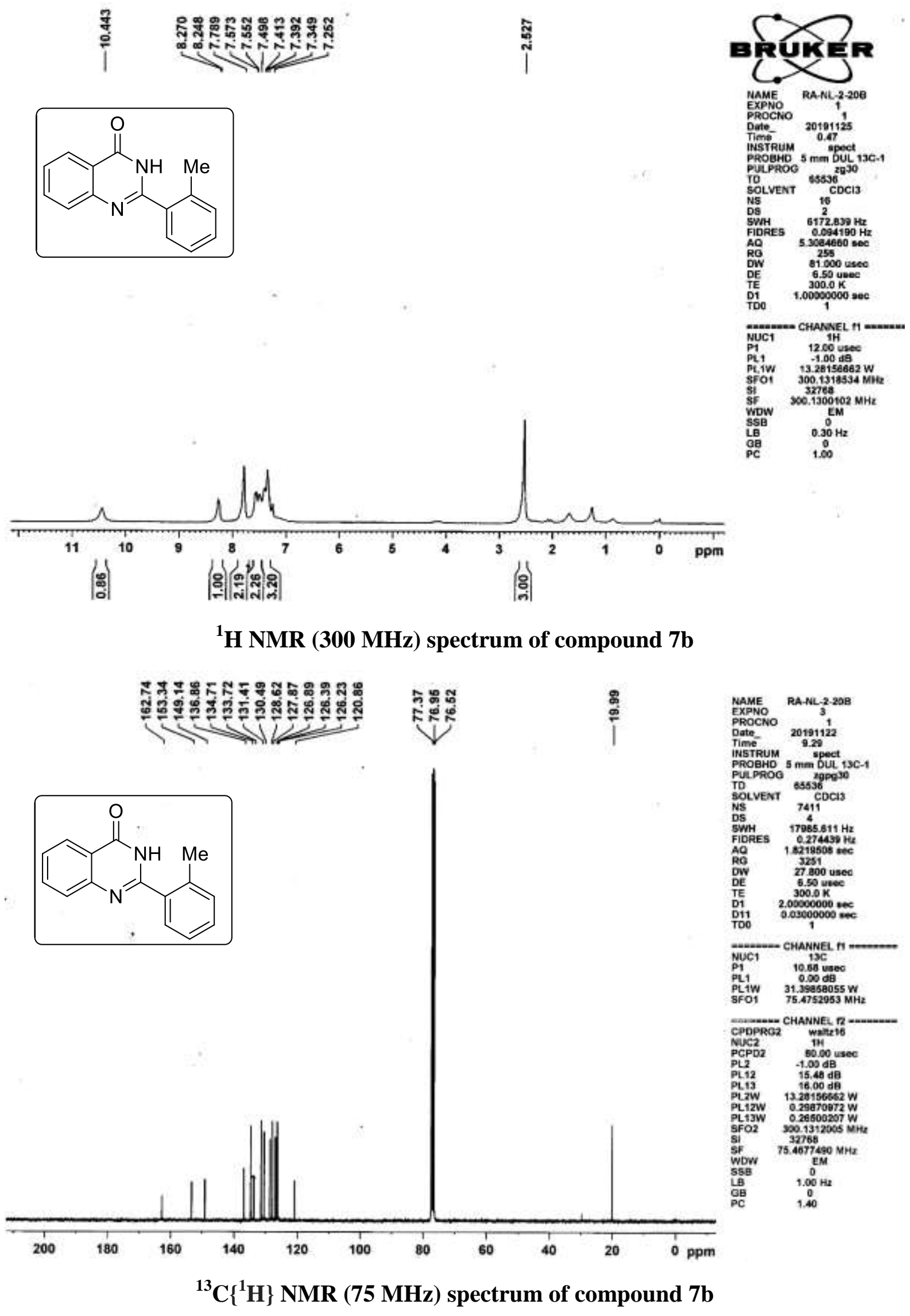




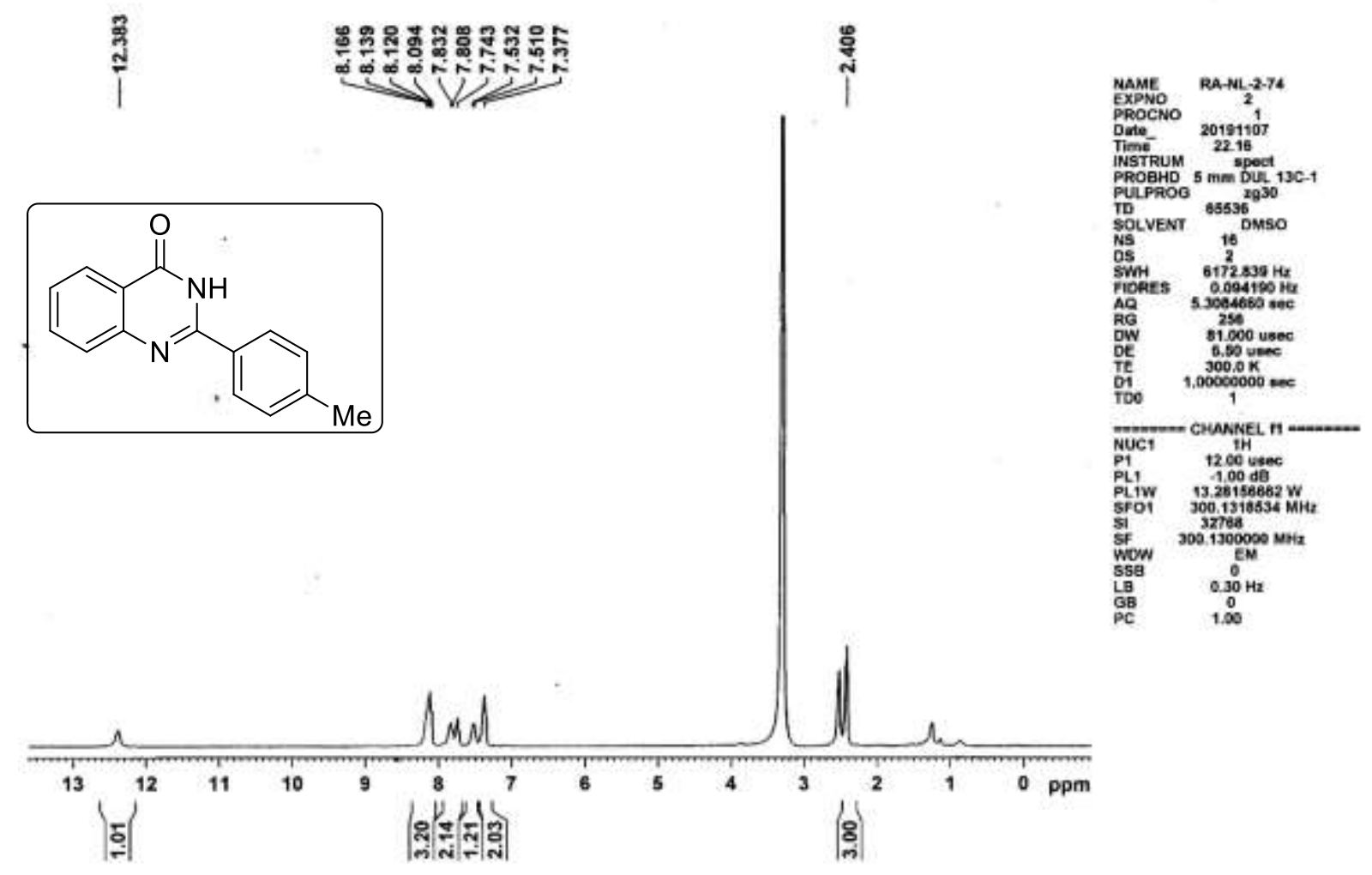

${ }^{1}$ H NMR (300 MHz) spectrum of compound 7c

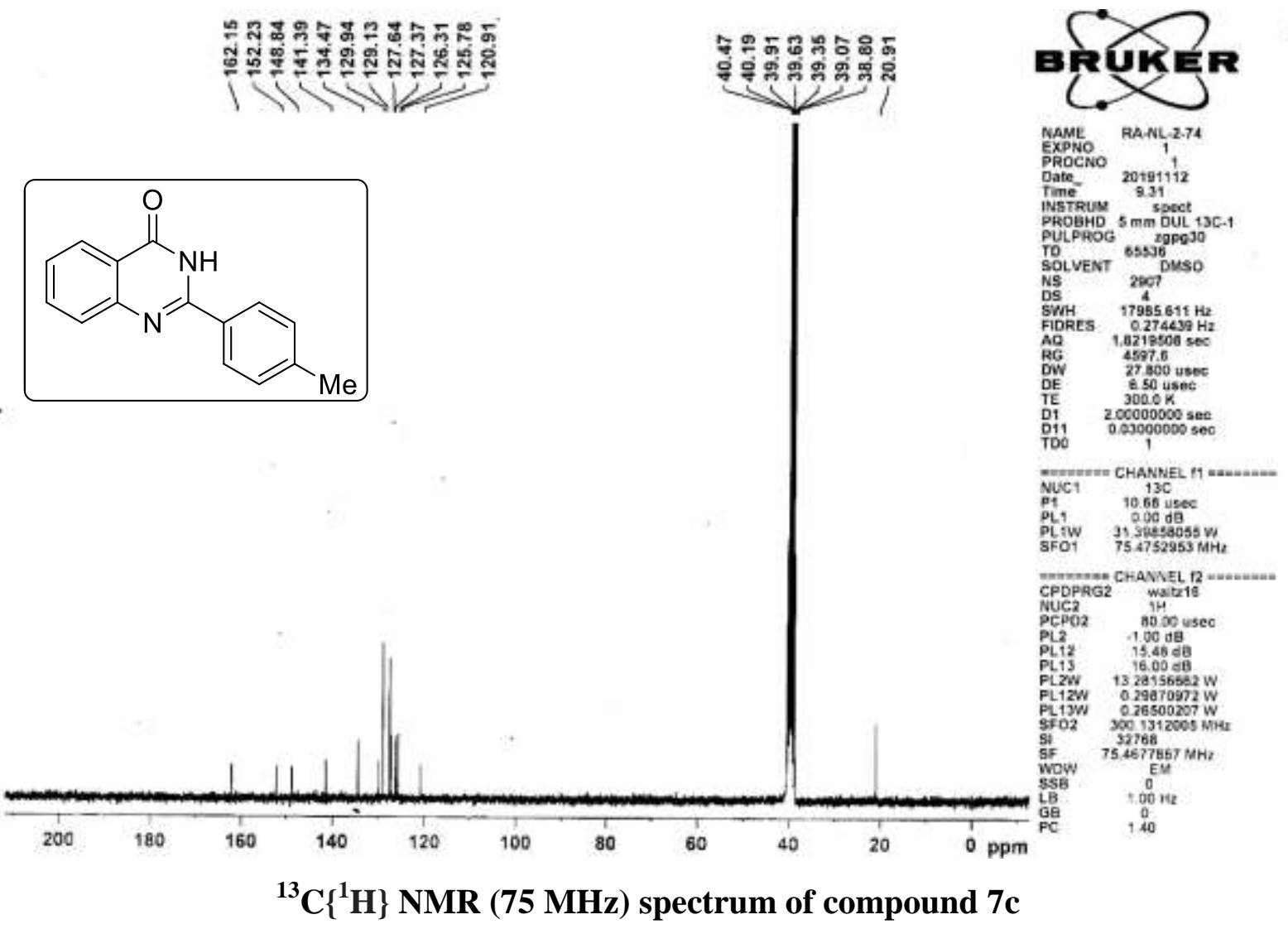




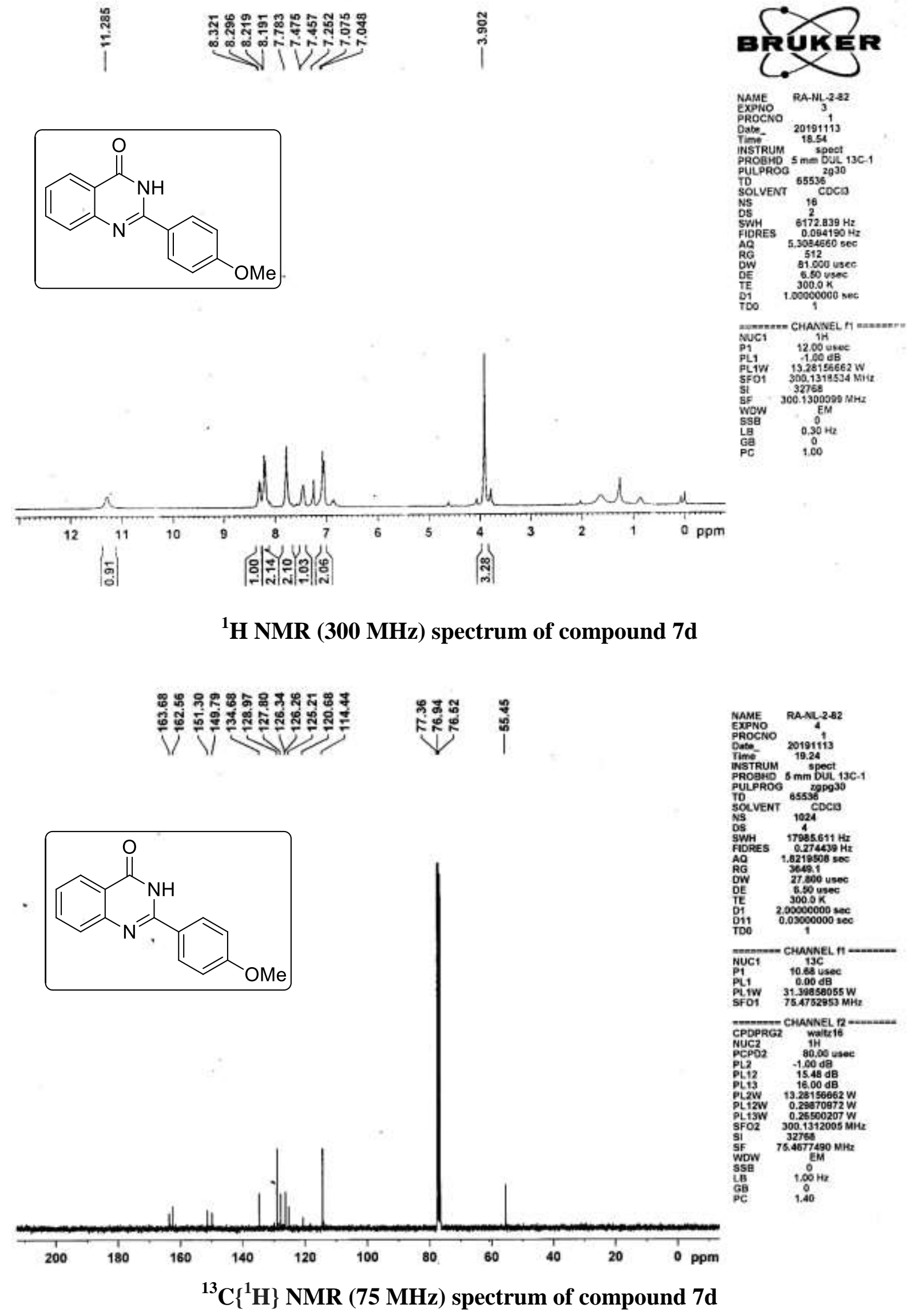




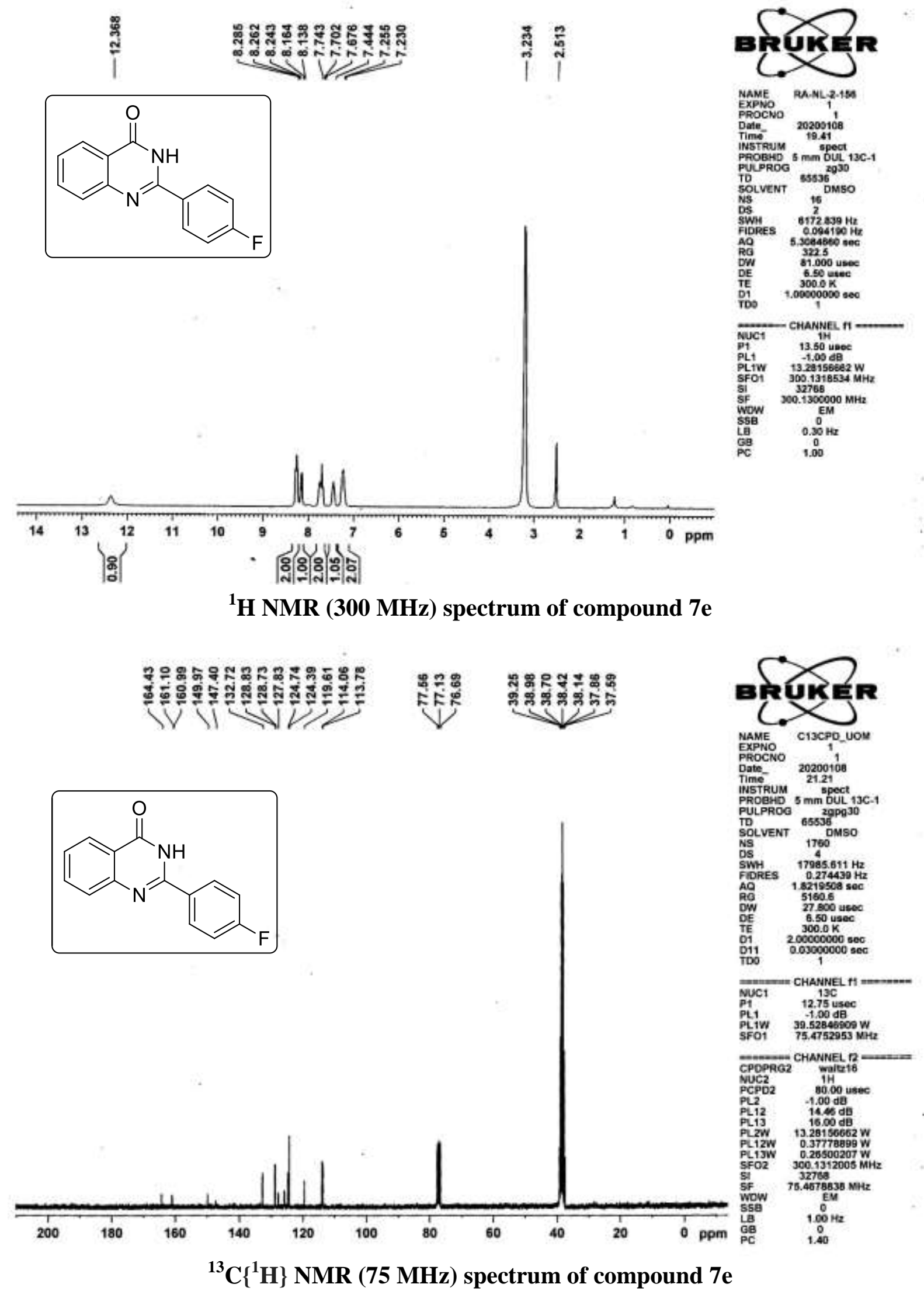




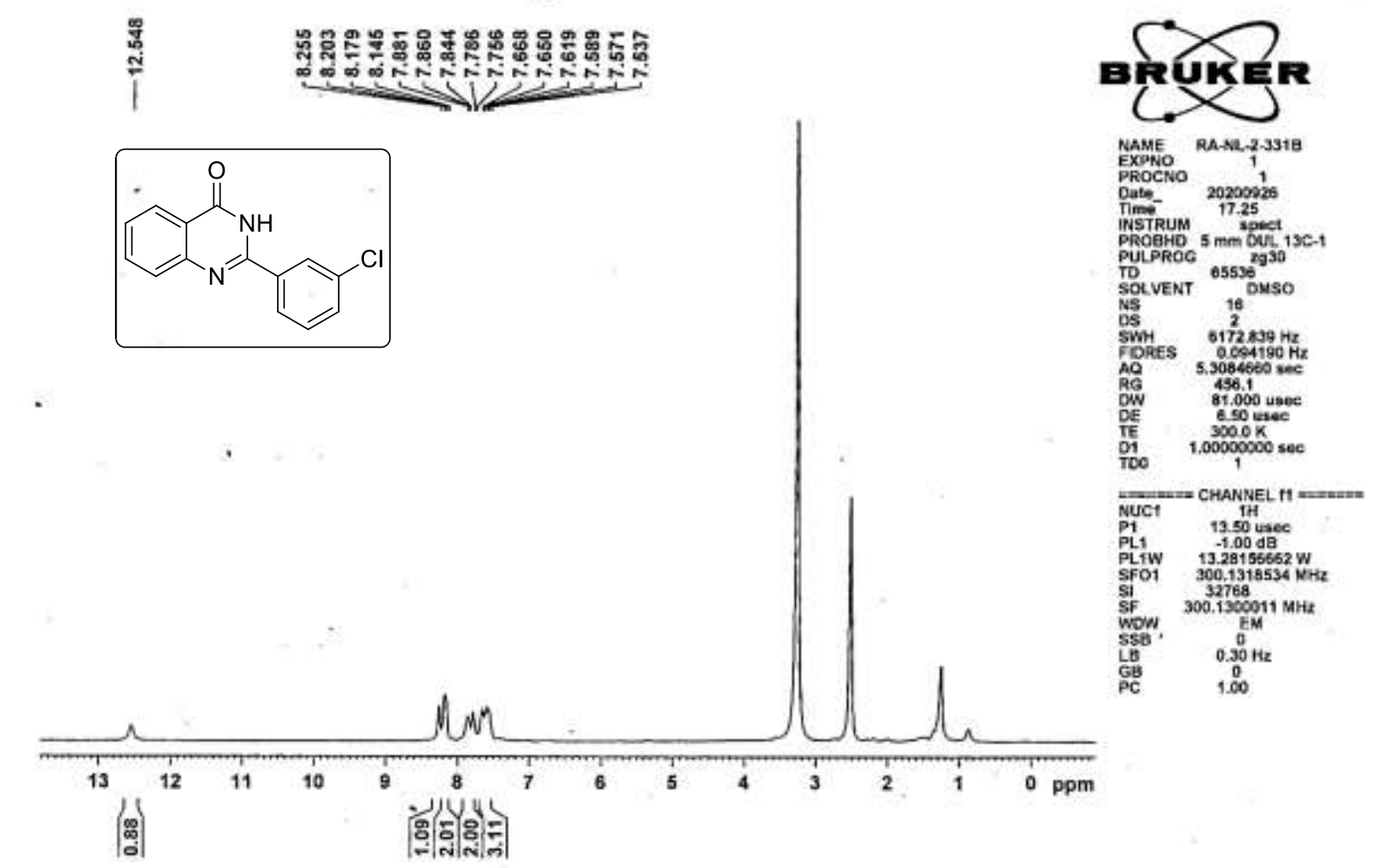

${ }^{1} \mathrm{H}$ NMR (300 MHz) spectrum of compound $7 f$

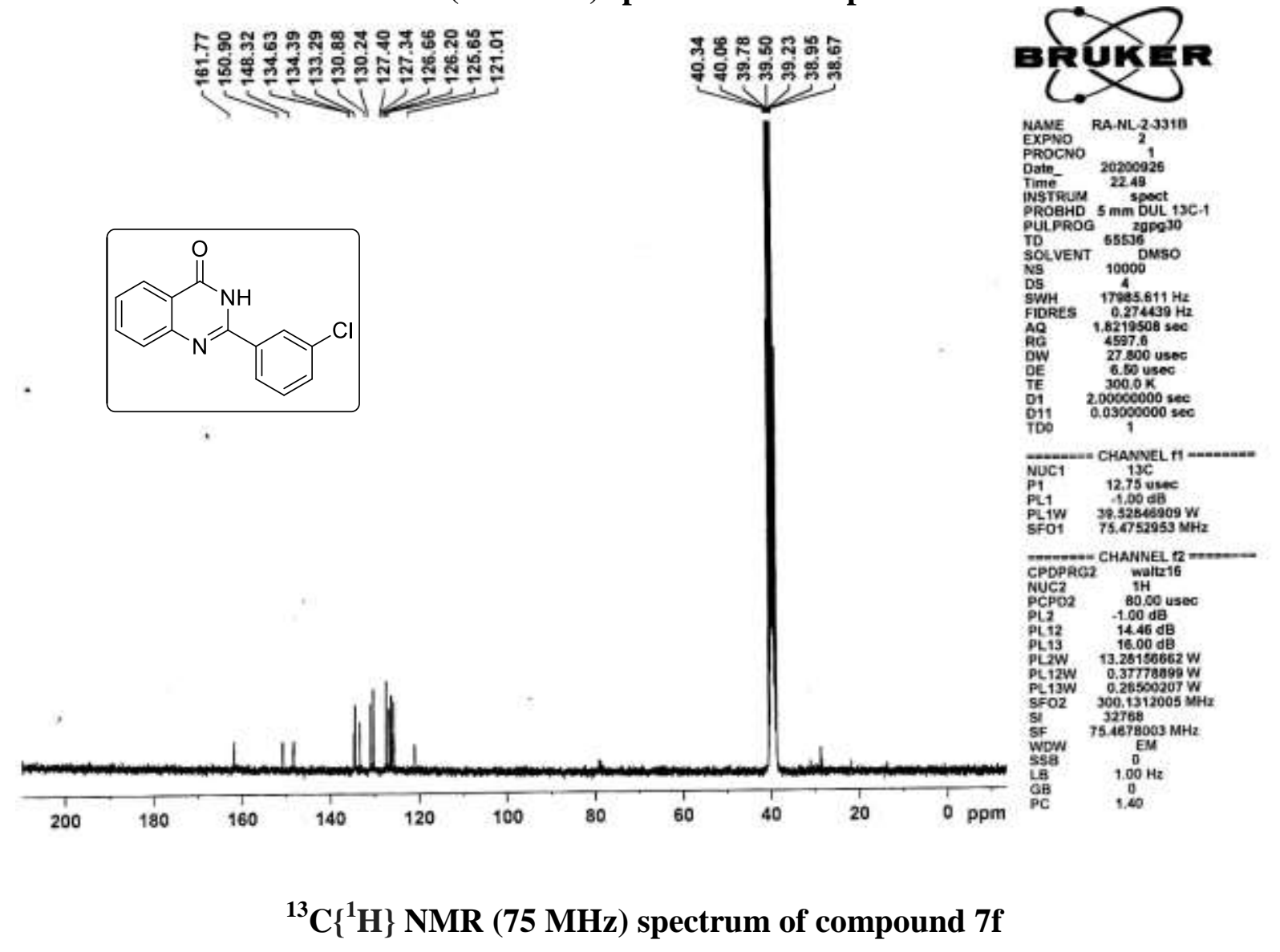




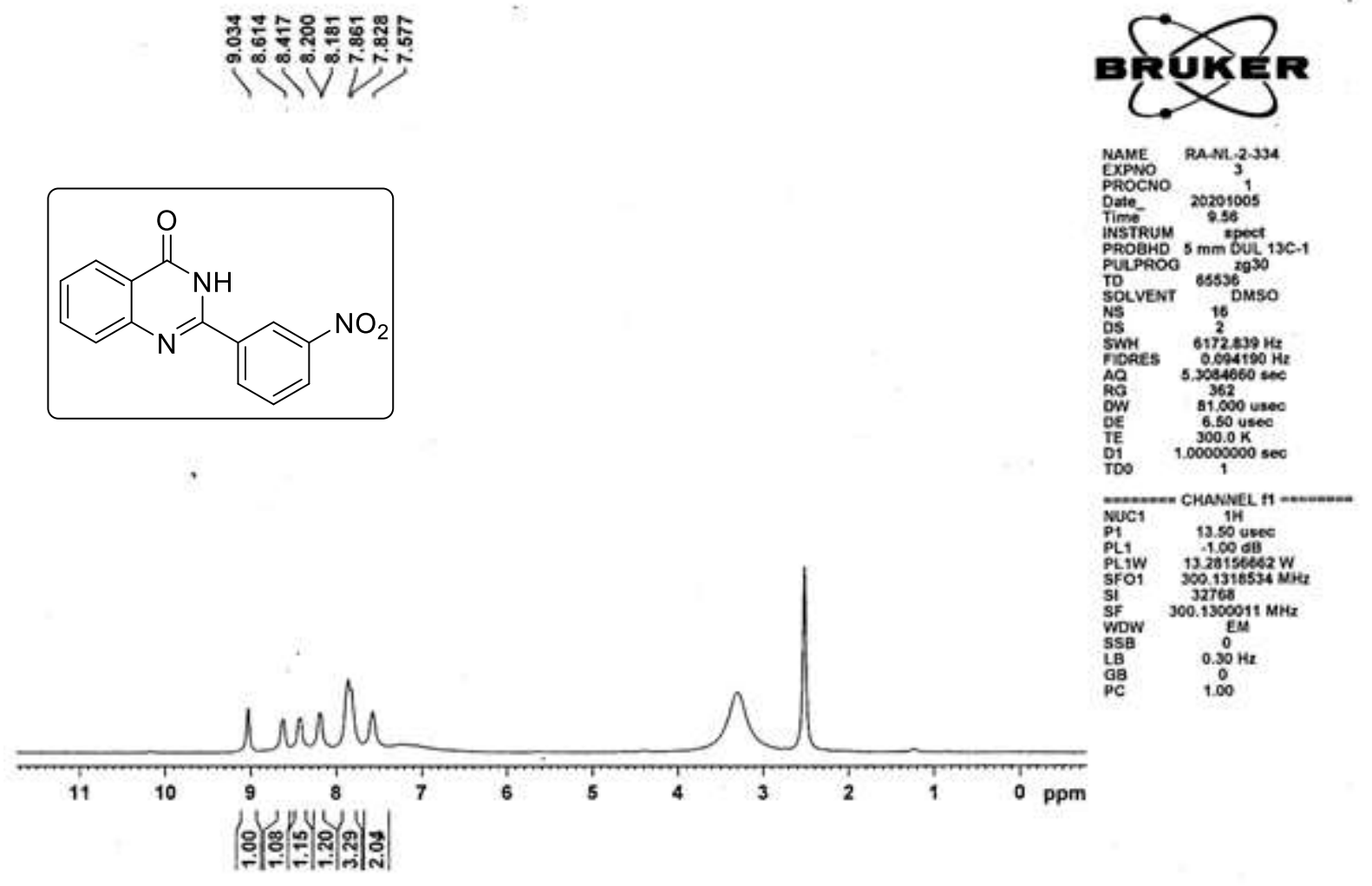

${ }^{1} \mathrm{H}$ NMR (300 MHz) spectrum of compound $7 \mathrm{~g}$

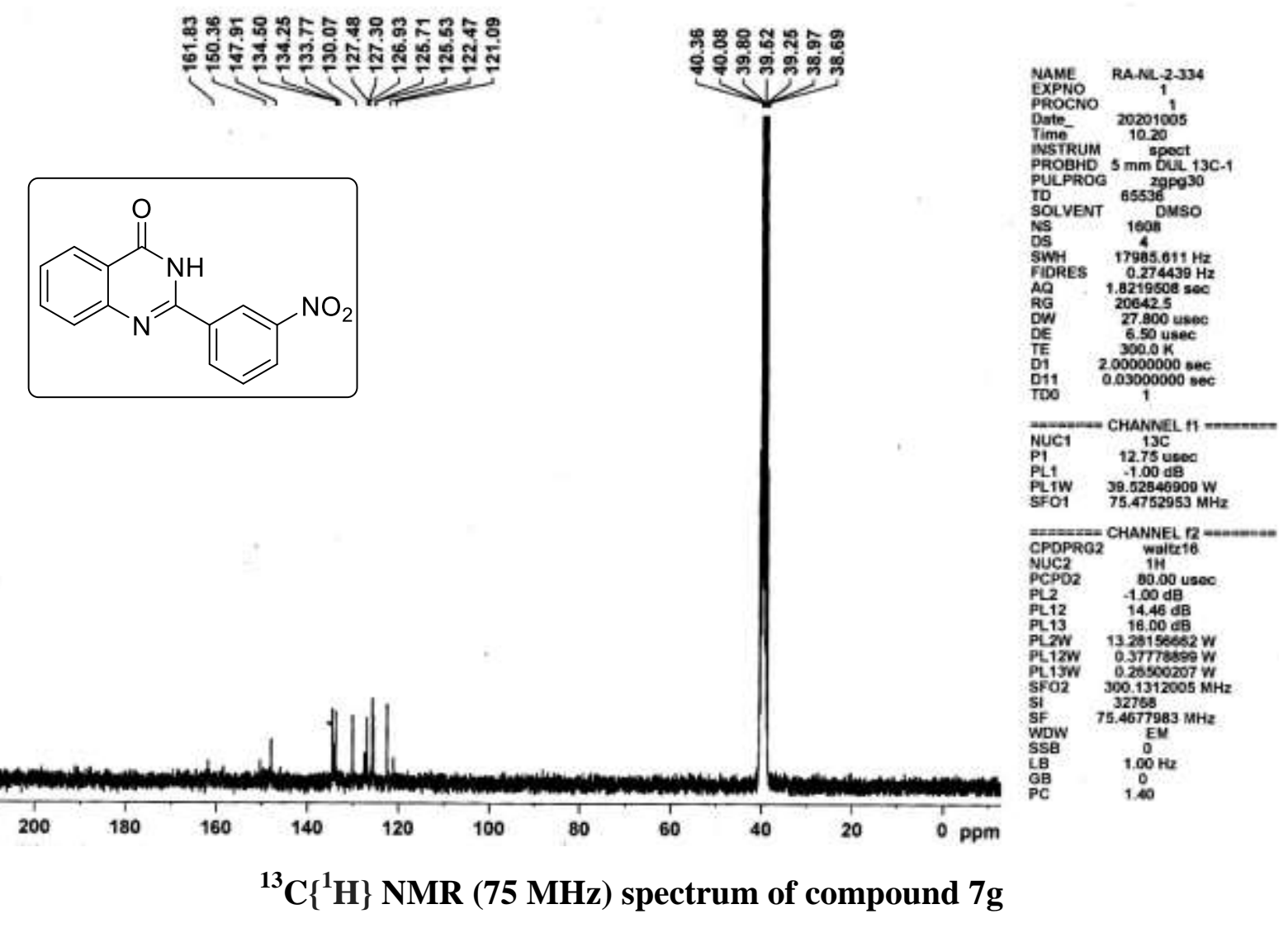




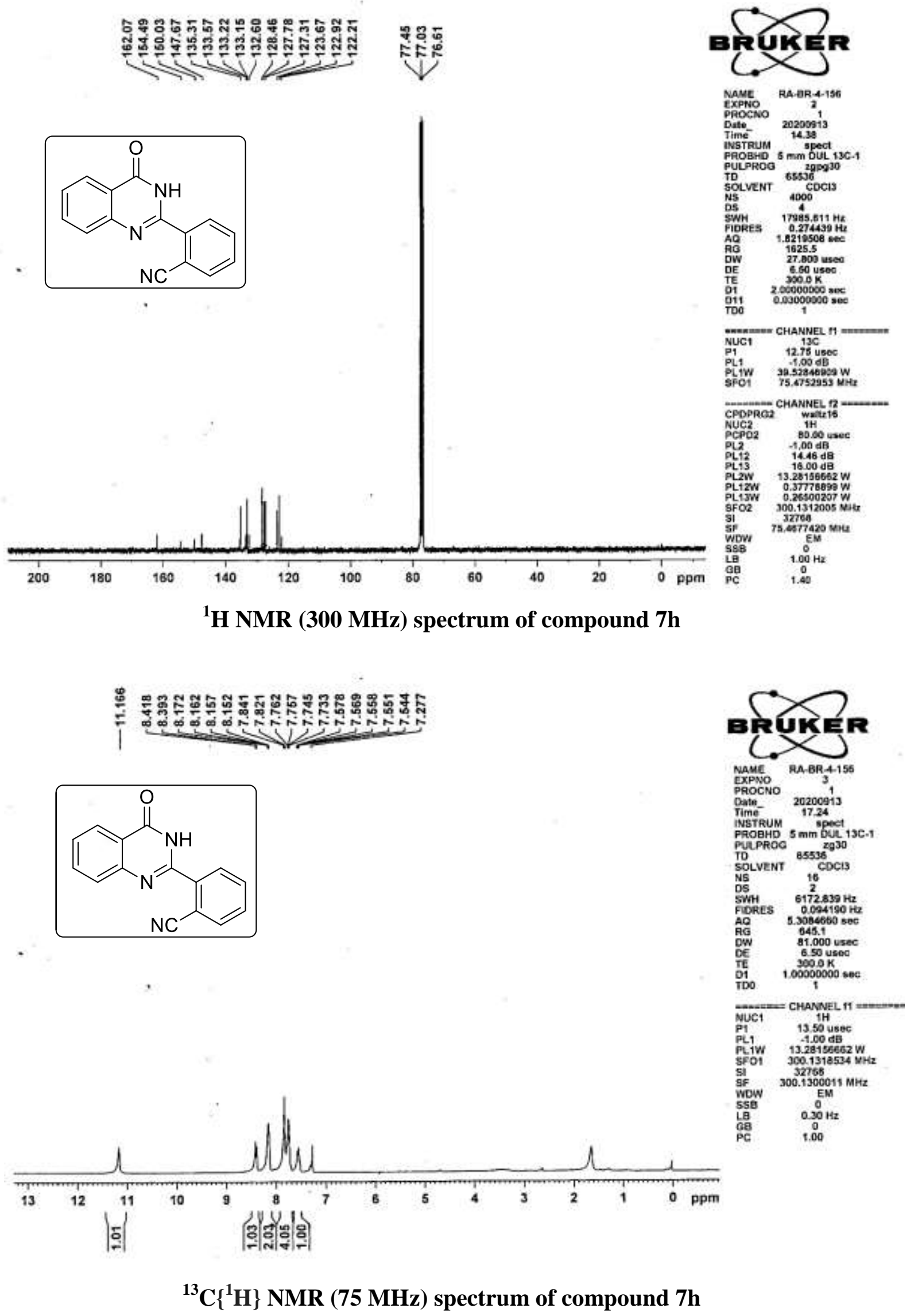




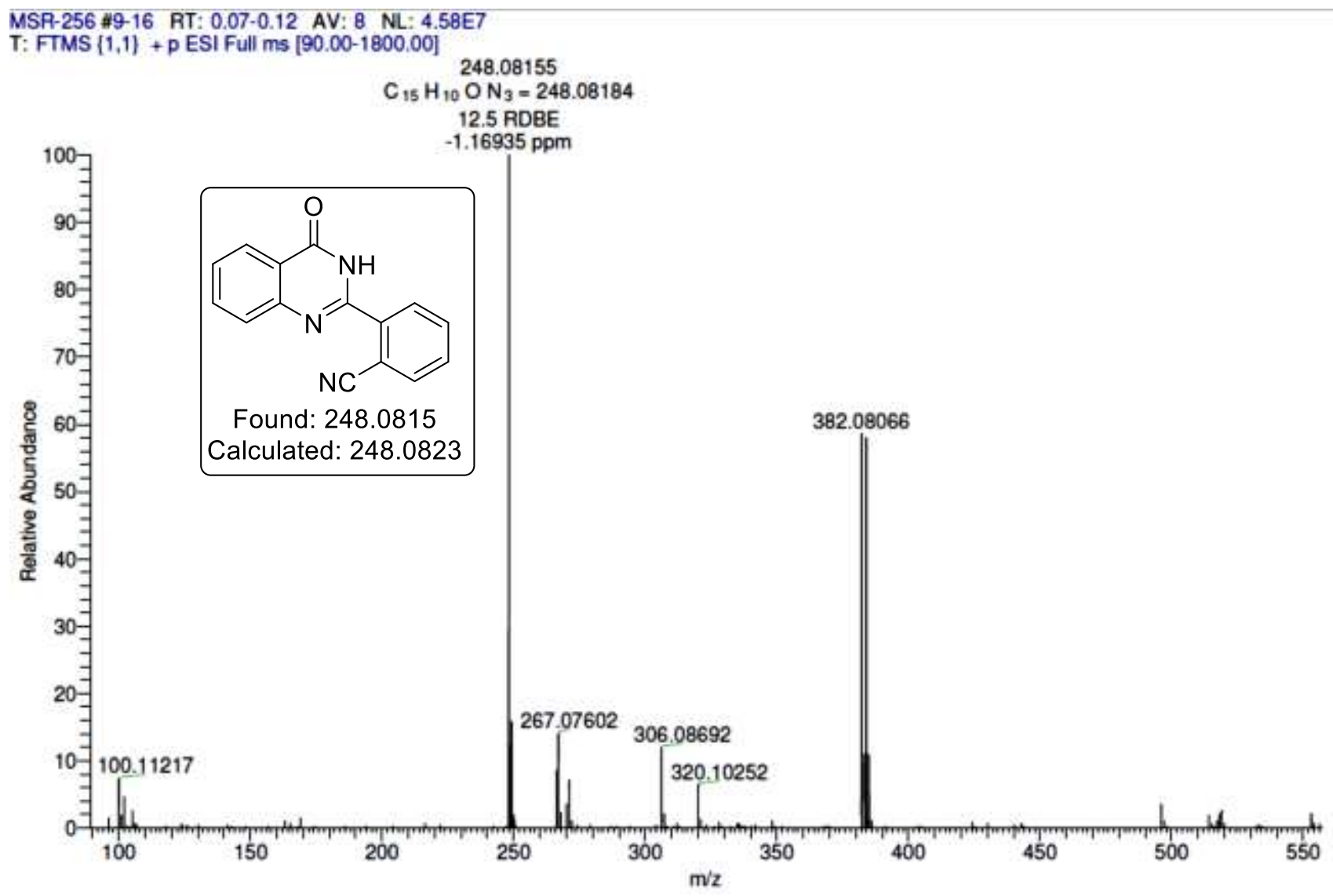

HRMS spectrum of compound 7h 


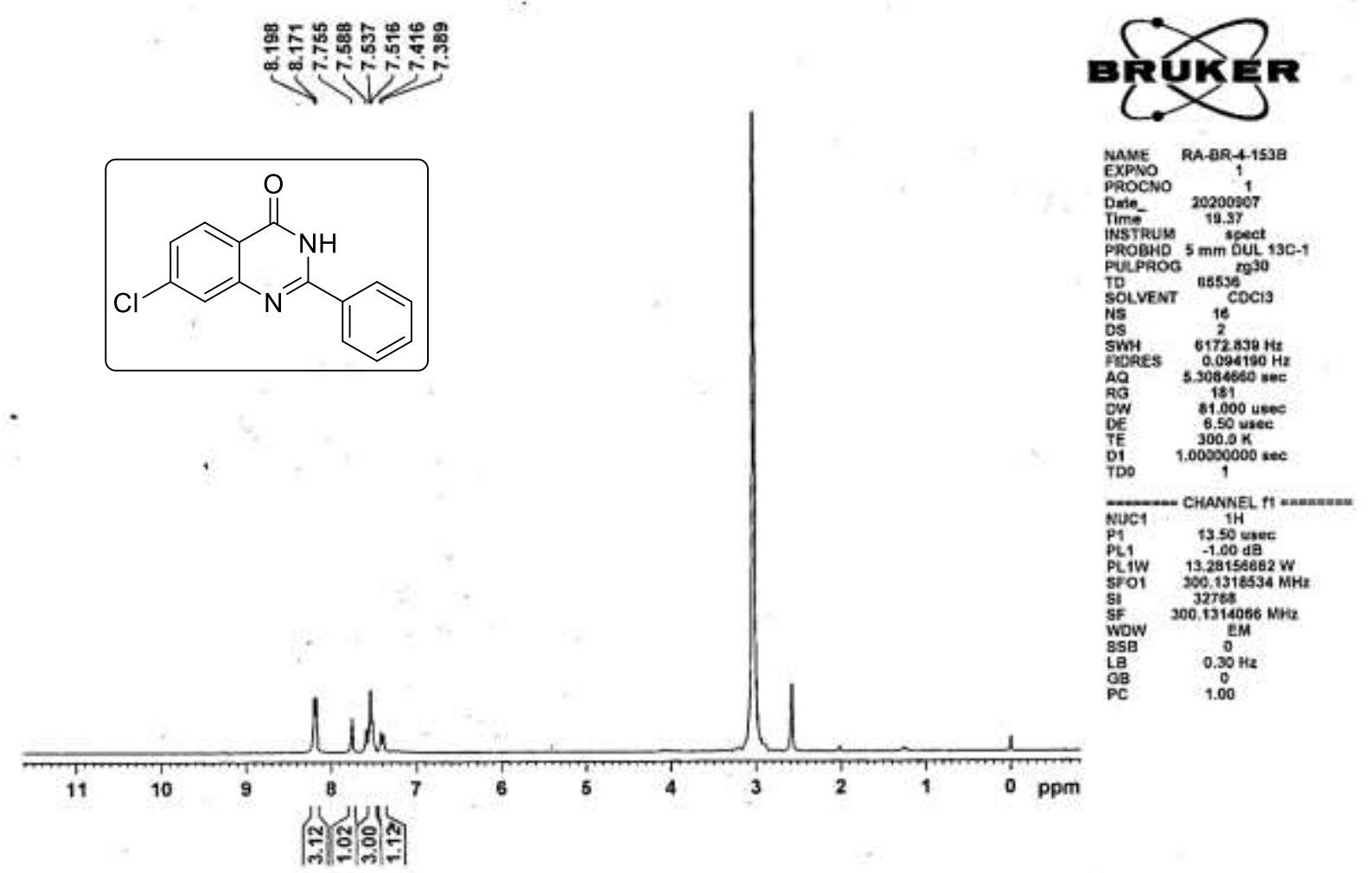

${ }^{1} \mathrm{H}$ NMR (300 MHz) spectrum of compound 7i

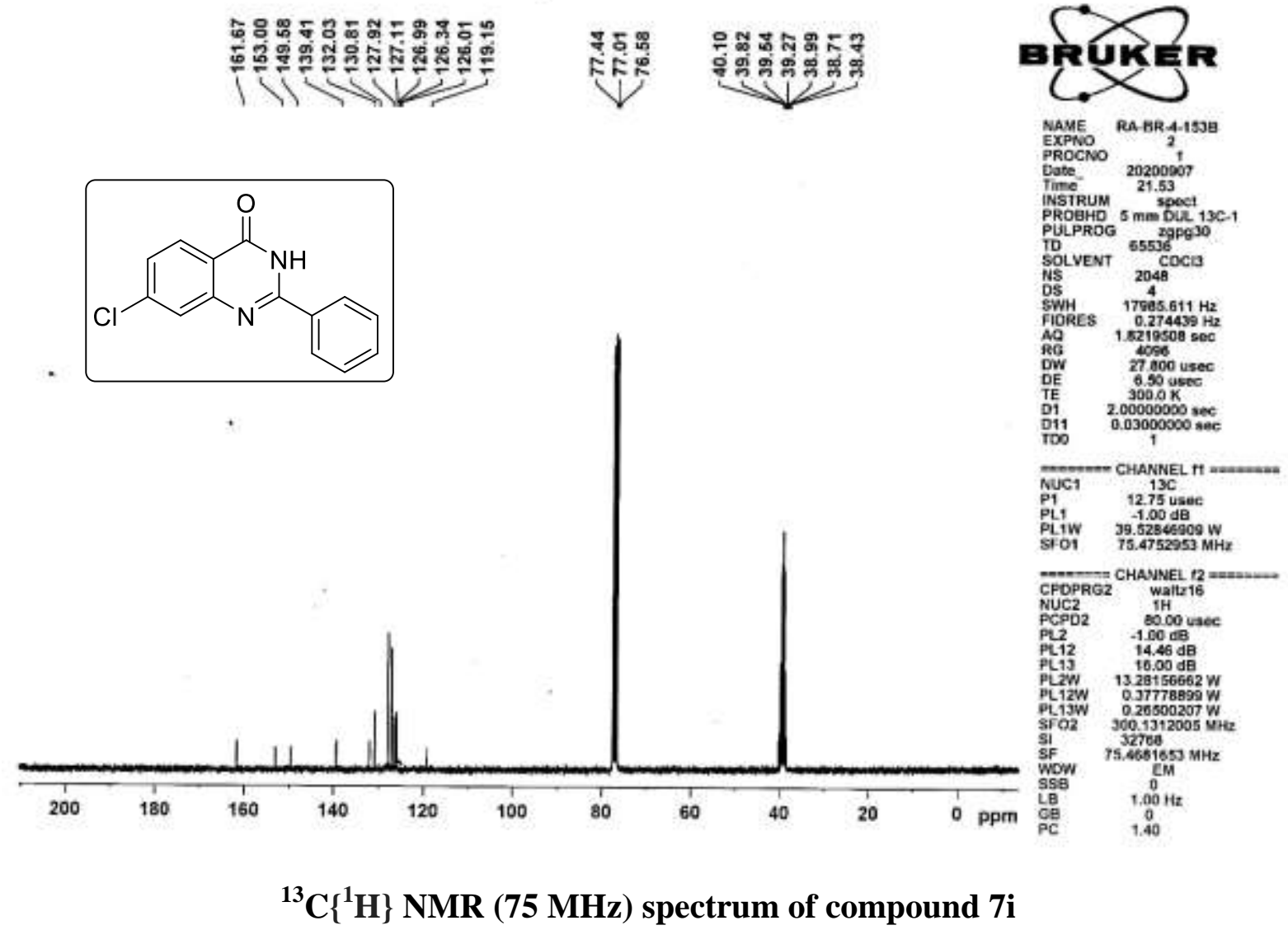




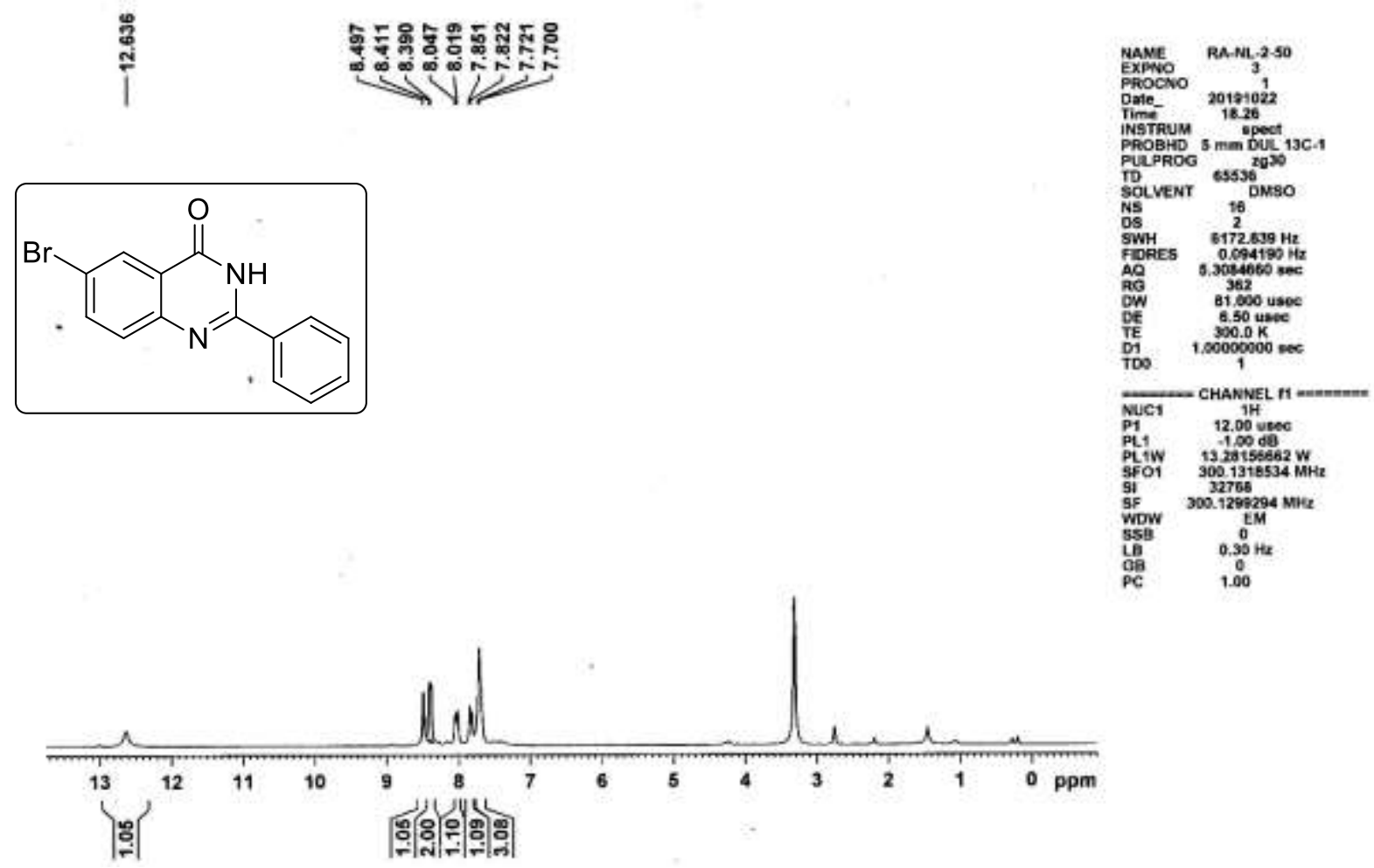

${ }^{1}$ H NMR (300 MHz) spectrum of compound 7j

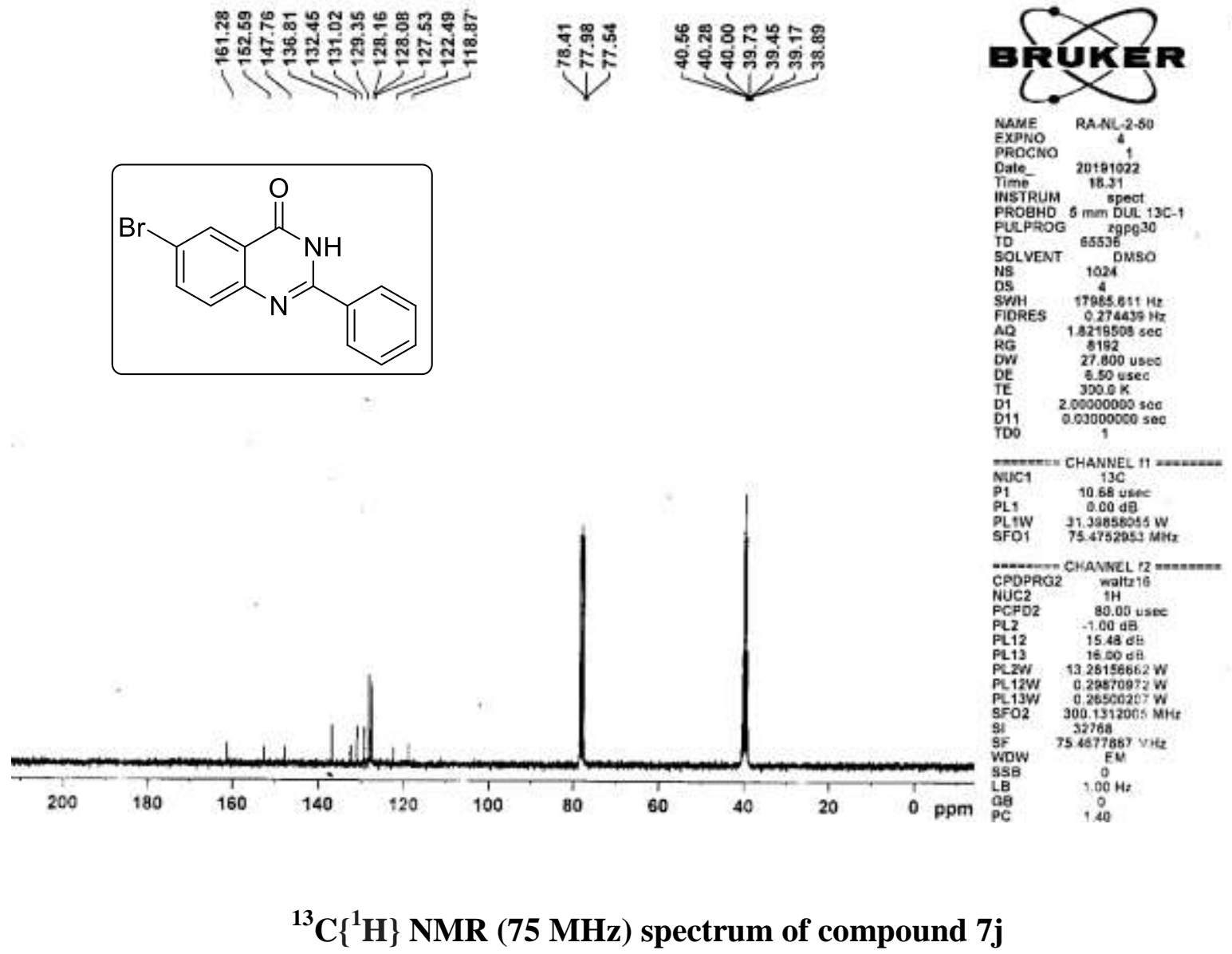




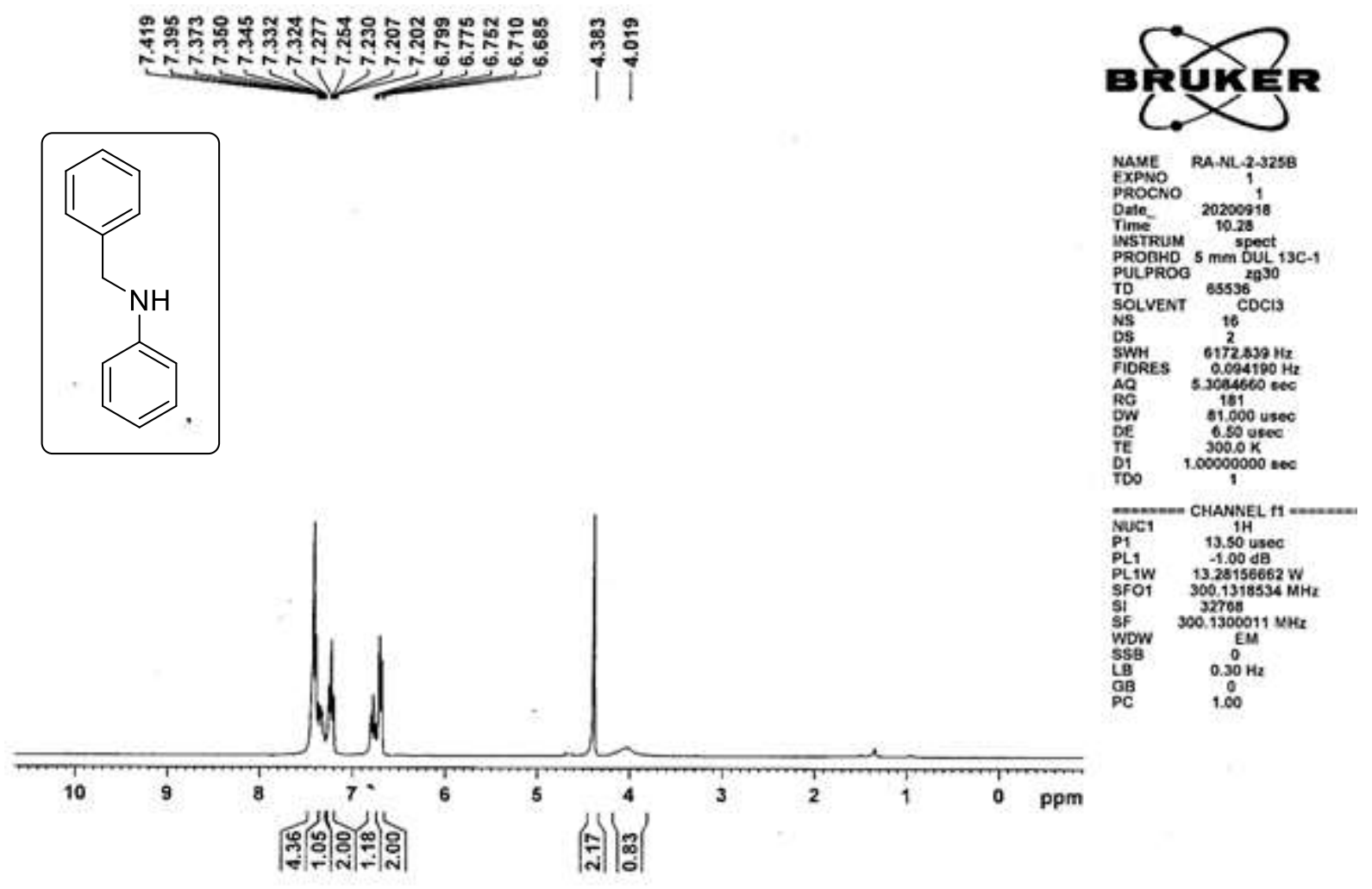

${ }^{1}$ H NMR (300 MHz) spectrum of compound 8 


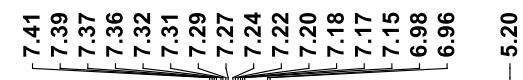
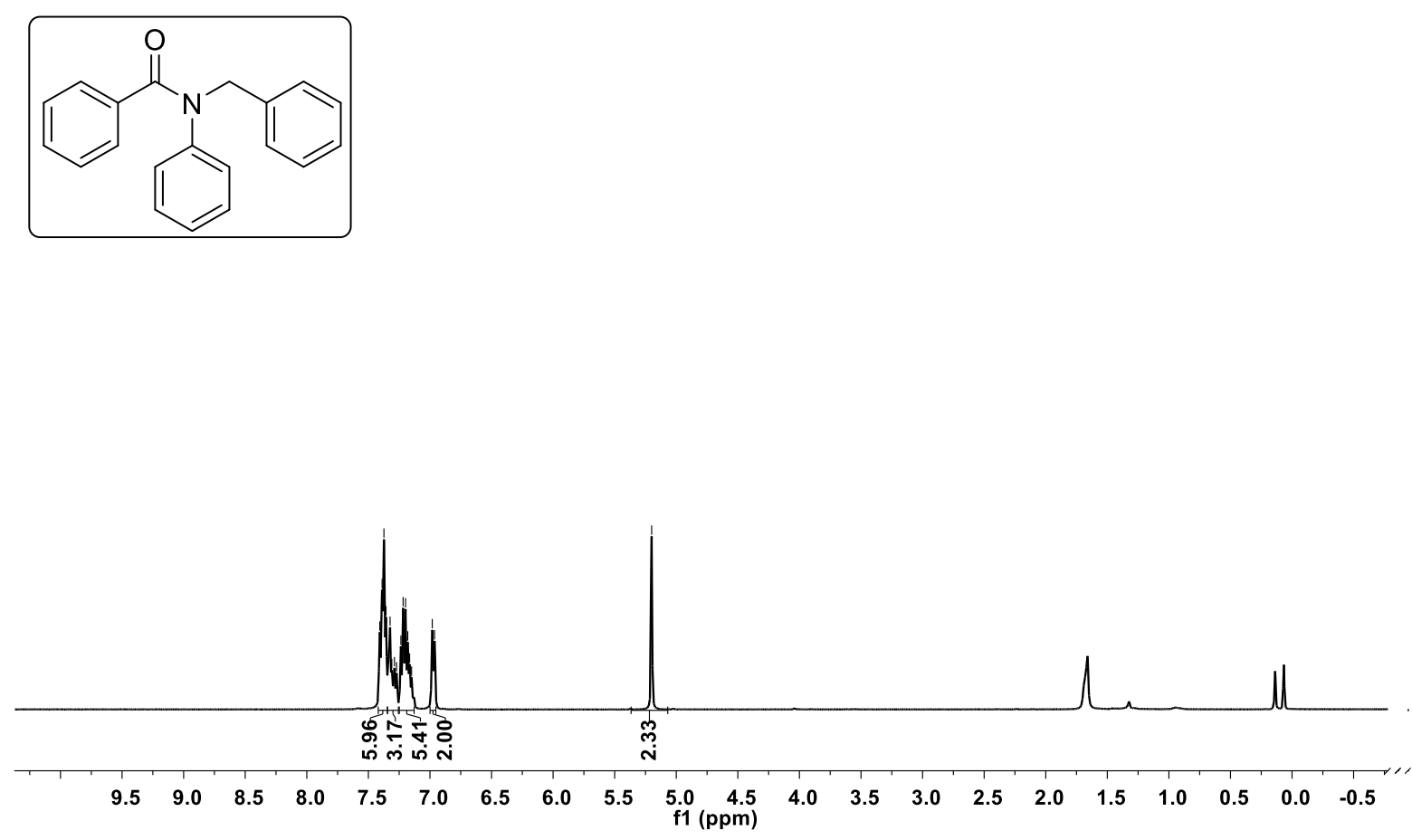

${ }^{1}$ H NMR (400 MHz) spectrum of compound 9

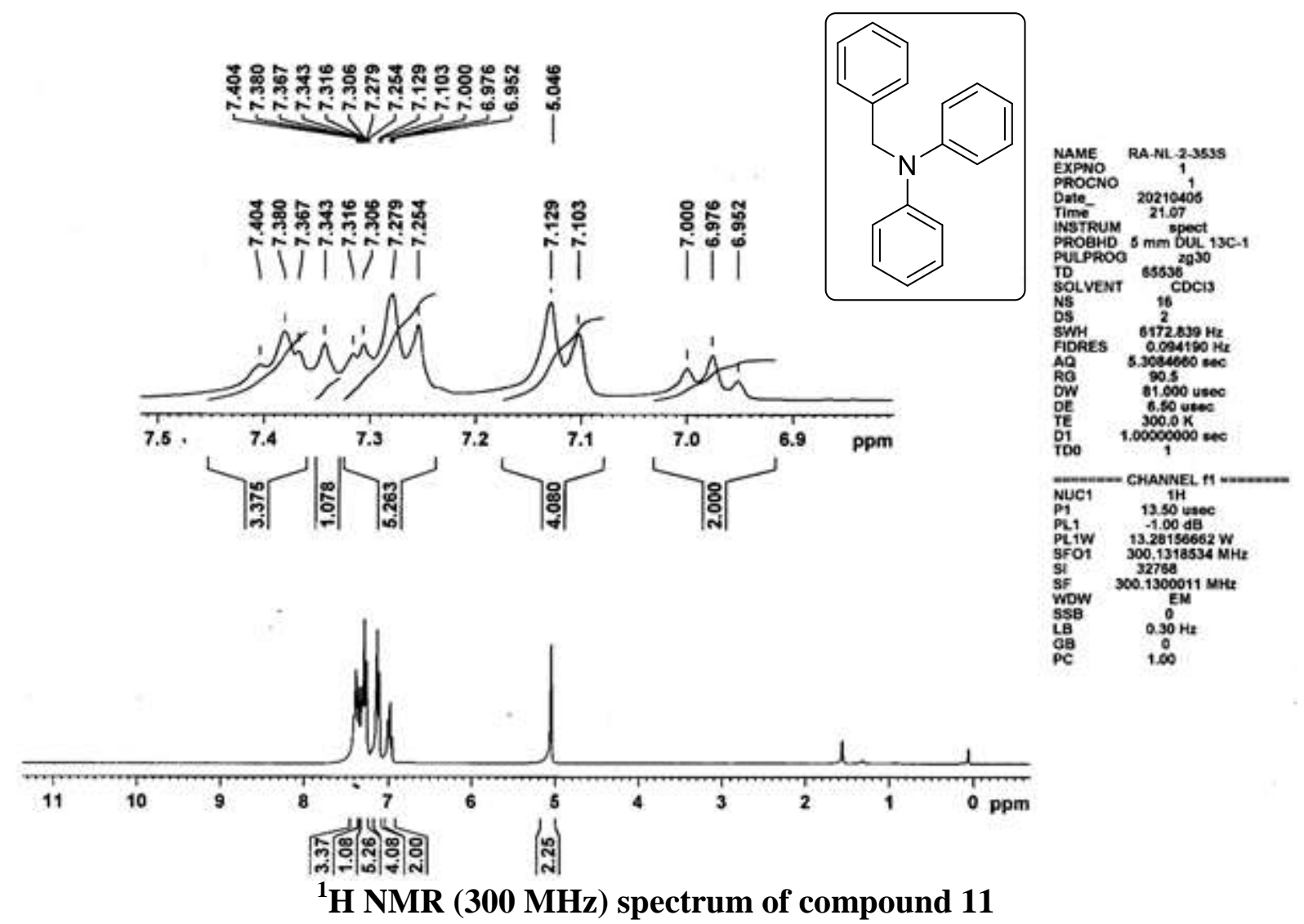



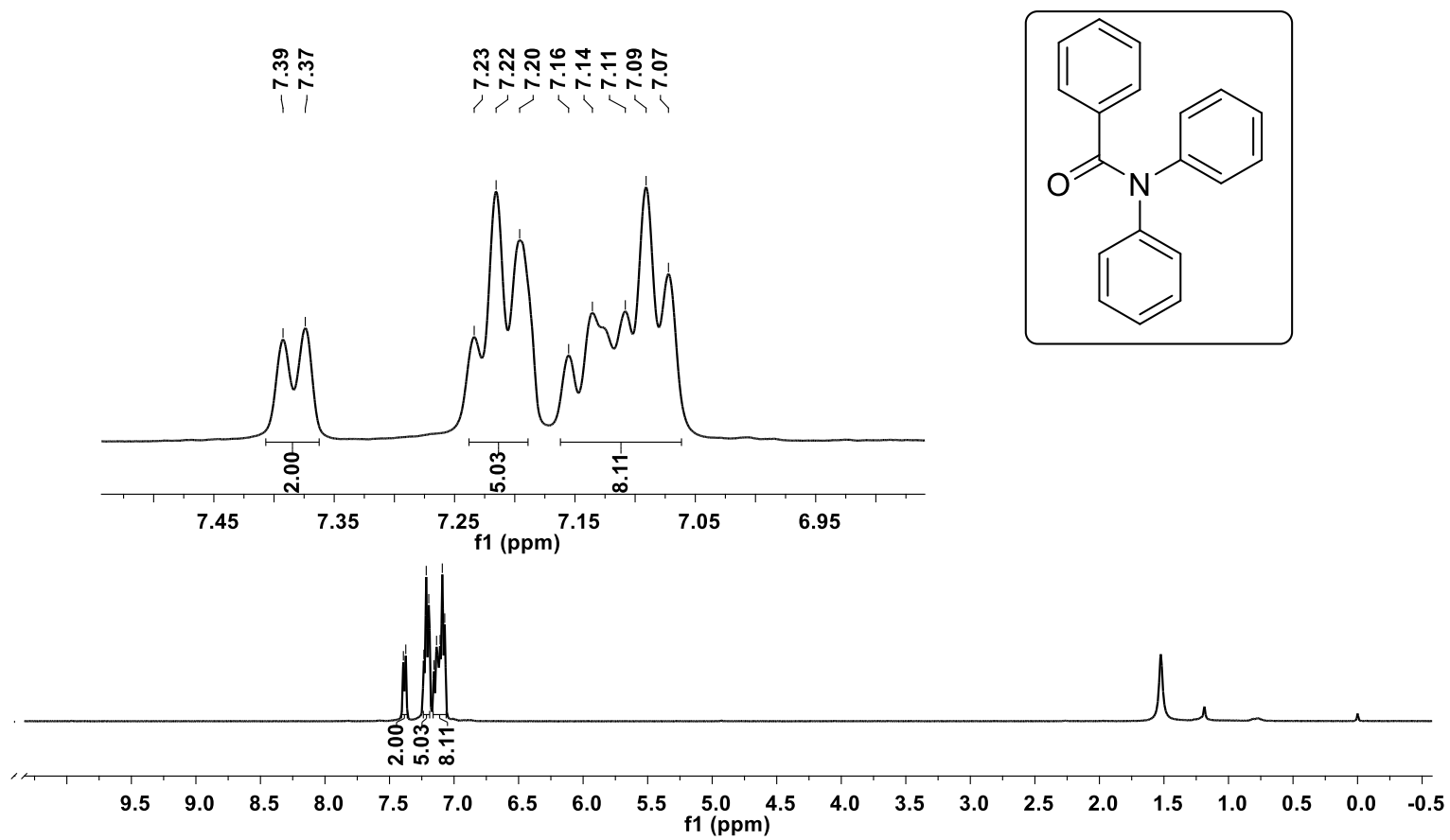

${ }^{1} \mathrm{H}$ NMR (400 MHz) spectrum of compound 12

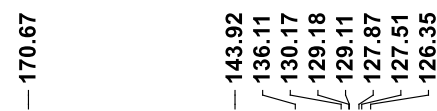

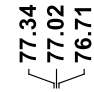

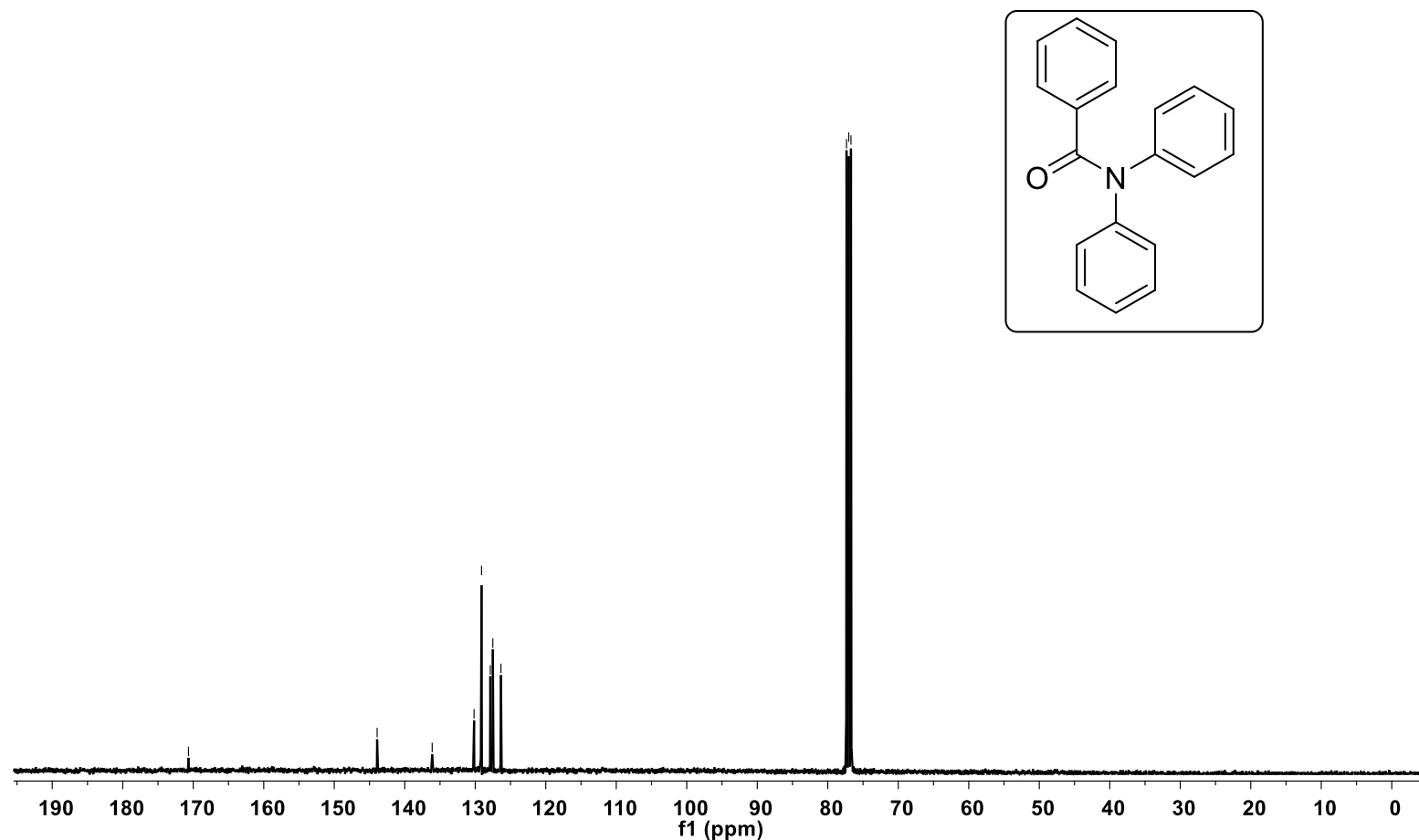

${ }^{13} \mathrm{C}\left\{{ }^{1} \mathrm{H}\right\}$ NMR (101 MHz) spectrum of compound 12 


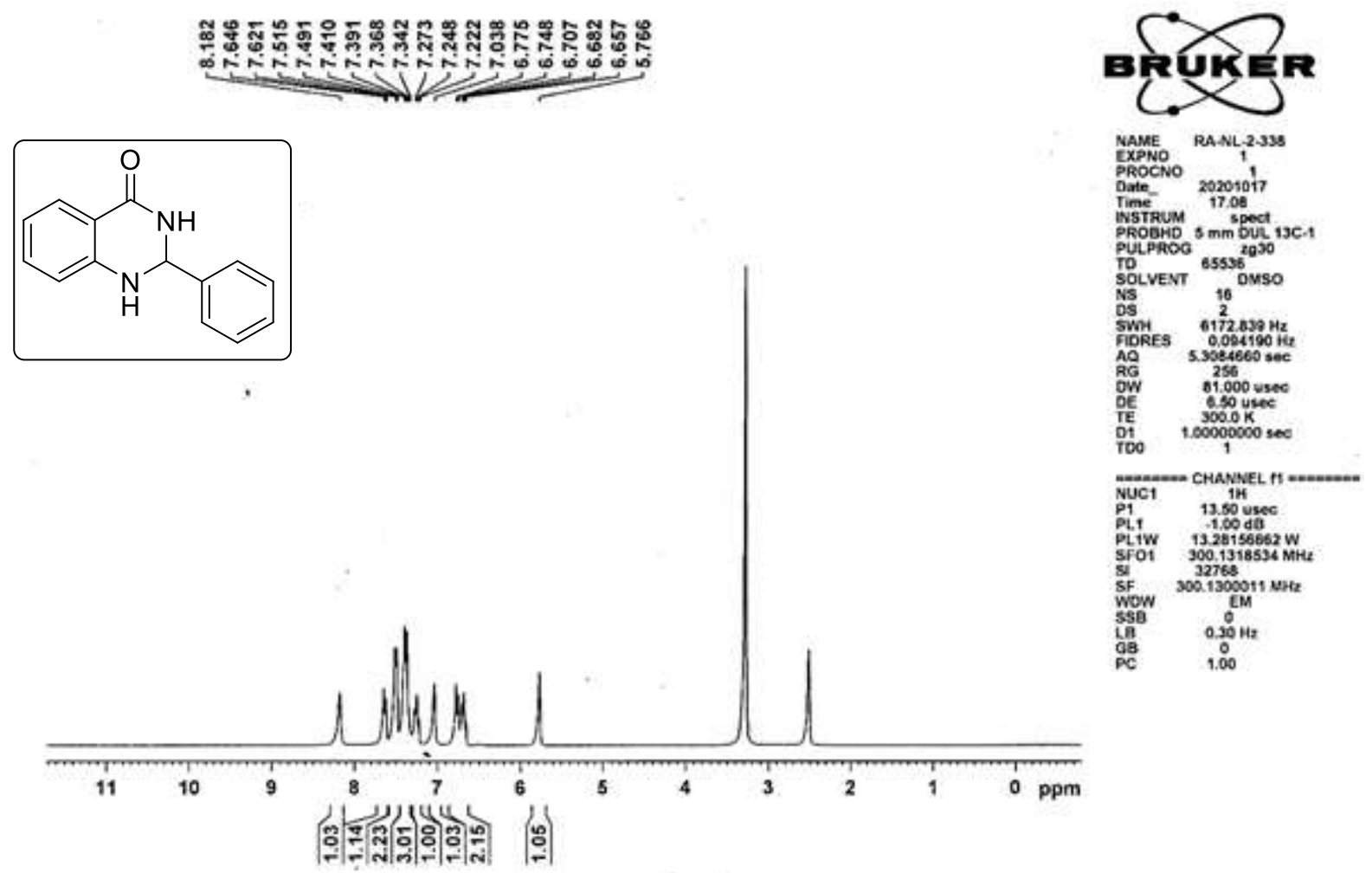

${ }^{1}$ H NMR (300 MHz) spectrum of compound 14

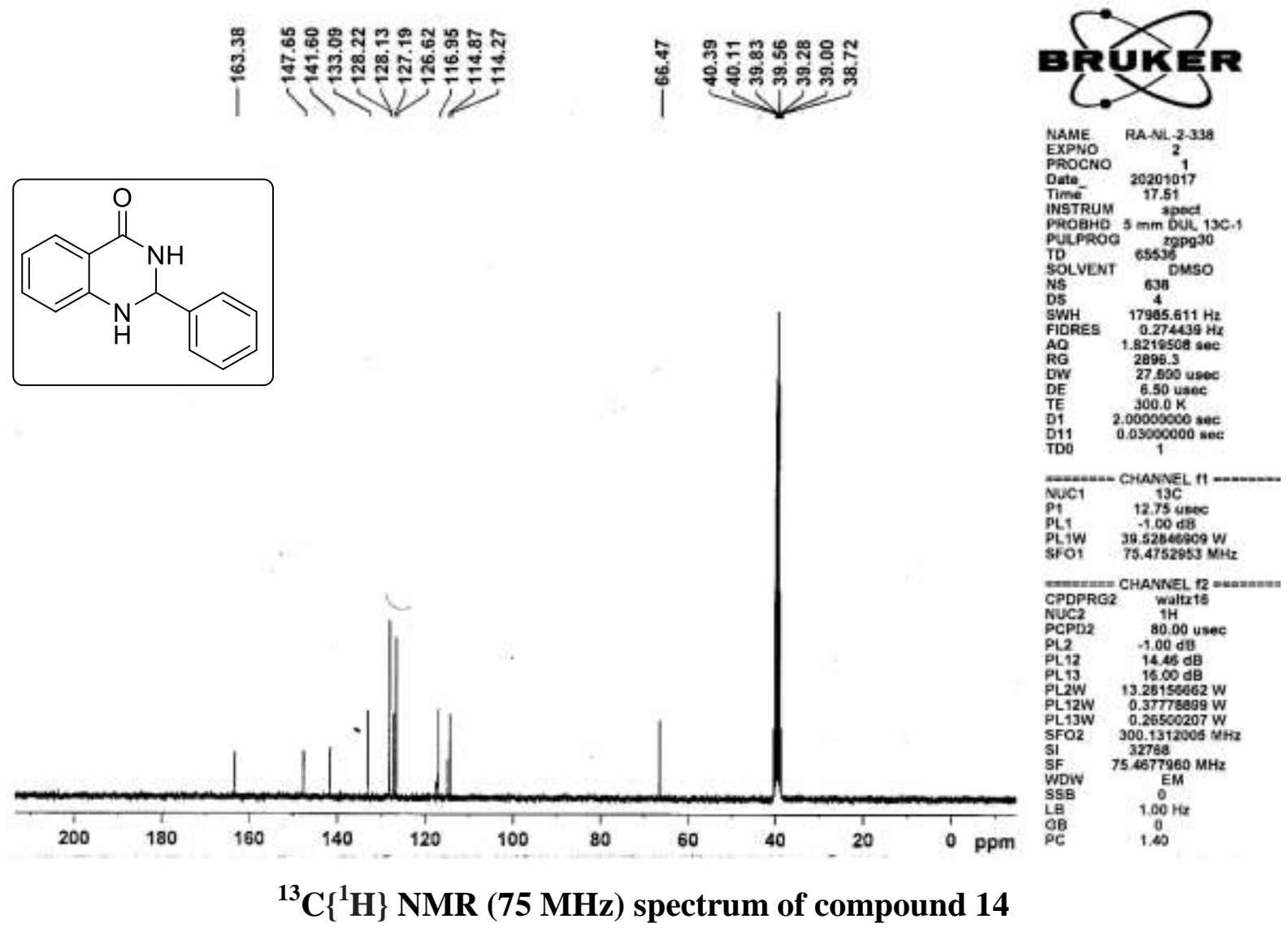

